Aus der Klinik für Klinische Neurophysiologie

(Prof. Dr. med. W. Paulus)

der Medizinischen Fakultät der Universität Göttingen

\title{
Sprechbezogene Veränderungen der Erregbarkeit des primären Motorkortex bei Stotternden und Kontrollprobanden
}

\author{
INAUGURAL-DISSERTATION \\ zur Erlangung des Doktorgrades \\ der Medizinischen Fakultät der \\ Georg-August-Universität zu Göttingen
}

vorgelegt von

Sina Hommel

aus Fritzlar

Göttingen 2019 
Dekan:

Referent:

Ko-Referentin:
Prof. Dr. med. Wolfgang Brück

Prof. Dr. med. Martin Sommer

PD Dr. rer. nat. Kirsten Jordan

Datum der mündlichen Prüfung: Dienstag, 09.06.2020 
Inhaltsverzeichnis

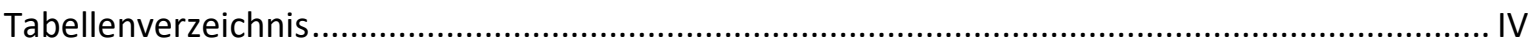

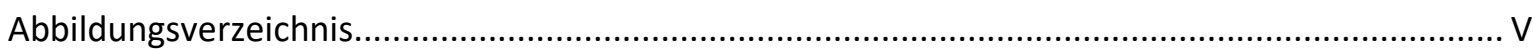

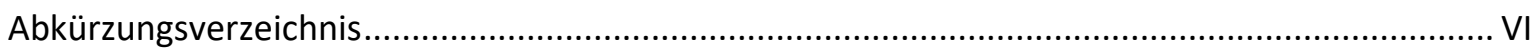

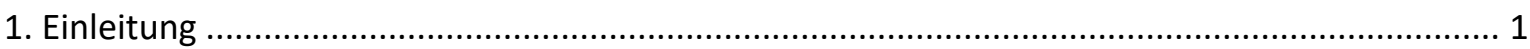

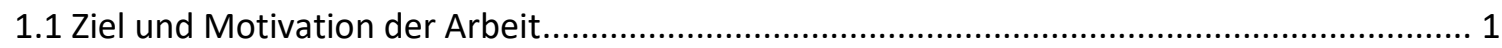

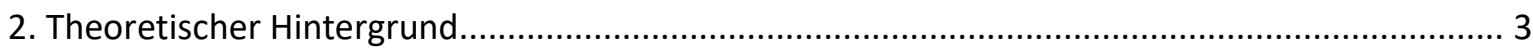

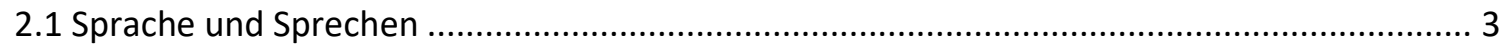

2.1.1 Wo und wie entsteht die Sprache? Neuroanatomische Grundlagen ............................... 4

2.1.2 DIVA-Modell und GODIVA-Modell nach Guenther ................................................... 5

2.1.3 Der weitere physiologische Sprechvorgang bis zum Ausführen des Sprechens............. 11

2.1.4 Anatomie und Repräsentation der Zunge im Kortex ............................................... 11

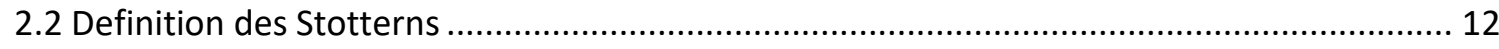

2.2.1 Phänomenologie und theoretische Grundlagen des Stotterns ................................... 12

2.3 Originäres neurogenes nicht-syndromales Stottern (OS) ................................................. 14

2.3.1 Epidemiologie und Definition ..................................................................................... 14

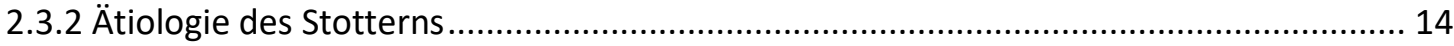

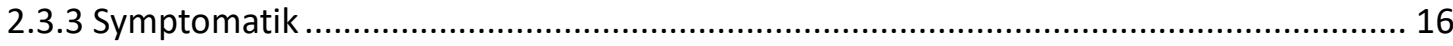

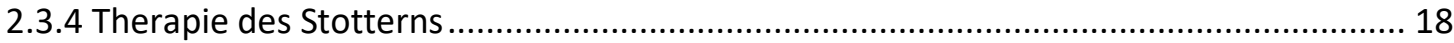

2.4 Aktueller Forschungsstand der zerebralen Befunde zum Stottern...................................... 20

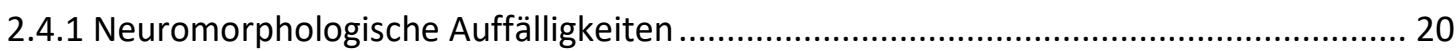

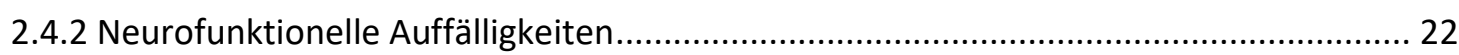

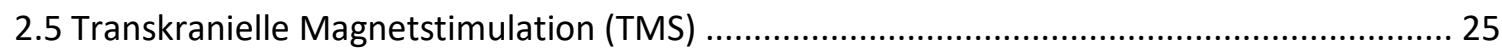

2.5.1 Entstehung der TMS und Physiologische Grundlagen .............................................. 25

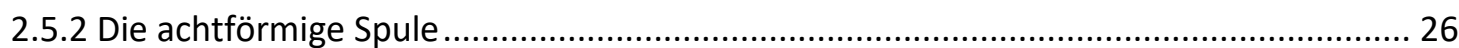

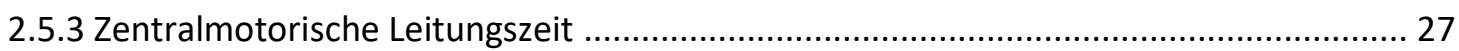

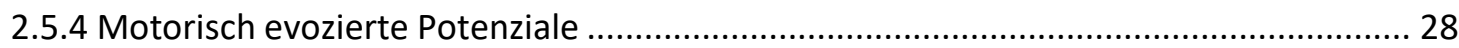

2.5.5 Ableitung des MEP mittels EMG - Allgemeine Vorgehensweise.................................. 29

2.5.6 Platzierung der Stimulationsspule über dem motorischen Kortex................................ 29

2.5.7 Motorische Reizschwelle und die Auswahl der Reizintensität .................................... 31

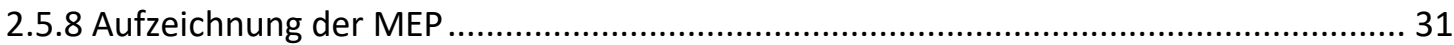

2.5.9 MEP-Ausmessung und Amplitudenquotientenberechnung ........................................ 32 
2.5.10 Stimulation der Zungenmuskulatur (N. hypoglossus)

2.5.11 Neurostimulation und Erregungsfortleitung bis zur MEP-Entstehung

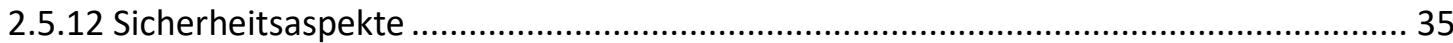

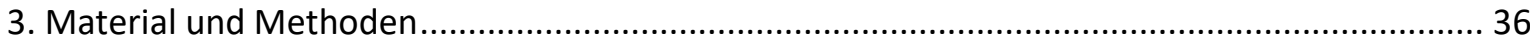

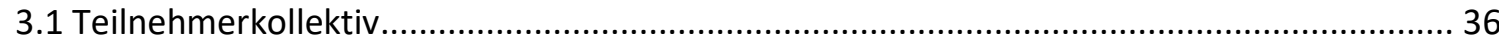

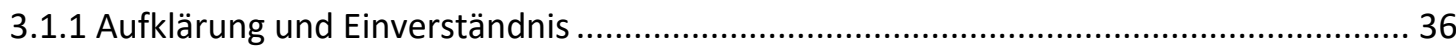

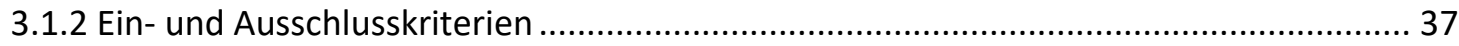

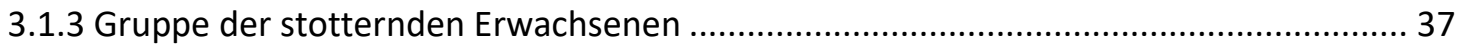

3.1.4 Gruppe der nichtstotternden Erwachsenen/Kontrollgruppe ....................................... 38

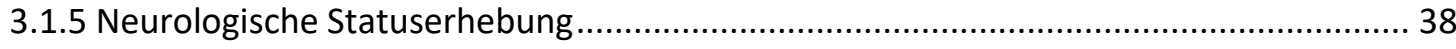

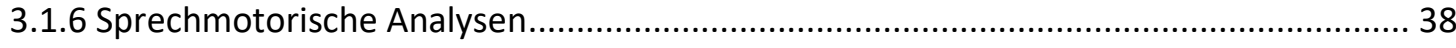

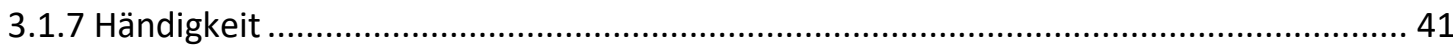

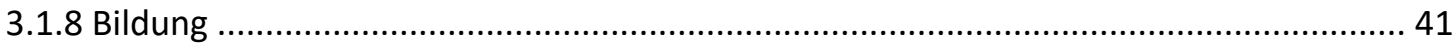

3.1.9 Sortierung und Auswertung der Teilnehmerdaten ..................................................... 42

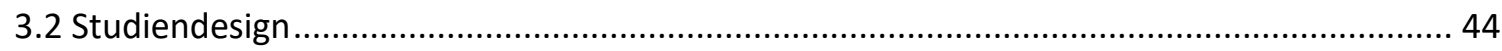

3.2.1 Datenerfassung mittels Elektromyographie und technischer Geräteaufbau ................. 44

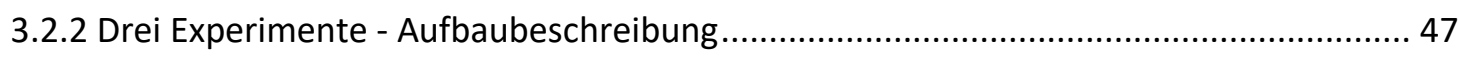

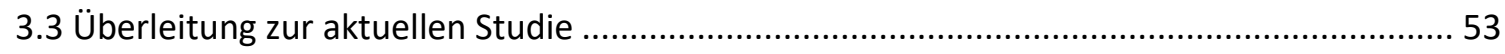

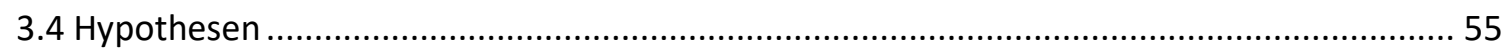

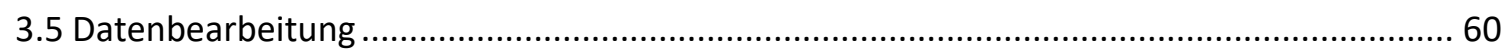

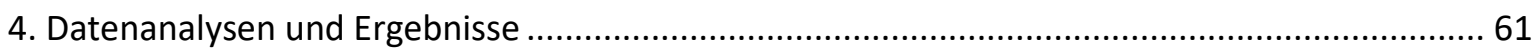

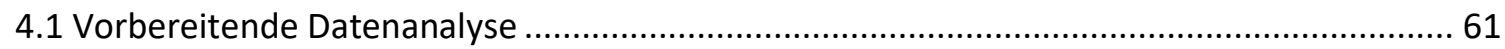

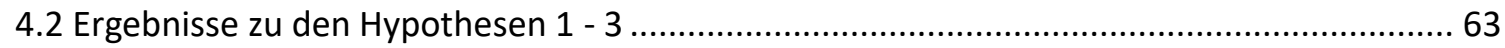

4.2.1 Ergebnisse zu den Hypothesen 1-3, ausführliche Darstellung für das Experiment 1 unter

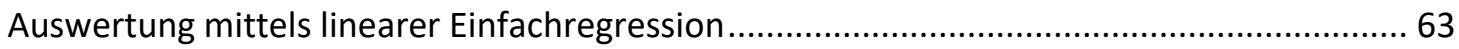

4.2.2 Ergebnisse zu den Hypothesen 1-3, ausführliche Darstellung für das Experiment 1 unter Auswertung mittels hierachischer (multipler) Regressionsanalyse.....

4.2.3 Ergebnisse zu den Hypothesen 1-3, ausführliche Darstellung für das Experiment 1 unter Auswertung mittels nichtlinearer Regressionsanalyse .......................................................... 69

4.2.4 Ergebnisse zu den Hypothesen 1 - 3 für Experiment 2 ............................................... 71

4.2.5 Ergebnisse zu den Hypothesen 1 - 3 für Experiment 3 …............................................. 74

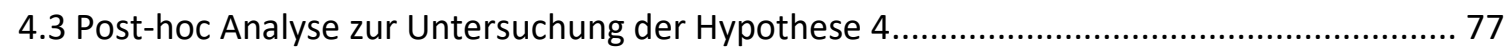

4.4 Ergebnisse zu Hypothese 5 - zum Gruppenunterschied in den Reaktionszeiten.................. 78

4.5 Lineare Einfachregression und Hierarchische multiple Einfachregression mit prozentual gestotterten Silben zur Untersuchung von Hypothese 6. 
5.1 Hypothese 1: Die MEP-Fazilitation steigt zum Sprechbeginn hin bei allen Teilnehmern und in allen drei Experimenten an.

5.2 Hypothese 2: Insgesamt ist das Fazilitationslevel bei AWS reduziert. 86

5.3 Hypothese 3: AWS zeigen einen reduzierten Anstieg der MEP-Fazilitation in der Sprechvorbereitung bezogen auf die TSO, dies zeigt der Interaktionseffekt. 89

5.4 Hypothese 4: Der Fazilitationsunterschied zwischen stotternden und nichtstotternden Erwachsenen ist beim spontanen Sprechen am größten ..... 91

5.5 Hypothese 5: Stotternde reagieren langsamer als nichtstotternde Erwachsene 94

5.6 Hypothese 6: Korrelation der Stotterhäufigkeit mit der MEP-Amplitude 95

6. Kritik und Limitationen 97

7. Zusammenfassung 100

8. Literaturverzeichnis 102

9. Anhang 110 


\section{Tabellenverzeichnis}

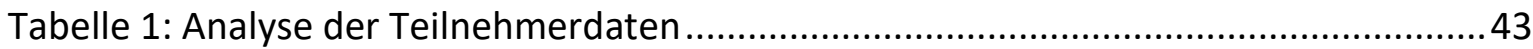

Tabelle 2: Experiment 1. Übersicht aller drei Analysen mit Gruppeneinteilung .................64

Tabelle 3: Ergebnisse der Hierarchischen multiplen Regressionsanalyse für Reaktionszeiten

Tabelle 4: Teilnehmerdaten 110

Tabelle 5: zugehörig zu Experiment 1. $R^{2}$ Berechnung für Regressionsanalyse 110

Tabelle 6: Experiment 2. Übersicht aller drei Analysen mit Gruppeneinteilung

Tabelle 7: zugehörig zu Experiment 2. $R^{2}$ Berechnung für Regressionsanalyse 111

Tabelle 8: Experiment 3. Übersicht aller drei Analysen mit Gruppeneinteilung 112

Tabelle 9: zugehörig zu Experiment 3. $R^{2}$ Berechnung für Regressionsanalyse.

Tabelle 10: Datenanalyse der Gruppenunterschiede zwischen Experiment 1 und 2

Tabelle 11: Datenanalyse der Gruppenunterschiede zwischen Experiment 1 und 3 113

Tabelle 12: lineare Einfachregression und HMRA für Exp. 1 unter Verwendung \% SS .....114

Tabelle 13: zugehörig zu Experiment 1 \% SS. R² Berechnung für Regressionsanalyse .....114

Tabelle 14: lineare Einfachregression und HMRA für Exp. 2 unter Verwendung \% SS .....115

Tabelle 15: zugehörig zu Experiment $2 \%$ SS. $R^{2}$ Berechnung für Regressionsanalyse .....115

Tabelle 16: lineare Einfachregression und HMRA für Exp. 3 unter Verwendung \% SS .....116

Tabelle 17: zugehörig zu Experiment 3 \% SS. R² Berechnung für Regressionsanalyse .....116 


\section{Abbildungsverzeichnis}

Abb. 1: Abstrahierte Großhirnrinde mit dem GODIVA-Modell .......................................

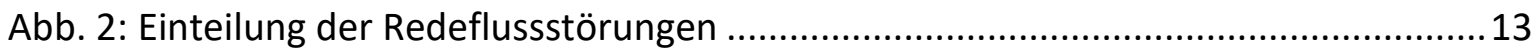

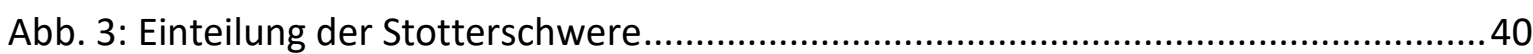

Abb. 4: Zungenlöffel mit Elektroden Abb. 5: Mikrofon auf Zungenlöffel .........................45

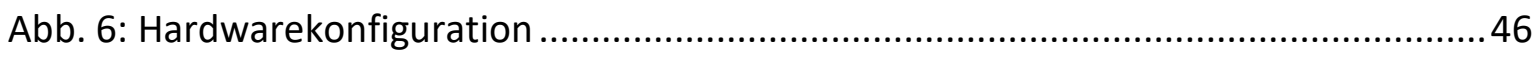

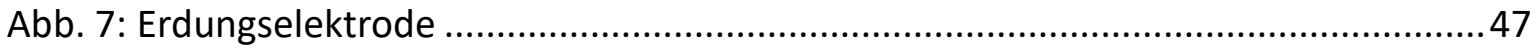

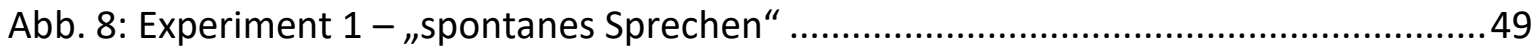

Abb. 9: Experiment 2 - „geplantes Sprechen ohne Taktung“ .............................................51

Abb. 10: Experiment 3 - „geplantes Sprechen mit Taktung“ ............................................52

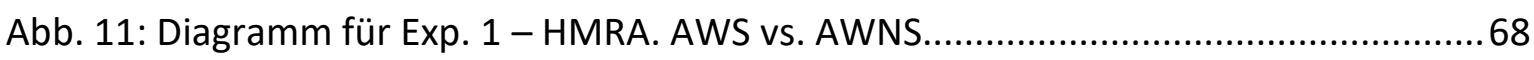

Abb. 12: Visualisierung der nichtlinearen Regression für Experiment 1...........................70

Abb. 13: Diagramm für Exp. 2 - Hierarchische multiple Regressionsanalyse AWS vs. AWNS

Abb. 14: Visualisierung der nichtlinearen Regression für Experiment 2.

Abb. 15: Diagramm für Exp. 3 - Hierarchische multiple Regressionsanalyse AWS vs. AWNS

Abb. 16: Visualisierung der Nichtlinearen Regression für Experiment 3 .76

Abb. 17 Ethikvotum 


\section{Abkürzungsverzeichnis}

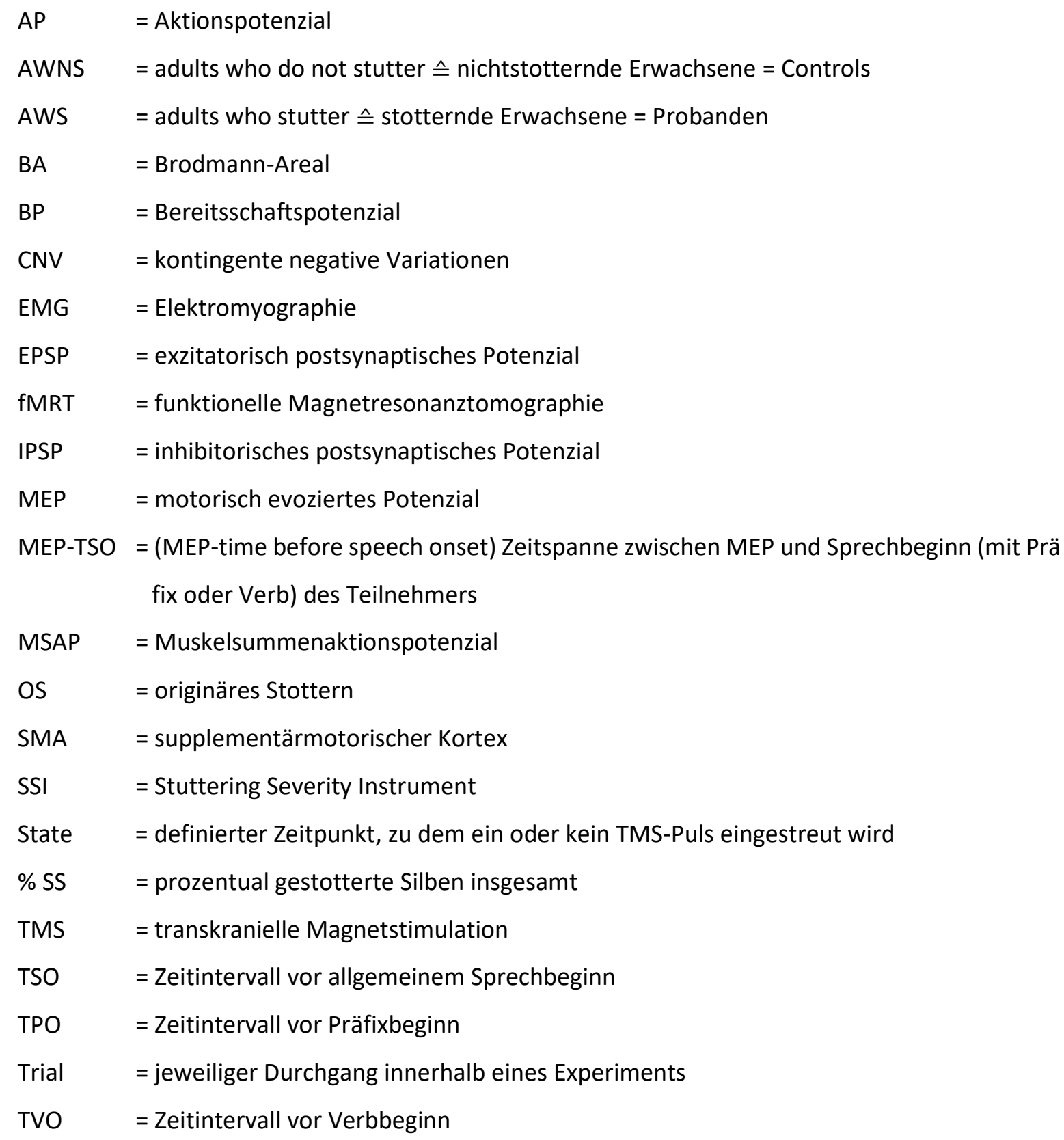

Zum Zweck der Verständlichkeit verwende ich im gesamten Text nur den Begriff Teilnehmer, wenn es um die Gesamtgruppe geht. Selbstverständlich ist damit immer der feminine Terminus gleichberechtigt gemeint und keine Wertung durch die Begrifflichkeit zu verstehen. 


\section{Einleitung}

\subsection{Ziel und Motivation der Arbeit}

Ziel der Transkraniellen-Magnetstimulations-Studie mit stotternden und nichtstotternden Erwachsenen ist der Vergleich der linkshemisphärischen motorkortikalen Erregbarkeit während der Vorbereitung auf drei unterschiedlich anspruchsvolle Sprechaufgaben. Hiermit soll zuerst eine verminderte kortikale Erregbarkeit in der Sprechvorbereitung bei stotternden Erwachsenen (AWS) nachgewiesen werden. Anschließend soll gezeigt werden, dass AWS - unter Berücksichtigung der Stotterschwere - bei anspruchsvollen Sprechaufgaben mit weniger Anpassungsfähigkeit reagieren, die sich in verminderter kortikaler Erregbarkeit verglichen mit nichtstotternden Erwachsenen widerspiegelt. Um der Ursache hierfür näher zu kommen, wird außerdem die Reaktionszeit zwischen beiden Gruppen verglichen. Die Ergebnisse sollen neue Hinweise zur fehlerhaften Sprechvorbereitung des Stotterns liefern. Der Grundgedanke geht aus einer vorangegangenen Studie von Neef und Kollegen hervor (Neef et al. 2015a), in der gezeigt wurde, dass bei AWS linkshemisphärisch während des Sprechens die kortikale Erregung reduziert war verglichen mit nichtstotternden Erwachsenen (AWNS). Obwohl die orofaziale Muskulatur gleichseitig innerviert ist (Trepel 2017), war die Erregbarkeit der linken Hemisphäre im Vergleich zur rechten Hemisphäre während des Sprechens bei AWNS signifikant größer. Zudem konnte eine inverse Korrelation zwischen der Stotterschwere und der verminderten kortikalen Erregung dargestellt werden (Neef et al. 2015a). Im Vergleich zur normalen Spontansprache war durch die Taktung der Sprechaufgabe eine deutliche externe Unterbrechung vorhanden (Neef et al. 
2015a). Es ist generell unklar, ob eine Sprechunterbrechung und Taktung als kognitive Belastung für AWS zu werten ist oder ob das verzögerte und getaktete Sprechen sogar zu einer ausgedehnteren Sprechvorbereitung verhilft und somit eine Erleichterung für AWS darstellt. Tatsächlich werden seit langem eine erhöhte kognitive Belastung und eine längere Bearbeitungszeit zum Kodieren von semantischen Phrasen mit der Stottersymptomatik in Verbindung gebracht (Bosshardt 2006). Um mehr Klarheit darüber zu schaffen, kreierten wir zwei neue Sprechaufgaben. Im ersten Experiment „spontanes Sprechen“ werden die Teilnehmer auf Kommando aufgefordert ein präsentiertes Verb direkt mit dem Präfix „auf“ zu verbinden. Im zweiten Experiment „geplantes Sprechen ohne Taktung" soll das präsentierte Verb eingeprägt werden, dann folgt ein Kommando zum Aussprechen des Verbs mit vorgeschaltetem Präfix. Das dritte Experiment „geplantes Sprechen mit Taktung“ ist identisch mit der Sprechaufgabe aus einer vorangegangenen TMS-Studie bei AWS, die 2015 von Neef und Kollegen veröffentlicht wurde und eine verminderte Exzitabilität (Erregbarkeit von Neuronen) bei AWS linkshemisphärisch während des Sprechens nachwies. Das präsentierte Verb soll vom Teilnehmer eingeprägt werden, dann folgt ein erstes Kommando zum Prolongieren des Präfixes „auf“ und ein zweites Kommando zum Anhängen des Verbs (Neef et al. 2015a). Da Stottern besonders oft am Wortanfang auftritt (Seth and Maruthy 2019), legte ich unseren Fokus auf die Vorbereitung der ersten artikulatorischen Geste im Motorkortex. Die Aktivität des Motorkortexes in diesem Bereich wurde sichtbar gemacht, indem wir den Teilnehmern transkranielle Magnetimpulse auf das linkshemisphärisch liegende Motorkortexareal der Zunge applizierten und die entstehenden moto- 
risch evozierten Potenziale (MEPs) über Elektromyographie (EMG) von der Zunge ableiteten. Die kortikale motorische Erregbarkeit spiegelt die mikrostrukturellen Eigenschaften der weißen Substanz des Gehirns wider (Klöppel 2008). Deshalb bot sich die Methode der transkraniellen Magnetstimulation (TMS) an um die Erregung messbar zu machen. Wir stimulierten lediglich die linke Hemisphäre, da wir aufgrund der vorhergegangenen Forschungsergebnisse von Neef und Kollegen von einer Fehlfunktion der linken Hemisphäre bei AWS ausgehen (Neef et al. 2015a). Außerdem gehen wir davon aus, dass bei ca. $93 \%$ aller Rechtshänder und über $85 \%$ aller Linkshänder eine linksseitige Sprachdominanz herrscht (Szaflarski et al. 2012). Insgesamt besteht unsere Studie aus drei verschiedenen Experimenten, die drei unterschiedliche Komplexitätsanforderungen des Sprechens repräsentieren. Über die Größe und die Modulationsfähigkeit der MEP-Amplitude sowie die Zeitpunkte des jeweiligen Sprechbeginns wurden im Gruppenvergleich Rückschlüsse auf die Ätiologie und Pathomechanismen des Stotterns gezogen. Zunächst soll ein allgemeiner Überblick zum originären Stottern, zur generellen Sprechmotorik sowie zur transkraniellen Magnetstimulation gegeben werden. Anschließend wird die angewandte Methodik erläutert, bevor die Ergebnisse dargestellt und diskutiert werden.

\section{Theoretischer Hintergrund}

\subsection{Sprache und Sprechen}

Sprache ist Merkmal unserer menschlichen Spezies und somit eine eigene Ausdrucksweise, deren Sinn die Kommunikation ist. Sie zeichnet sich aus durch Kreativität und die Fähigkeit 
zu begrifflicher Abstraktion sowie die Möglichkeit zu metasprachlicher Reflexion. Das Sprechen ist die wahrscheinlich komplizierteste motorische Fähigkeit, die der Mensch erlernen kann und anwendet, ohne dass er sich die zeitliche und räumliche Präzision, die für flüssiges Sprechen erforderlich ist, bewusst macht. Schließlich müssen während des Sprechens über 100 Muskeln koordiniert werden und die drei verschiedenen Funktionen der Phonation, Artikulation und Atmung integriert werden, um zehn bis 15 Laute pro Sekunde zu produzieren, um verständliche Sprache zu produzieren (Natke und Alpermann 2010).

\subsubsection{Wo und wie entsteht die Sprache? Neuroanatomische Grundlagen} 1909 veröffentlichte der deutsche Neuroanatom Korbinian Brodmann seine Einteilung der Großhirnrinde in initial 52 Felder, die bis heute die Grundlage der Hirnrindengliederung darstellt. Er mutmaßte in den Arealen 44, 45 und 47 eine Beteiligung an kortikalen Sprachvorgängen (Brodmann 1909; Poeck und Hacke 2006). Diese Lokalisation hatte auch Paul Broca bereits 1861 aufgrund seiner Aphasieforschung benannt. Die grobe Unterteilung zwischen den beiden Sprachverarbeitungsarealen Broca und Wernicke wird noch zur Orientierung benutzt, wenn es zum Beispiel um das Beschreiben von Ausfallerscheinungen geht. Das motorische Sprachzentrum wurde 1861 von Paul Broca (1824-1880) entdeckt, beschrieben und nach inm benannt. Anatomisch nimmt es den Bereich der Pars opercularis und zum Teil den des Pars triangularis des Gyrus frontalis inferior ein, dies entspricht den Brodmann-Arealen (BA) 44 und 45. Das Wernicke-Zentrum bildet das sensorische Sprachzentrum und wurde benannt nach dem deutschen Neurologen Carl Wernicke (1848-1905), es nimmt die Kortexareale 42 und 22 nach Brodmann ein (Trepel 2017). Nach heutigem 
Verständnis ist für die Sprachentstehung und Verarbeitung ein großes neuronales Netzwerk verantwortlich. Das Sprachareal wird nicht mehr, wie früher angenommen, ausschließlich den zwei Kortexarealen Broca und Wernicke-Areal zugeordnet, sondern es besteht aus einem Arrangement neuronaler Netzwerke, an denen unterschiedlich sprachrelevante Hirnareale beteiligt sind (Catani et al. 2005).

\subsubsection{DIVA-Modell und GODIVA-Modell nach Guenther}

Das GODIVA-Modell füllt die aktuelle Lücke in der Sprachforschung, indem auf der Grundlage von Neuroanatomie und Physiologie formale Hypothesen sowohl über phonologische als auch phonetische Prozesse geliefert werden (Bohland et al. 2010). Es wird erklärt, wie das Gehirn Sequenzen einfacher, gelernter Sprachlaute produzieren kann. Das GODIVAModell baut auf dem Vorgänger Modell namens DIVA auf. DIVA steht für „Directions Into Velocities of Articulators", und GODIVA für "Gradient Order Directions Into Velocities of Articulators“(Bohland et al. 2010). Das DIVA-Modell stellt Zusammenhänge und Grundlagen der neuronalen Verarbeitung von Sprachwahrnehmung und der Sprechproduktion dar (Guenther et al. 2006). Es beginnt mit der Aktivierung sogenannter Speech Sound Maps (abstrakte Repräsentationen der Silben) im linken ventralen prämotorischen Kortex, die als Verbindungsstück zwischen der Sprachwahrnehmung und Sprachproduktion fungieren. Insbesondere die Koordination von Atmung, Stimmgebung und Muskelinnervation sind hier relevant. Die Sprachproduktion wird im DIVA-Modell durch zwei parallel aktive Kontrollsysteme veranschaulicht, ein Feedforward Control Subsystem und ein Feedback Control Subsystem. Die Produktion einer Silbe beginnt mit der Aktivierung der Speech Sound 
Maps, dann folgt die Auswahl der zu artikulierenden Laute und es werden sprechmotorische Engramme im Motorkortex aktiviert, diese ermöglichen die Kontrolle über das Sprechen. Das Feedforward Control Subsystems kontrolliert die zeitliche Abfolge, parallel werden die zu erwartenden auditiven und somatosensorischen Eindrücke im superioren temporalen und inferioren parietalen Kortex aktiviert und mit den Erwartungskarten abgeglichen. Es wird angenommen, dass der Feedforward-Motor-Befehl sowohl direkt als auch über das Cerebellum vom ventrolateralen prämotorischen Kortex zum primären Motorkortex projiziert. Mit Hilfe der Erwartungskarten wird der Sprechvorgang effizient abgeglichen. Sollte ein Fehler erkannt werden, so wird dieser an den Motorkortex geschickt und korrigiert (Feedback Control Subsystem) (Guenther et al. 2006). In der Weiterentwicklung, dem GODIVA-Modell existiert eine Vielzahl von Planungs- und Entscheidungszentren (Plan cells und Choice Cells), die sich gegenseitig aktiv hemmen oder anregen können bis zur endgültigen Wortgeneration im Motorkortex. Nach dem GODIVA-Modell (Bohland et al. 2010) sind folgende Areale am Sprechmotorischen Netzwerk beteiligt: linker ventraler prämotorischer Kortex (kaudaler Anteil BA 6), inferiorer parietaler Kortex (BA 39, 40), superiorer temporaler Kortex (BA 22, 41, 42), linker inferiorer frontaler Gyrus (BA 44, 45, 47), (prä)supplementärmotorischer Kortex (BA 8), bilateraler Motorkortex (BA 4), frontales Operculum, Cerebellum, Basalganglien, Lobus caudatus, Globus pallidus internus, Putamen und Thalamus.

In unserer Studie werden die Teilnehmer aufgefordert die gesehenen Worte in modifizierter Form und auf Anweisung nachzusprechen. Die folgende Grafik (Abb. 1) soll den physiologischen Vorgang beim Lesen und Sprechen nach dem GODIVA-Modell veranschaulichen, 
indem die sprachassoziierten Schaltkreise abstrahiert vorgestellt werden und die roten

Pfeile den Weg der Sprachproduktion anzeigen.

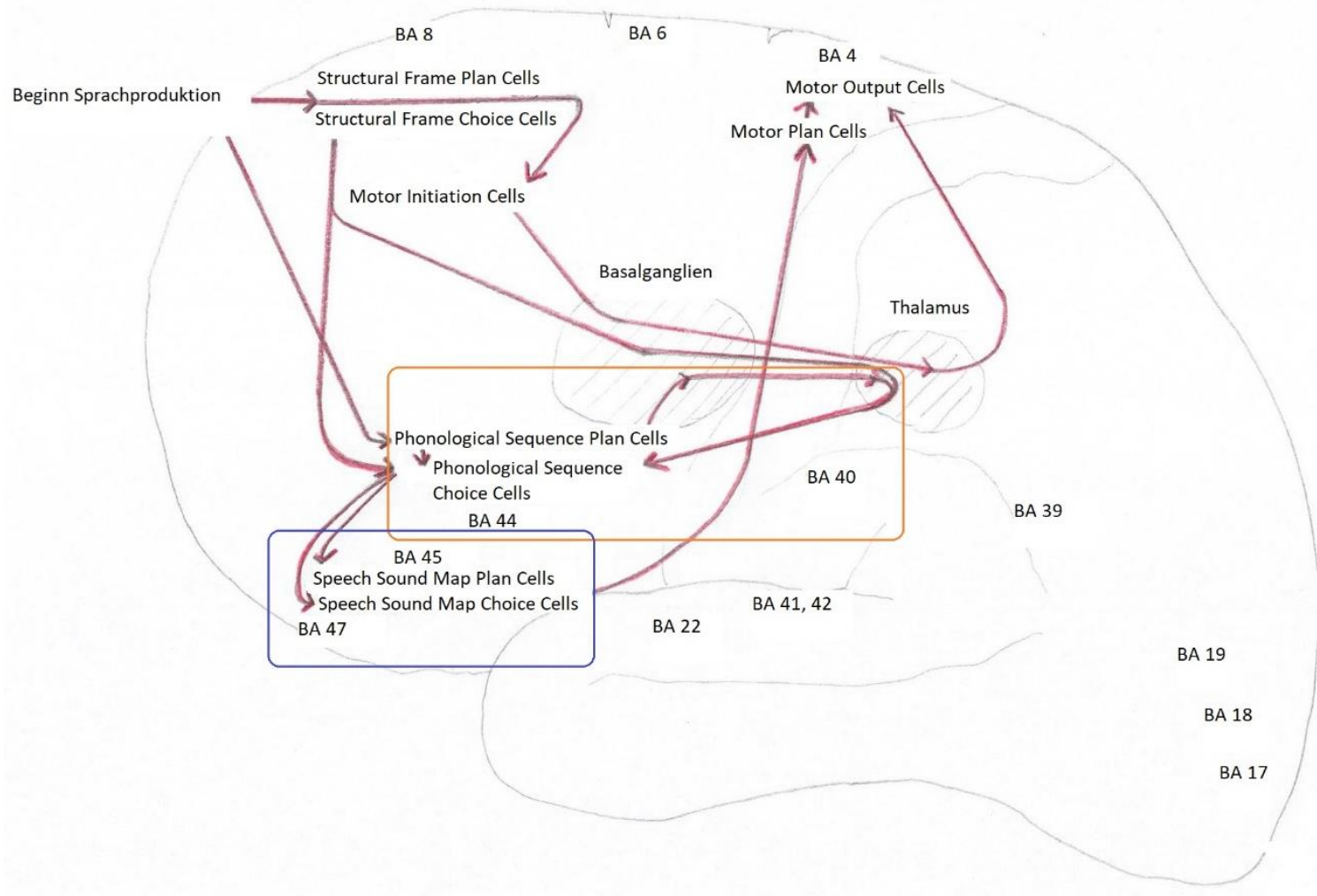

Abb. 1: Abstrahierte Großhirnrinde mit dem GODIVA-Modell

Gliederung der Großhirnrinde mit abstrahierten Schaltkreisen der Sprachproduktion nach dem GODIVA-Modell. BA 4 = Gyrus precentralis/Motorkortex, $6=$ prämotorischer Kortex, 8 $=$ (prä-)supplementärmotorischer Kortex, primäre visuellen Rinde (BA 17), sekundäre visuellen Rinde (BA 18 und 19), 22 = klassisches sensorisches Sprachzentrum/Wernicke-Areal, 39/40 = Übergangsregion zwischen sekundären sensorischen Projektionszentren zu tertiärem Assoziationsgebiet (Gyrus angularis und Gyrus supramarginalis), 41 = primäre Hörrinde, 42 = sekundäre Hörrinde, 44/45/47 = linker inferiorer frontaler Gyrus. Große schraffierte Fläche = Basalganglien, kleine schraffierte Fläche $=$ Thalamus. Die roten Pfeile zeigen den Weg der Sprachproduktion nach dem GODIVA-Modell an. Blauer Kasten: Speicher für Motorprogramme (Bewegungsabläufe der gebräuchlichen Silben einer erlernten Sprache). Oranger Kasten: Planungsschleife Basalganglien (phonologische Entscheidungsareale, hier findet Modifikation und Korrektur statt). Die dargestellten Abläufe bis zur Aussprache finden parallel statt und ergänzen sich gegenseitig. Zur detaillierten Erklärung siehe Text. [Quelle: angelehnt an Lateralansicht des Großhirns und Schaltkreise, die zum Nachsprechen oder Lesen erforderlich sind - in Ausarbeitung von Sina Hommel] (Trepel 2017) (Bohland et al. 2010). 
Beim Lesen gelangen die visuellen Reize auf die Retina, dann über die sogenannte Sehbahn zur primären visuellen Rinde (BA 17), von dort weitergeleitet an die sekundäre visuelle Rinde (BA 18 und 19), wo die Reize als Schrift erkannt und interpretiert werden. Von der sekundären visuellen Rinde geht es über den Gyrus angularis (BA 39) zum sensorischen Sprachzentrum (BA 22), wo die Schrift mit einem Sinn verknüpft wird. Beim Vorlesen wird dieser Sprachimpuls mittels Fasciculus arcuatus an das motorische Sprachzentrum übermittelt (Trepel 2017). Man nimmt an, dass die Eingabe zur Sprachproduktion in das GODIVA-Modell aus lexikalischen, semantischen oder syntaktischen Verarbeitungsbereichen der inferioren präfrontalen Kortexregionen BA 45 oder bei Wiederholungsaufgaben aus posterioren Regionen stammt (Bohland et al. 2010). Diese Eingaben initiieren die Aktivierung von zwei parallelen und komplementären Darstellungen für eine bevorstehende Äußerung: eine phonologische Inhaltsdarstellung, von der angenommen wird, dass sie im linken inferioren frontalen Gyrus der linken Hemisphäre existiert, und eine strukturelle Rahmendarstellung, von der angenommen wird, dass sie im (prä-)supplementärmotorischen Kortex existiert. Beide Darstellungen stellen Planungsräume oder Formen des Arbeitsgedächtnisses dar, in denen repräsentative Neuronen einen kortikalen Code für die potenziellen Phoneme oder abstrakten Silben beinhalten, die die Äußerung definieren. Im GODIVA-Modell codieren diese Darstellungen gleichzeitig für mehrere bevorstehende Phoneme und Silbenrahmen, zudem existieren Aktivierungscodes, welche die serielle Reihenfolge regeln, in der die Sprache hergestellt wird. Diese Verläufe über Plan-Zellen (plan cells) werden durch wiederkehrende Dynamik für kurze Zeit beibehalten und können neue Eingaben bis zu einer bestimmten Elementkapazität zuverlässig verarbeiten. Diese treffen ein, 
ohne die laufende Leistung zu beeinträchtigen (Bohland et al. 2010). In Abb. 1 sind diese Abläufe konkret visualisiert und mit Hilfe der roten Pfeile nachzuvollziehen, im Folgenden wird der Ablauf erklärt.

Es werden Informationen empfangen, die Verschlüsselungen für Worte und kurze Phrasen enthalten. Konkret werden diese Informationen weitergeleitet an die Structural Frame Plan Cells mit den dazugehörigen Choice Cells im BA 8 im prä-supplementärmotorischen Kortex (Weg der strukturellen Rahmendarstellung) und an die Phonological Sequence Plan Cells im linken inferioren frontalen Gyrus mit den dazugehörigen Choice Cells im BA 44 (Weg der phonologischen Inhaltsdarstellung). Die Structural Frame Plan Cells kodieren in abstrakter Form verschiedene Silben einer Sprache, die häufig verwendet werden. Die Phonological Sequence Plan Cells sind assoziiert mit einer erhöhten Aktivität bei gedächtnisgesteuerten Sprechaufgaben, insbesondere wenn die serielle Komplexität einer sprachlichen Äußerung erhöht wird. Im Modell geht man davon aus, dass hier die Darstellung des bevorstehenden Sprechplans enthalten ist und diskrete phonologische Codierungsaufgaben erledigt werden (Bohland et al. 2010). Die Phonological Sequence Plan Cells (Weg der phonologischen Inhaltsdarstellung) aktivieren sowohl ihre zugehörigen Choice Cells als auch eine Planungsschleife in den Basalganglien, welche über den Thalamus in die Phonological Sequence Choice Cells, die phonologischen Entscheidungsareale, projizieren. Die über diese Schleife modifizierten und korrigierten Sprachinformationen des Kortex werden nun zum frontalen Operculum in die Speech Sound Map Plan Cells sowie Speech Sound Map Choice Cells weitergeleitet, die den Speicher für Motorprogramme darstellen. Hier sind Bewegungsabläufe 
der gebräuchlichsten Silben einer erlernten Sprache abgelegt. Nach einer erneuten Korrektur schicken die Speech Sound Map Choice Cells das Programm über die hauptsächlich in der linken Hemisphäre gelegenen Motor Plan Cells weiter, wo das vorbereitete Programm gefiltert wird und mit Informationen aus dem prä-supplementärmotorischen Kortex (strukturelle Rahmendarstellung) konkurriert (in Abb.1 ist der Einfluss aus dem prä-supplementärmotorischen Kortex auf die Motor plan cells nicht eingezeichnet). Die zur Produktion geplanten Programme werden nun in die bilateral gelegenen Motor Output Cells weitergeleitet. Hier treffen die Programme von beiden Wegen zusammen und werden erneut abgeglichen. Der andere Weg (strukturelle Rahmendarstellung) geht über die Aktivierung der Structural Frame Plan Cells über die ebenfalls im supplementärmotorischen Kortex gelegenen Motor Initiation Cells zu einer motorischen Schleife der Basalganglien, die über den Thalamus, in diesem Fall direkt, in die bilateralen Motor Output Cells projiziert. Die Basalganglienschleife ist für die entsprechende Freigabe geplanter Sprachgeräusche an das Ausführungssystem zuständig. Außerdem werden die Basalganglien auch von den Structural Frame Choice Cells angesteuert um dann weiter über den Thalamus in die Phonological Sequence Choice Cells zu projizieren um in die bereits oben erklärte Planungsschleife in Richtung Speech Sound Map zu steuern, wo die Bewegungsabläufe der gebräuchlichsten Silben hinterlegt. In den Motor Output Cells (bilateral im Kortex vorhanden) findet, wie bereits oben beschrieben, der Abgleich der unterschiedlichen Vorbereitungswege kurz vor Sprechbeginn statt (Bohland et al. 2010). Diese Darstellung soll nur einen kleinen Einblick in das GODIVA-Modell herstellen, um eine Vorstellung von den komplexen Vorgängen der neuronalen Sprechmotorik zu bekommen. 
2.1.3 Der weitere physiologische Sprechvorgang bis zum Ausführen des Sprechens

Der Gyrus precentralis (BA 4) aktiviert wiederum über kortikonukleäre Bahnen die entsprechenden Hirnstammkerne, welche die für die Sprache wichtigen Muskeln vor allem im Kehlkopf und Rachen sowie die mimische Muskulatur versorgen. Besonders fein differenzierte Körperteile wie die Zunge, die Hand oder das Gesicht insgesamt, nehmen demzufolge ein großes Areal im motorischen Kortex ein. Die wichtigste Funktion des Gyrus precentralis ist die willkürliche Versorgung der kontralateralen Körperhälfte über den Tractus corticospinalis und corticonuclearis, wie beispielsweise die Feinmotorik der Zunge (Trepel 2017).

\subsubsection{Anatomie und Repräsentation der Zunge im Kortex}

Die Zunge spielt eine Hauptrolle beim Sprechakt (Trepel 2017). Sie ist ein schleimhautbedeckter Muskelkörper, welcher sich embryologisch aus Anteilen der ersten drei Schlundbögen entwickelt (Drews 2006) und motorisch an der Nahrungsaufnahme und Artikulation beteiligt ist. Sensorisch beherbergt die Zunge das Geschmacksorgan und nimmt mechanische Reize auf (Aumüller et al. 2006). Motorisch wird die Zunge durch den N. hypoglossus (XII) innerviert, der als einziger Hirnnerv mit mehreren Faserbündeln vor der Olive aus der Medulla oblongata entspringt und sich später mit seinen Endästen in der gesamten Zungenmuskulatur verteilt (Trepel 2017). Seine Kommandos bekommt er vom Gyrus precentralis (wie bereits oben beschrieben) in dem das Zungenareal weit lateral liegt, zwischen dem Zuständigkeitsbereich des Kiefers sowie des Schluckens und nicht weit entfernt vom Handareal (Aumüller et al. 2006). Das primär sensorische Zungenareal liegt im Gyrus postcentralis des Kortex, lateral der Gesichtsregion (Nakamura et al. 1998; Miyamoto et al. 2006). Die sekundär somatosensorische kortikale Repräsentation (S2) der Zunge wurde 2008 von der Arbeitsgruppe um Sakamoto untersucht und befindet sich unmittelbar am 
S2-Areal der Hand und bedeutend weiter anterior als die S2-Fuß-Region (Sakamoto et al. 2008). Sekundärfelder sind für die erste integratorische Verarbeitung, also die Interpretation von der Sinneswahrnehmung zuständig und befinden sich im BA 40 und 43, nachgeschaltet sind die Assoziationsfelder, die Handlungskonsequenzen auf diese Wahrnehmungen initiieren (Trepel 2017). In unserer Studie wird mittels transkranieller Magnetstimulation das motorische Zungenareal im Gyrus precentralis aufgesucht und stimuliert.

\subsection{Definition des Stotterns}

\subsubsection{Phänomenologie und theoretische Grundlagen des Stotterns}

Stottern kommt in allen Kulturen und sozioökonomischen Gesellschaften vor und begleitet die Menschheit schon sehr lange. Viele berühmte Menschen haben gestottert, unter anderem Charles Darwin, König Georg VI. von England, Winston Churchill und einige mehr. Stottern scheint ein vielschichtiges Problem zu sein, und jede stotternde Person kennt Erlebnisse und Situationen, in denen sie symptomfrei sprechen kann (Natke und Alpermann 2010). Stottern wird oft als Redeflussstörung, die ohne auslösendes Ereignis in der Kindheit entstandenen ist, beschrieben. Im Englischen wird es daher auch developmental stuttering genannt. Dies führte bei falscher Übersetzung häufig zu Verwirrung und wurde als Entwicklungsstottern fehlinterpretiert. Im deutschsprachigen Raum wurde es bis 2016 als idiopathisches Stottern bezeichnet (Andrews et al. 1983) und aufgrund neuer Forschungserkenntnisse umbenannt. Seit 2016 gilt die von der Deutschen Gesellschaft für Phoniatrie und Pädaudiologie (DGPP) herausgegebene AWMF-Leitlinie, die neue Einblicke liefert auf die pathophysiologischen genetischen und neurologischen Grundlagen. Vor diesem Hintergrund wurde eine neue Definition für Stottern und Poltern erarbeitet. Diese unterscheidet zwi- 
schen originärem (neurogenem nicht-syndromalen und neurogenem syndromalen) und erworbenem (neurogenen und psychogenem) Stottern. Die bisher als idiopathisches Stottern bezeichnete Redeflussstörung heißt seit 2016 „originäres neurogenes nicht-syndromales Stottern“, kurz „originäres Stottern“ (Neumann et al. 2016). Um das originäre Stottern (OS) geht es in dieser Arbeit. Es zeichnet sich dadurch aus, dass es in der Kindheit oder vor der Pubertät beginnt, plötzlich oder graduell, und über diese hinaus besteht. Es lässt sich abgrenzen vom erworbenen neurogenen, dem psychogenen und dem originären neurogenen syndromalen Stottern, wie Abb. 2 zu entnehmen ist (Neumann et al. 2016). Die Erblichkeit des OS liegt bei $>80 \%$, es zählt zu den Redeflussstörungen und ist gekennzeichnet durch Stockungen des Sprechablaufs, Repetitionen von Lauten und Teilen eines Worts (Yairi und Ambrose 2013).

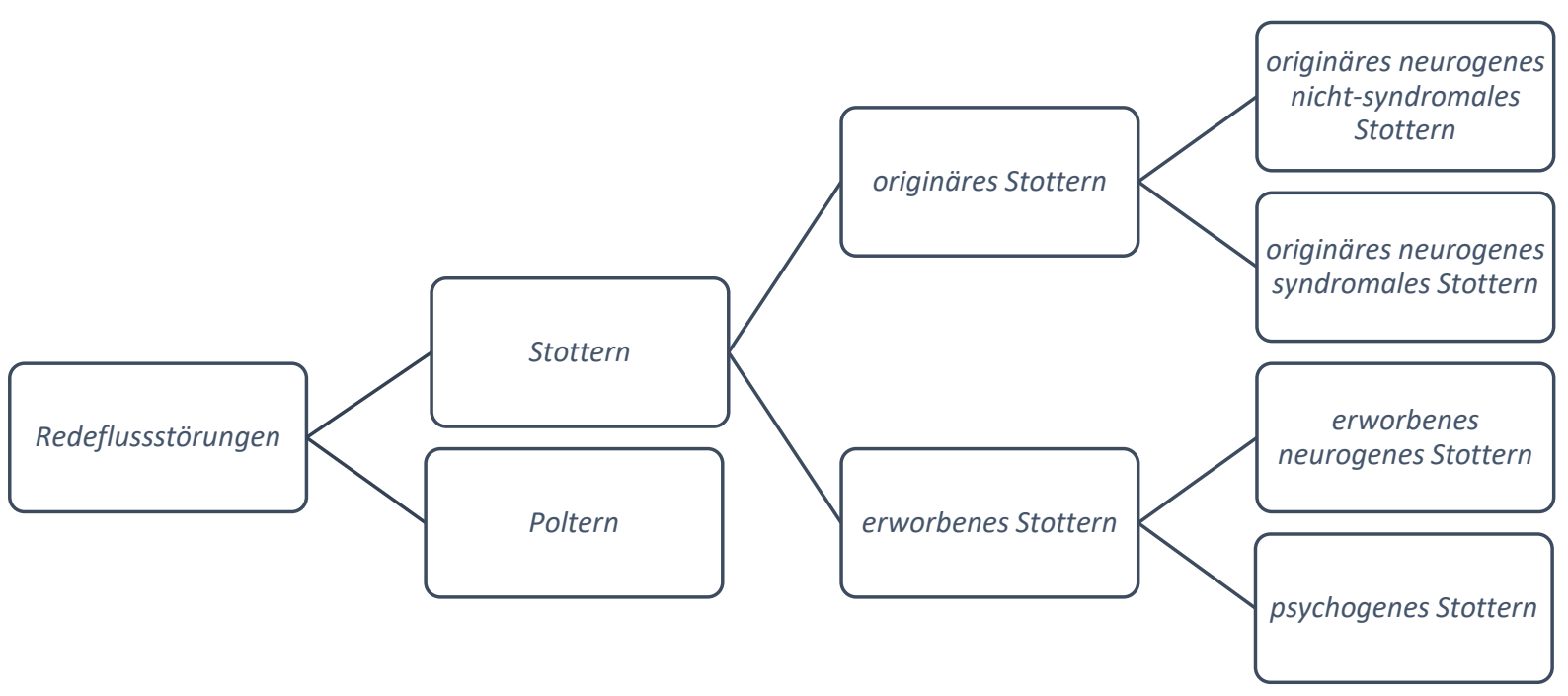

Abb. 2: Einteilung der Redeflussstörungen

(Modifiziert und angelehnt an Leitlinie Redeflussstörungen, Neumann et al. 2016, S. 18). 


\subsection{Originäres neurogenes nicht-syndromales Stottern (OS)}

\subsubsection{Epidemiologie und Definition}

Etwa $1 \%$ der erwachsenen Bevölkerung stottert. Meistens entsteht das Stottern vor dem 6. Lebensjahr (in $90 \%$ ) und in den meisten Fällen zwischen dem 2. und 5. Lebensjahr und bei nahezu allen vor dem 12. Lebensjahr. Das originäre Stottern, welches ohne äußeren Anlass entsteht, betrifft ca. fünf Prozent der Kinder im Alter von drei bis sechs Jahren. Der Großteil (50-80 \%) dieser stotternden Kinder erfährt bis zur Pubertät eine spontane Remission (Yairi und Ambrose 2013), wobei Mädchen häufiger remittieren als Jungen, sodass im Erwachsenenalter Männer vier- bis fünfmal häufiger stottern als Frauen. Nach der Pubertät wird das Stottern offiziell als originäres neurogenes nicht-syndromales Stottern bezeichnet, kurz originäres Stottern (OS). Die aktuelle Leitlinie definiert das originäre Stottern folgendermaßen:

„Das originäre neurogene nicht-syndromale Stottern ist eine zentralnervöse Störung des Sprechens und seiner Planung, die in der Kindheit hauptsächlich auf Grund einer genetischen Disposition zustande kommt. Es umfasst eine Kernsymptomatik mit stottertypischen Sprechunflüssigkeiten und eine Begleitsymptomatik mit vegetativen, motorischen und emotionalen Reaktionen auf die Sprechunflüssigkeit." (Neumann et al. 2016, S. 21)

\subsection{2 Ätiologie des Stotterns}

Um ätiologische Aussagen über das Stottern treffen zu können, werden molekulargenetische und verhaltensgenetische Studien herangezogen. Molekulargenetische Untersuchungen lokalisieren die Gene oder Allele der Chromosomen, die zur Ausprägung des Phänotyps 
Stottern beitragen. Verhaltensgenetische Untersuchungen differenzieren den Varianzanteil des Phänotyps von Umwelteinflüssen und von genetischen Anteilen, um zu schauen, wie stark das Verhalten genetisch beeinflusst ist. Hierzu werden Familien- oder Zwillingsstudien interpretiert. Die molekulargenetischen Studien haben bisher diverse Dispositionsorte für Stottern auf den Chromosomen 1, 2, 3, 5, 7, 9, 12, 13, 15, 16, 18 und 21 lokalisiert (Neumann et al. 2016) und vier Gene identifiziert, die für insgesamt $20 \%$ des chronisch idiopathischen Stotterns verantwortlich sind (Frigerio-Domingues und Drayna 2017). Eine 2011 publizierte Studie beschreibt eine Mutation namens Glu1200Lys des Gens GNPTAB auf Chromosom 12, die in einer Reihe von pakistanischen stotternden Familien und mehreren nicht verwandten betroffenen Personen südasiatischer Abstammung gefunden wurde. Hierbei zeigte sich sogar ein gemeinsamer Haplotyp, was impliziert, dass es sich um eine Gründermutation handeln könnte, also einer Abstammung von einem gemeinsamen Vorfahren (Fedyna et al. 2011). Auf Chromosom 9 zeigte sich eine Region die mit remittierten und persistierenden Stotternden gekoppelt ist und auf Chromosom 15 eine Region, die nur mit persistierendem Stottern in Verbindung gebracht wird. Stotternde Männer zeigen eine Kopplung an das Chromosom 9 und Frauen an Chromosom 21 (Suresh et al. 2006). Allerdings konnten bisher noch keine Einflussfaktoren ermittelt werden, die für den Ausprägungsgrad des Phänotyps verantwortlich sind (Kraft und Yairi 2012), hierzu werden weitere Genanalysen von stotternden Personen benötigt. Verhaltensgenetische Untersuchungen bestätigen eine Erblichkeit für stotternde Erwachsene von bis zu 82 \% (Rautakoski et al. 2012). Aktuell wird Stottern als multifaktorielle polygenetische Störung betrachtet, die 
zu ca. 20 - 30 \% von Umwelteinflüssen und hauptsächlich von verschiedenen Genen geprägt wird. Der ausstehende Varianzanteil von weniger als $30 \%$ ist also Umwelteinflüssen zuzuschreiben, diese Umwelteinflüsse gliedern sich in „geteilte Umwelteinflüsse“ und „nicht-geteilte Umwelteinflüsse“ - Ersteres beschreibt die Umwelt des stotternden Kindes denen Geschwisterkinder gleichermaßen ausgesetzt sind und die sie deshalb von anderen Kindern unterscheiden. Letzteres umfasst alle Beeinflussungen von außen auf das Genom, hierzu können physiologische oder anatomische Eindrücke sowie die individuelle Gedankenwelt zählen. Die nicht-geteilten Umwelteinflüsse zählen hinsichtlich der Stotterätiologie zu den wirksamen Umwelteinflüssen (Fagnani et al. 2011), sodass der elterliche Erziehungsstil nicht für die Symptomatik herangezogen werden kann. Bei eineiigen Zwillingen zeigt sich eine Konkordanz des Stotterns im Vergleich zu zweieiigen Zwillingen, nämlich 44,9 \% zu 12,0 \%, dies hat Neumann aus sechs Untersuchungen zwischen 1976 und 2007 gemittelt (Neumann et al. 2016). Obwohl hier von einer identischen Genetik und geteilten Umwelt ausgegangen wird, zeigen nicht alle Geschwisterkinder von stotternden eineiigen Zwillingen die Symptomatik. Hier muss also lediglich von der Vererbung einer Prädisposition ausgegangen werden, die zusätzlich den nicht-geteilten Umweltfaktor bedarf um den Phänotyp Stottern zu entwickeln.

\subsubsection{Symptomatik}

Die Symptomatik des Stotterns (OS) beinhaltet primäre Auffälligkeiten im Sprechfluss, die als Kernsymptomatik bezeichnet wird, sowie die sekundären Reaktionen auf die Kernsymptomatik, die sich als körperliche und psychische Begleiterscheinungen manifestieren. Die Kernsymptomatik zeichnet sich aus durch Repetitionen (Wiederholungen von Lauten und 
Silben; schnell, unrhythmische oder angespannte Wiederholungen einsilbiger ganzer Wörter), Prolongationen sowie untypischen Wortunterbrechungen, womit ein hörbares oder stummes Blockieren von Artikulation oder Phonation gemeint ist (Neumann et al. 2016). Die Stärke und Häufigkeit der Symptomatik kann intraindividuelle Schwankungen aufweisen, sowie auch innerhalb der Lebensgeschichte schwanken (Fox et al.1996). Hingegen gibt es einige Gesetzmäßigkeiten, die bei allen Stotternden auftreten. Dazu zählt, dass Stottern gehäuft an gewissen Loci auftritt. Diese Loci sind vor allem Worte mit hohem Informationsgehalt, eher Konsonanten als Vokale, lange Wörter und eher betonte als unbetonte Silben (Natke und Alpermann 2010). Außerdem hängt das Störungsbild von der Sprechsituation ab. Die Symptomatik steigt bei erhöhtem Kommunikationsdruck und stressbeladenen Situationen wie zum Beispiel bei steigender Zuhörerzahl (Caruso et al. 1994). Die unwillkürliche Begleitsymptomatik dient unbewusst initial dem Auflösen von Blockierungen und zeichnet sich aus durch Mitbewegungen des Körpers (Mimik, Gestik, Rumpf und Extremitäten), veränderte Sprechatmung, unkontrollierter Sprechlautstärke und Tonhöhe oder gepresstem Stimmklang (Natke und Alpermann 2010). Neben der Begleitsymptomatik gibt es Komorbiditäten des Stotterns. Inwieweit diese Folge oder einfach nur koexistent zum Stottern sind lässt sich nicht klären. Die seit vielen Jahren verbreitete Annahme, dass Stottern und generelle Sprachfähigkeiten im Sinne von Sprachentwicklungsstörungen von Kindern in enger Verbindung stehen, ist zu bezweifeln. Die Studienlage weist eher auf ein beeinträchtigtes Motorkontrollsystem, das Kindern das „Vorankommen“ im Sprechen erschwert. Dies ist nicht zu verwechseln mit einer Fehlfunktion im linguistischen System. Die Kinder haben 
lediglich das Problem die intendierte Bedeutung über das unzureichende sprechmotorische System auszudrücken (Nippold 2012). Neben dieser körperlichen Komorbidität existieren psychische Komorbiditäten, die sich wiederum in sozioökonomischen Defiziten widerspiegeln. Hierzu zählt, dass AWS ein erhöhtes Risiko für alle Arten von Angststörungen (Iverach und Rapee 2014), insbesondere für generalisierte Angststörungen, soziale Phobien (Craig und Tran 2014) und Panikattacken aufweisen. Mit Eintritt in das Schul- und Arbeitsalter machen sich die sozioökonomischen Faktoren stärker bemerkbar, sodass es trotz uneingeschränkter kognitiver Leistungsfähigkeit aufgrund des Stotterns zu einer schlechteren Bewertung der Leistungen kommen kann sowie zu Einschränkungen bei der Lebensgestaltung (Ausbildung, Beruf, Partnerwahl, Einkommen, soziale Aktivitäten) (McAllister et al.2012). Auch bei AWNS treten Auffälligkeiten im Sprechfluss auf, hier gilt es eine Unterscheidung zwischen normalen und stottertypischen Unflüssigkeiten vorzunehmen. Im Vergleich zu der o.g. stottertypischen Symptomatik zeichnen sich die normalen Unflüssigkeiten durch Pausen, abgebrochene Wörter, Revisionen von Wörtern und Wiederholungen von Wörtern oder Phrasen während des Sprechens aus (Neumann et al. 2016). Die Diagnose Stottern ist zu stellen, wenn mehr als $3 \%$ stottertypische Unflüssigkeiten vorliegen, die in einer repräsentativen Sprechprobe erhoben wurden (Natke und Alpermann 2010). Die genaue Vorgehensweise, die wir auch in dieser Studie verwendet haben, ist im SSI-3 (Stuttering Severity Instrument, 3rd edition, Riley 1994) dargelegt.

\subsubsection{Therapie des Stotterns}

Da die Ursache des Stotterns ungeklärt ist, gibt es bisher keine kausalen Therapien und somit keine Möglichkeit, für die Gesamtgruppe eine Therapie zu erarbeiten. Die aktuellen 
Therapien streben die Reduktion der Symptomatik inklusive Begleitsymptomatik an sowie bessere soziale Integration der Betroffenen und eine Verbesserung der Lebensaktivität und -Qualität (Neumann et al. 2016). Es existieren international und im deutschen Sprachraum insgesamt fünf Therapieansätze, deren Wirksamkeit hinsichtlich der genannten Ziele belegt ist. Das Verfahren der globalen Sprechrestrukturierung möchte ich am Beispiel des Fluency Shaping im Folgenden darstellen. Es gilt als verhaltenstherapeutisches Übungsverfahren und ist dem Evidenzlevel 1 zuzuschreiben (Neumann et al. 2016), was nach aktueller Studienlage bei vorliegenden randomisierten und kontrollierten Forschungsarbeiten als gesicherte Empfehlung zu verstehen ist (Oxford Centre for Evidence-based Medicine). Die Sprechrestrukturierung beinhaltet minimal unterschiedliche Ansätze (Fluency Shaping, Camperdown-Programm, Slowed Speech). Bei der Therapie des Fluency Shaping erlernt der Teilnehmer zunächst ein neues Sprechmuster bei dem keine Stotterereignisse auftreten. Nach und nach wird dieses in das Alltagssprechen übertragen, automatisch sollen sich hierbei die negativen Gefühle vermindern und das Selbstbewusstsein des Teilnehmers stärken. Um das Sprechmuster zu erlernen ist intensives Training notwendig. Deshalb werden die Kurse als mehrwöchige Intensivkurse angeboten. Inhaltlich wird initial die Sprechgeschwindigkeit stark gedrosselt. Dabei werden entweder alle Laute oder Vokale prolongiert, bei den Anfangslauten wird die Stimme weich eingesetzt oder es werden deutliche Atmungsphasen gemacht und die Wörter beim Ausatmen verbunden, sodass eine kontinuierliche Artikulation vorliegt. Das Sprechen hört sich eigenartig an, als würden die Teilnehmer in einem monotonen Singsang sprechen. Stottern kommt dabei nicht vor. Nun gilt es diesen 
monotonen Singsang zu verinnerlichen und alle möglichen Transferübungen zu absolvieren. Sobald das Stottern wieder auftritt, wird empfohlen erneut die Sprechgeschwindigkeit zu drosseln und in Anwendung zu sprechen (Natke und Alpermann 2010).

\subsection{Aktueller Forschungsstand der zerebralen Befunde zum Stottern}

\subsubsection{Neuromorphologische Auffälligkeiten}

Die bildgebenden Verfahren haben in den letzten Jahren zunehmend exaktere hirnstrukturelle Differenzen zwischen AWS und AWNS geliefert. Dabei zeigten sich unter anderem wegweisende Anomalien der linken Hemisphäre bei AWS (Sommer et al. 2002, Neef et al. 2015b). Ich werde mich im folgenden Abschnitt auf die Darstellung der bedeutsamsten neuromorphologischen Auffälligkeiten der linken Hemisphäre beschränken, da in meiner Studie lediglich die linke Hemisphäre stimuliert wird. Im linken Gyrus frontalis inferior (einschließlich der klassischen Broca-Region) wurde mittels fMRT (funktionelle Magnetresonanztomographie) eine Reduktion der grauen Substanz gefunden, die bei AWS positiv mit der Symptomschwere korrelierte, bei remittierten Erwachsenen ebenfalls noch weiterhin vorhanden war und sich bei stotternden und remittierten Kindern bilateral temporal darstellte (Chang et al. 2008, Kell et al. 2009). Im linken Gyrus frontalis inferior befinden sich die motorischen und sensorischen Planungsschleifen (Phonological Sequence Cells und Speech Sound Map Cells), sodass man hier wahrscheinlich von einer primären Läsion ausgehen kann. Kompensatorisch zeigten sich vor allem rechtshemisphärisch Substanzzunahmen der grauen und weißen Substanz in frontalen, parietalen und anderen temporalen Regionen (Neumann und Euler 2010). Man kann davon ausgehen, dass die rechtshemisphärischen Substanzzunahmen bei Erwachsenen vom persistierenden Stottern kommen, da 
bei stotternden oder remittierten Kindern keine rechtshemisphärischen Substanzzunahmen zu verzeichnen waren (Chang et al. 2008). Zudem konnte mittels DiffusionstensorBildgebung (Diffusion Tensor Imaging, DTI) eine Reduktion der fraktionalen Anisotropie (Gerichtetheit, Integrität und Dichte) der weißen Substanz im linken Rolandischen Operculum, kaudal von BA 44, unterhalb der linkshemisphärischen orofazialen Motorregion bei AWS nachgewiesen werden (Sommer et al. 2002, Connally et al. 2014). Dazu zählt der Fasciculus arcuatus sowie der Fasciculus longitudinalis superior, der unter anderem auditorische (BA 22) und frontale (BA 44, 45) Kortexregionen verbindet. Die Reifung des Bereichs geschieht in den ersten Lebensjahren, zeitlich passend zu erstmaliger Beobachtung des Stotterns in der Sprechentwicklung, deshalb geht man hier von einem Reifungsproblem der Faserbahnen aus (Sommer et al. 2002). In einer weiteren DTI-Studie wurde für stotternde Kinder eine reduzierte fraktionale Anisotropie unter anderem im Corpus callosum gefunden (Chang et al. 2008), die sich auch bei Erwachsenen nachweisen ließ (Civier et al. 2015). Das Corpus callosum zählt zur weißen Substanz und verbindet abgesehen von der primären Hör- und Sehrinde alle Teile der Hemisphären miteinander (Trepel 2017). Die Anomalien im frontalen Corpus callosum bei AWS weisen auf eine fehlangepasste Reduktion interhemisphärischer Inhibition hin, die wahrscheinlich eine unvorteilhafte Rekrutierung rechtsfrontaler Kortexareale für die Sprachproduktion zur Folge hat (Civier et al. 2015). Ein weiterer Befund der DTI Studie von Connally et al. beschreibt linksseitige Störungen der Faserverbindungen des Tractus corticospinalis und Tractus corticunuclearis zu den Effektor-Mo- 
torneuronen (Connally et al. 2014), welche für die willkürmotorische Versorgung der kontralateralen Körperhälfte zuständig sind, insbesondere für die Feinmotorik der distalen Extremitätenabschnitte und die Kopfregion (Gesicht, Zunge) (Trepel 2017).

\subsubsection{Neurofunktionelle Auffälligkeiten}

Seit den 1990er Jahren weisen neurofunktionelle Bildgebungsforschungen Korrelate des Stotterns in frontalen und präfrontalen Regionen nach, die sich hauptsächlich durch anormale Mehraktivierung von rechtslateralen motorischen Hirnregionen wie dem BA 47 und fehlender auditorischer Aktivierung beim Stottern äußern (Brown et al. 2005). Allerdings möchte ich mich auch bei der Darstellung der hirnfunktionellen Auswirkungen auf die linksseitige Hemisphäre begrenzen, weil die Aufführung aller Forschungsergebnisse in dem Bereich zu weit führt. Aktuelle fMRT-Metaanalysen zeigten, dass die Stottersymptomatik mit einer reduzierten linkshemisphärischen fronto-parieto-temporalen Aktivität einhergeht (Belyk et al. 2015, Budde et al. 2014). Etwas konkreter konnte in der bereits oben beschriebenen TMS-Studie von Neef und Kollegen eine reduzierte Dynamik und reduzierte MEPAktivität beim Sprechvorgang im linken primären Motorkortex bei AWS dargestellt werden (Neef et al. 2015a). Außerdem konnte mittels Magnetenzephalographie (MEG) gezeigt werden, dass AWS eine umgekehrte Abfolge der Kortexaktivität während des Sprechens haben. Bei AWS wird zuerst der linke Motorkortex aktiv und anschließend der linke inferiore frontale Kortex (Salmelin et al. 2000). Vermutlich besteht eine fehlerhafte Verbindung zwischen der linken sensomotorischen und frontalen Kortexregion (unter anderem der klassischen Broca-Region, BA 47) wie bereits im Kapitel neuromorphologische Auffälligkeiten beschrieben wurde (Kell et al. 2009, Sommer et al. 2002). Zudem zeigte sich in einer weiteren MEG- 
Studie eine linkshemisphärische Minderaktivität auditorischer Gebiete beim Stottern im Vergleich zu einer Mehraktivierung beim Flüssigsprechen bei AWS, was auf eine fehlerhafte Unterdrückung linkshemisphärischer auditorischer Hirnaktivität während des Sprechens hindeutet (Kikuchi et al. 2011). Nach einer erfolgreichen stotterreduzierenden Fluency Shaping Therapie zeigten sich ausgedehntere Hirnaktivierungen in frontalen motorischen Sprech- und Sprachregionen und eine Aktivitätsverschiebung in linkshemisphärische Regionen, insbesondere dort wo vorher Faseranomalien des Fasciculus arcuatus sichtbar waren (Neumann et al. 2003, 2005). Zusätzlich normalisierte sich die gestörte Funktion der Basalganglien, der anterioren Insula und des auditorischen Kortex bilateral (Integration des sensorimotorischen/auditorischen Feedbacks in das motorische System) (Giraud et al. 2008). Die bereits oben zitierten neueren fMRT-Metaanalysen präzisierten, dass posttherapeutisch eine erhöhte Sprechflüssigkeit mit verstärkten Koaktivierungen rechtsseitiger fronto-parieto-temporaler Gebiete verbunden ist (Belyk et al. 2015, Budde et al. 2014). Dies wurde durch eine weiterhin bestehende negative Korrelation in der rechten BA 47/12 (orbitofrontaler Kortex: linguistisch, z.B. Wortfindung, motorisch z.B. Zielbewegung) bestätigt (Kell et al. 2009). Hierbei kann man von einer Kompensation durch das homologe (kontralaterale) rechtshemisphärische Areal der Broca-Region (BA 47) ausgehen (Brown et al. 2005). In fMRT-Studien an remittierten AWS zeigte sich als mehraktive Region ein Gebiet im linken orbitofrontalen Kortex, homolog zur rechtsseitigen Kompensationsregion BA 47/12 bei stotternden Erwachsenen (Kell et al. 2009). Die neue linksseitige Aktivierung in dieser Regionen (BA 47/12) scheint die Sprechunflüssigkeiten komplett reduzieren zu können, wobei auf dem Weg zur endgültigen Remission die rechtsseitige Region (BA 47/12) 
kompensiert (Kell et al. 2009). Zwei Jahre nach Therapieende wurde eine erneut verstärkte Aktivität der rechten Hemisphäre beobachtet (Kell et al. 2018). Das lässt vermuten, dass sich Stottern nicht bloß durch strukturelle Unterschiede erklären lässt, sondern auch der Gebrauch und die Plastizität des Gehirns eine Rolle spielen. Passend dazu zeigte Kell (Kell et al. 2018), dass stotternde Männer posttherapeutisch und nach spontanem Rückgang der Symptomatik eine Zunahme der linkshemisphärischen Aktivität zeigten, vermutlich induziert durch eine Verbesserung der Hörrinde, denn nach der Therapie waren neue Verbindungen mit dem auditorischen Kortex (Gyrus temporalis anterior superior) nachzuweisen. Es kann vermutet werden, dass eine wirksame Therapie die rechtsseitige Kompensation in linksseitige homologe Regionen verlagert, ähnlich wie bei schlaganfallinduzierten Aphasien die Verlagerung in periläsionäre Regionen (Brownsett et al. 2014). Die Fluency Shaping Therapie als sprechflüssigkeitsverbessernde Technik bedient sich eines langsamen und gleichmäßigen Sprechrhythmus. Vermutlich dient der Rhythmus als externer Schrittmacher und schafft es den gestörten Ablauf zwischen auditorischen, somatosensorischen und sprechmotorischen Neuronennetzwerken zu synchronisieren (Neumann et al. 2005). Zusammenfassend wird aktuell davon ausgegangen, dass die Sprechflüssigkeit nur durch ständige dynamische Synchronisation zwischen auditorischen, somatosensorischen und sprechmotorischen Neuronennetzwerken gewährleistet werden kann. Die überwiegende Störung liegt in der Sprechmotorikkontrolle der auditiv-motorischen Integration, sodass eine adäquate Einpassung der eigenen gehörten Sprache in die sprechmotorische Planung und Ausführung nicht erfolgen kann. Bezogen auf das DIVA-Modell liegt hier eine gestörte Verarbeitung interner Feedforward-Mechanismen (Projektionen des motorischen Plans, die für 
eine Perzeption der geplanten Bewegung an das sensorische System gesendet werden) und auditiver Feedback-Mechanismen (GODIVA-Modell) vor (Neumann et al. 2016).

\subsection{Transkranielle Magnetstimulation (TMS)}

Die transkranielle Magnetstimulation (TMS) ist eine nicht-invasive Stimulationstechnik, die es erstmals möglich machte, die intrakortikale Erregbarkeit des Zungenareals bei AWS zu untersuchen und Veränderungen der TMS-induzierten Erregbarkeitsmodulation bei AWS zu beschreiben (Neef et al. 2011). Studien mit TMS waren bei AWS bis vor wenigen Jahren ungewöhnlich, was erstaunlich ist angesichts der Beziehung zwischen der Funktionalität des Motorsystems und Stottern und der weit verbreiteten Verwendung von TMS bei motorischen Störungen wie Parkinson (Chen und Chen 2019) oder Tourette-Syndrom (Grados et al. 2018). Bislang hat TMS zum Verständnis des exzitatorischen und inhibitorischen Verhältnisses der motorischen Funktionen von Stottern beigetragen und dabei geholfen, Belege für Stottermechanismen, die mit verschiedenen Techniken erworben wurden, besser zu verstehen und kritisch zu hinterfragen (Busan et al. 2017). In unserer Studie geht es um die Beurteilung der Modulationsfähigkeit/Dynamik der kortikalen Erregbarkeit und nicht um die bloße Aktivierung des Kortex, aus diesem Grund ist die TMS eine geeignete Methode für unsere Studie. Die Methode der transkraniellen Magnetstimulation wird im Folgenden erklärt.

\subsubsection{Entstehung der TMS und Physiologische Grundlagen}

1820 gelang dem dänischen Physikprofessor Christian Oersted der Nachweis, dass ein elektrischer Strom eine ursprünglich parallel zu ihm ausgerichtete Magnetnadel ablenkt. 
Hiermit stellte er eine Verknüpfung der beiden Gebiete Elektrik und Magnetik her. Die Folgerung aus diesem Versuch war, dass neben einem elektrischen Feld ein magnetisches Feld entsteht, wenn zum Beispiel durch eine Spule Strom geleitet wird. Die TMS erzeugt indirekt über ein magnetisches Feldes einen elektrischen Strom in den Körperzellen. Während der TMS fungiert das Gehirn wie die kleinste Einheit einer Spule in der das elektrische Feld entsteht (Hess 2007). Die neurophysiologischen Mechanismen der TMS sind aufgrund ihrer Komplexität bisher noch nicht gänzlich erklärbar im Gegensatz zur elektrischen Stimulation eines Nervs. Es steht fest, dass die neuronale Aktivierung ohne mechanischen Kontakt, nur mittels elektromagnetischem Feld eine Erregung auf Nervenzellen induzieren kann. Die Basisfunktion der Erregung von Nervenzellen besteht darin, dass es ein zu ladendes intra- und extrazelluläres Zellvolumen gibt, welches ein elektrisches Feld darstellt. Depolarisation und Hyperpolarisation sind hierbei die grundlegenden Eigenschaften. Durch die achtförmige Reizspule, die auf den Kopf aufgelegt wird, induziert der Magnetreiz ein parallel ausgerichtetes elektrisches Feld. Vermutlich löst die TMS bevorzugt Aktionspotenziale (AP) in parallel zum induzierten elektrischen Feld und gebogen verlaufenden Axonen aus. Im stimulierten Kortex breiten sich die APs nun über synaptische Verbindungen aus und induzieren somit inhibitorische und exzitatorische postsynaptische APs und führen zur Stimulation der verbundenen Hirnregion (Siebner et al. 2007).

\subsubsection{Die achtförmige Spule}

Wir haben in unserer Studie die achtförmige Doppelspule verwendet (engl. figure-of-eight coil). Diese besteht aus zwei Rundspulen, die nebeneinander angeordnet und verbunden sind. Dabei fließt der Strom erst durch die eine und dann entgegengesetzt durch die zweite 
Teilspule. Durch die beschriebene Gegenläufigkeit summieren sich die elektrischen Felder am Schnittpunkt der Teilspulen und bilden ein punktuelles Magnetfeld. Trotzdem trifft die Stimulation insbesondere bei der tiefen TMS nicht nur isoliert einen kleinen Zielpunkt im Gehirn, sondern auch das Nervengewebe in der Umgebung (Weyh et al. 2007).

\subsubsection{Zentralmotorische Leitungszeit}

Die zentralmotorische Leitungszeit (ZML), die kortikale Reizschwelle und die MEPAmplitude sind die wichtigsten Landmarken zur Beurteilung der Axone und somit wichtige Kriterien in der Diagnostik mit TMS. Die ZML beurteilt die Integrität schnellleitender Axone des kortikospinalen Traktes. Definiert ist sie als minimale Latenz vom Beginn der TMS des primär motorischen Kortex bis zur Erregung des peripheren Neurons. Sie wird als Differenz aus der kortikomuskulären Leitungszeit $(\mathrm{KML})$ und peripherer motorischer Leitungszeit (PML) berechnet. Um die ZML bestimmen zu können, ist zusätzlich zur Magnetstimulation des Kortex die isolierte Stimulation des peripheren Motoneurons nötig. Die KML wird ermittelt, indem mit einem transkraniellen Puls der Motorkortex erregt wird und dann vom willkürlich leicht vorgespannten Zielmuskel das MEP mit Oberflächenelektroden abgeleitet wird. Die PML kann entweder mit der F-Wellen-Methode bestimmt werden oder mit transkutan elektrischer oder magnetischer Reizung des proximalen Spinalnervs in der Nähe seines Durchtritts durch das Foramen intervertebrale. Bei der F-Wellen-Methode wird der den Zielmuskel innervierende Nerv in der Nähe des Muskels gereizt, die Reizintensität wird so lange erhöht, bis die Amplitude der direkten Muskelantwort (M-Welle, orthodrome Erregungsfortleitung) nicht mehr steigt. Die antidrome Erregungsfortleitung, welche durch die Aktivierung spinaler Motoneurone entsteht, bildet die F-Welle. Die peripher motorische 
Leitungszeit berechnet sich wie folgt: „PML[ms]=0,5x(F+M-1)“ (Müller und Ziemann 2007, S. 73). Die elektrische Stimulation erfolgt entweder mittels Nadelelektrode oder transkutan. Bei beiden Methoden gibt es eine Anode und Kathode, und es wird entweder mittels Hochvoltstimulator oder magnetischer Stimulation gereizt. Die entstehende Latenz zwischen Stimulus und dem ausgelösten Muskelsummenaktionspotenzial (MSAP) entspricht der PML. Die ZML lässt sich berechnen, indem die PML von der KML subtrahiert wird (Müller und Ziemann 2007).

\subsubsection{Motorisch evozierte Potenziale}

Am häufigsten wird die TMS angewandt zur Ableitung und Beurteilung von motorisch evozierten Potenzialen (MEPs) (Rossini et al. 2015). Diese bestehen aus der elektromyographischen Summenantwort des peripheren Muskels, welche im primär motorischen Kortex durch TMS ausgelöst wird. Das MEP darf nicht verwechselt werden mit dem MSAP, welches durch supramaximale elektrische Nervenstimulation ausgelöst wird. Die elektrische Stimulation führt beim MSAP zu einem AP in allen motorischen Axonen und somit zur Aktivierung aller motorischen Einheiten. Es kommt hier nicht zu einer wesentlichen Phasenauslöschung, und die wiederholte Nervenreizung führt zu einem gut reproduzierbaren MSAP, welches wenig variiert in der Latenz, Amplitude und Form. Anders verhält es sich bei dem transkraniellen Magnetimpuls. Die hier ausgelöste Erregung der motorischen Einheiten ist viel komplizierter als nach einer supramaximalen elektrischen Stimulation, weil das MEP durch die Stimulation der schnell leitenden Nerven entsteht und durch mehrere räumliche und zeitliche Phänomene beeinflusst wird. Die kortikomuskuläre Erregungsausbreitung 
verläuft asynchron und kann somit zum gegenseitigen Auslöschen der elektrischen Potenziale führen. Deshalb hat das transkraniell ausgelöste MEP verglichen mit dem peripher ausgelösten MSAP eine kleinere „Spitze-zu-Spitze-Amplitude“ und mehr Richtungsinversionen. Die TMS ist somit sehr vom Untersucher und der Situation abhängig (Müller und Ziemann 2007).

\subsubsection{Ableitung des MEP mittels EMG - Allgemeine Vorgehensweise}

Um die Summenantwort möglichst vieler motorischer Einheiten zu erfassen, werden die MEPs in der Regel mit Oberflächenelektroden abgeleitet. Durch EMG wird die Aktivität der motorischen Einheit über Oberflächenelektroden erfasst, und im Elektromyogramm werden die SummenAPs aufgezeichnet. Der elektrische Widerstand zwischen Körperteil und Elektrode kann mit Elektrodengel verringert werden. Die Erdung wird an einem Ort zwischen der transkraniellen Stimulation und den Ableitelektroden angebracht. In unserem Fall bietet sich die Stirn an. Eine gute Erdung trägt entscheidend zur Minimierung der Artefakte bei (Kaelin-Lang 2007).

\subsubsection{Platzierung der Stimulationsspule über dem motorischen Kortex}

Die Platzierung der Spule hängt vom Zielmuskel ab, der stimuliert werden soll. Die Spule muss an der Schädeloberfläche hin und her verschoben werden, bis ein MEP ausgelöst wird (engl. motor hotspot). Bisher existieren zwei verschiedene Spulentypen: die einfache Rundspule und die achtförmige Doppelspule. Die Doppelspule ermöglicht es, ein Kortexareal zu reizen, welches genau unter dem Spulenzentrum liegt. Bei der einfachen Rundspule ist der Stimulationsort etwas diffuser. Wenn man die TMS diagnostisch anwendet, benutzt man die einfache Rundspule, da es einfacher ist, die Spule über dem Zielareal zu platzieren. Die 
Rundspule hat weniger fokale Stimulationswirkung und ermöglicht somit klinisch verwertbare Messungen der kortikospinalen motorischen Überleitung bei wenig Zeitaufwand (Hess et al. 1987). Um wissenschaftliche Fragestellungen zu beantworten, verwendet man die fokale Doppelspule. Mit ihr dauert es länger den kortikalen Ort des Zielmuskels zu finden und diesen während länger dauernden Messungen zu erhalten, jedoch ist die Stimulation etwas genauer. Die Suche des hotspot (kortikale Stelle, an der sich zuverlässig MEPs am Zielmuskel auslösen lassen) sollte zuerst mit einer überschwelligen Intensität begonnen werden um sich an suboptimalen Stellen grob orientieren zu können. Je näher am idealen Reizort stimuliert wird, desto niedriger kann die Intensität eingestellt werden. Die größte Dichte an kortikospinalen Verbindungen zum Zielmuskel stellt den hotspot dar und über diesem Punkt sollte die Spule positioniert werden. Besonders bei der Doppelspule kann eine minimale Veränderung der Kippung den Stimulationsort verschieben und zur besseren Erregung des hotspot führen, ohne dass die Spule verschoben wird (Kaelin-Lang 2007). Wenn die zu reizende Stelle nicht ideal von der Stimulation getroffen wird, dann wird eine höhere Reizschwelle benötigt als am hotspot (Conforto et al. 2004), außerdem führt dies bei gleichbleibender Reizintensität zu einer Reduzierung und Variabilität der durchschnittlichen MEP-Amplitude. Das MEP ist also nicht sicher reproduzierbar bei suboptimaler Reizung. Die Spulen-Position des primär motorischen Kortex zur Erregung der Zunge ist $8 \mathrm{~cm}$ lateral des Vertex zu finden. Wenn man die Repräsentationsstelle der Hand zur Orientierung nimmt, befindet sich der hotspot der Zungenrepräsentation ca. 2 bis $3 \mathrm{~cm}$ anterior und 1 bis $2 \mathrm{~cm}$ lateral von der Handrepräsentation (Svensson et al. 2003). Wurde diese 
Stelle lokalisiert, kann sie mit einem wasserfesten Stift markiert werden und als hotspot bezeichnet werden. Anschließend wird die Motorschwelle des hotspots bestimmt.

\subsubsection{Motorische Reizschwelle und die Auswahl der Reizintensität}

Die motorische Reizschwelle (Englisch: motor threshold) ist definiert als die Reizintensität des Stimulators, die bei mindestens 3 von 6 Stimulationen ein MEP evoziert, welches eine Amplitude von mindestens $50 \mu \mathrm{V}$ aufweist (Rothwell et al. 1999). Die motorische Reizschwelle wird auch als Ruheschwelle bezeichnet, das Gegenteil ist die aktive Schwelle, diese wird bestimmt, indem man den Zielmuskel vorspannt. Einerseits kann die Intensität des transkraniellen Stimulus angegeben werden als individuelle kortikale Reizschwelle, z. B. $120 \%$ oder in Bezug auf die Stimulatorleistung, z. B. $40 \%$ der maximalen Ausgangsleistung des Stimulators. Um eine objektive Standardisierung zu gewährleisten wird die Intensität des TMS meist mit der individuellen Reizschwelle angegeben und da sich die Reizintensität von ca. 120 - 140 \% der Ruheschwelle nur unwesentlich verändert, wird für klinische oder experimentelle Messungen häufig eine Reizintensität von $120-140 \%$ der individuellen kortikalen Ruheschwelle gewählt (Kaelin-Lang 2007).

\subsubsection{Aufzeichnung der MEP}

MEP-Amplituden sind trotz einheitlicher Stimulationsbedingungen und wiederholter Messung sehr veränderlich im Gegensatz zu den gut reproduzierbaren MSAPs (Hess et al. 1987). Hauptsächlich verantwortlich für die Schwankungen der MEPs, eine sorgfältige Arbeitsweise vorausgesetzt, sind die physiologischen Schwankungen der kortikalen und spinalen Erregbarkeit. Ursachen für diese Schwankungen können Veränderungen der Aufmerksamkeit, Wachheit oder Unterschiede in der Anspannung von Muskeln sein. Ziel ist es die TMS- 
Versuche so konstant wie möglich zu gestalten. Abgesehen davon gibt es eine intrinsische Variabilität, die unabhängig von den standardisierten Bedingungen auftritt. Zu dieser intrinsischen Variabilität gehören zum Beispiel die desynchrone kortikospinale Erregungsausbreitung und multiple Entladungen der spinalen Motoneurone. Wie stark die MEPAmplitude durch die einzelnen Faktoren beeinflusst wird, lässt sich nicht genau ableiten. Deshalb wird der Mittelwert mehrerer aufeinanderfolgender MEPs als Maß für die kortikospinale Erregbarkeit benutzt (Kaelin-Lang 2007). MEP-Amplituden liegen oft über 0,1 mV und sind von der Ausgangsaktivität bei guter Muskelentspannung einfach abzugrenzen. Jedes Potenzial kann einzeln ausgemessen werden. Anschließend wird die Spitze-zu-SpitzeAmplitude ausgemessen. Um Erwartungs- und Habituationseffekte durch den Teilnehmer zu minimieren, ist es empfehlenswert das Intervall der TMS zwischen 5 und 8 Sekunden zu variieren (Kaelin-Lang und Cohen 2000).

\subsubsection{MEP-Ausmessung und Amplitudenquotientenberechnung}

Das MEP kann durch verschiedene Parameter gemessen werden. Dazu zählen die Amplitude, die Latenz, die Dauer, die Zahl der Nulldurchgänge, die Fläche unter der Kurve der negativen Phase oder des gesamten rektifizierten MEPs. Die Kennwerte können mit Hilfe von Computerprogrammen automatisch ausgemessen werden. Meist wird beim MEP die Spitze-zu-Spitze-Amplitude gemessen, da sie robust gegen Störfaktoren wie Rauschen oder instabile Grundlinie ist (Kaelin-Lang und Cohen 2000). Fehleranfällig wird die Methode, wenn ein MEP zum Beispiel länger andauert. Deshalb wird häufig die sogenannte mittlere rektifizierte MEP-Amplitude gemessen, welche direkt proportional zur Gesamtfläche ist. Rektifiziert bedeutet, dass alle Messpunkte des MEP berücksichtigt werden und die 
Fläche im negativen Bereich positiviert wird. Die positiven Werte des MEP werden über die Gesamtdauer gemittelt. Ein Nachteil hierbei ist, dass dieser Kennwert durch Rauschen oder eine unstabile Grundlinie (z. B. durch ein TMS-Artefakt) stärker verfälscht als die „Spitzezu-Spitze-Methode“. Außerdem ist der Anfang und das Ende der MEP-Amplitude nicht immer sicher zu erkennen. Trotzdem ist bei gesunden Teilnehmern und entspanntem Zielmuskel die mittlere rektifizierte MEP-Amplitude ein gutes Maß für die Abmessung der motorischen Antwort (Kaelin-Lang 2007). In unserer Studie haben wir den Beginn und das Ende des MEPs visuell, also händisch bestimmt. Damit konnten die übermäßig langen MEPs und somit auch die Fehleranfälligkeit der Spitze-zu-Spitze-Amplitudenmethode beseitigt werden und wir konnten die Spitze-zu-Spitze-Amplitude guten Gewissens anwenden.

\subsubsection{Stimulation der Zungenmuskulatur (N. hypoglossus)}

Durch die TMS wird bei der Stimulation der Zungenmuskulatur magnetisch der Motorkortex und somit indirekt der proximale und distale Teil des N. hypoglossus erregt. Die Ableitung der MEPs besteht über den Zungenhälften. Hierbei wird eine löffelförmige Elektrodenhalterung aus Kunststoff benötigt, die in der Regel im zahntechnischen Labor angefertigt werden kann. Auf der Stirn kann die Erdungselektrode platziert werden. Die TMS-Spule wird temporooccipital ipsilateral zur Ableitseite angelegt um das Zungenareal im linken Motorkortex zu stimulieren. Abgeleitet wird von beiden Zungenhälften, weil die Zunge gleichseitig innerviert wird. Der Teilnehmer wird gebeten den Zungenlöffel leicht mit der Zunge gegen den knöchernen Gaumen zu drücken, damit dieser als Widerlager dient. Dadurch wird eine geringe Vorinnervation erreicht und der sichere Kontakt zwischen Zun- 
genoberfläche und Ableitelektrode ist sichergestellt. Bei neurophysiologischen Experimenten ist eine völlige Entspannung des Zielmuskels wichtig um vergleichbare Ergebnisse mit unbeeinflusster Reizschwelle zu haben. Die Anspannung (Vorinnervation) der Zunge wird lediglich zur Experimentvorbereitung genutzt, um das gesuchte Zungenareal besser lokalisieren zu können, ohne direkt die maximale Stimulusintensität nutzen zu müssen (Urban 2007).

2.5.11 Neurostimulation und Erregungsfortleitung bis zur MEP-Entstehung Das Aktionspotential (AP), welches normalerweise in Muskelzellen oder Neuronen in typischer Form abläuft, lässt sich unterteilen in die folgenden Phasen: 1. Die Initiationsphase. Hierbei hebt sich das Membranpotenzial durch einen Reiz bis zum Schwellenpotenzial an. 2. Die Depolarisationsphase bezeichnet den steilen Potenzialanstieg vom negativen bis in den positiven Bereich. 3. Die Repolarisationsphase beschreibt den Abfall des Ruhepotenzials. Wenn das Potenzial noch weiter absinkt unter das Niveau des Ruhepotenzials, dann spricht man von der Nachhyperpolarisation. Beim Abklingen des APs und kurze Zeit danach ist das Axon nicht mehr erregbar. Diese Phase nennt man Refraktärzeit. Die Zeitspanne benötigen die spannungsabhängigen Natriumkanäle zur Wiederaktivierung. Die absolute Refraktärzeit beträgt weniger als eine Millisekunde und die relative Refraktärphase beträgt wenige Millisekunden. Im Gegensatz zum AP ist das postsynaptische Potenzial keine Allesoder-Nichts-Antwort, sondern hängt von der Anzahl der synchronen präsynaptischen Erregungen ab, wodurch postsynaptisch die Neurotransmitter über Rezeptoren die lonenkanäle für Natrium und Calcium aktivieren. Bei der transkraniellen Stimulation des primären 
motorischen Kortex spielt das eine große Rolle, denn die Verbindung zu den zervikalen spinalen Motoneuronen geht über poly- oder monosynaptische Verbindungen. Bei der transkraniellen Magnetstimulation werden abhängig von der Reizintensität, der Spulenausrichtung und Reizkonfiguration unterschiedlich viele deszendierende Erregungswellen mittels Fortleitung von APs über die kortikokortikalen Neurone fortgeleitet und von dort wiederum unter Summation der depolarisierenden EPSPs bei Überschreiten der Reizschwelle als AP auf monosynaptischen Verbindungen mit den spinalen Motoneuronen übertragen. Die einzelnen APs summieren sich zu EPSPs, sobald der Schwellenwert überschritten ist, und die Erregung kann über die monosynaptischen Verbindungen zu den spinalen Motoneuronen weitergeleitet werden. Hinzu kommt, dass an inhibitorischen Synapsen über hemmende Botenstoffe wie GABA ein inhibitorisches Signal generiert werden kann, sodass EPSP und IPSP sich gegenseitig auslöschen können und die Summe darüber entscheidet, ob an der postsynaptischen Zelle ein AP ausgelöst wird. Überragen die EPSPs, wird ein exzitatorisches postsynaptisches Potenzial ausgelöst, welches man, im Zielmuskel angekommen, als MEP bezeichnet. Die Erregung kann nur in die Richtung vom prä- auf das postsynaptische Neuron laufen (Siebner et al. 2007).

\subsubsection{Sicherheitsaspekte}

Bei hirngesunden Menschen gilt die TMS-Reizung als sicher und unkompliziert. Die Anwendungsrichtlinien und Kontraindikationen für Einzelreiz-, Doppelreiz- oder rTMS-Modus sind identisch. Die TMS-Anwendung unterliegt der gesetzlichen Regelung für Medizinprodukte und es muss eine CE-Zertifizierung des Stimulationsgerätes vorliegen. Kontraindikationen waren in unserer Studie das Vorliegen internistischer oder psychiatrischer Erkrankungen 
sowie eine erhöhte zerebralen Anfallsbereitschaft oder eine Schwangerschaft. Weiterhin durften keine Patienten mit implantierten biomedizinischen Geräten wie z.B. einem Cochleaimplantat oder einer Medikamentenpumpe oder Patienten mit intrakraniellen Metallpartikeln (z.B. Gefäßclips) teilnehmen. Auch stellt ein Herzschrittmacher eine Kontraindikation dar. Bei Patienten mit Herz- oder Hirnschrittmachern darf die TMS-Spule unter keinen Umständen in unmittelbare Nähe $(<5 \mathrm{~cm})$ des implantierten Generators gelangen, dies kann zur Entladung oder irreversiblen Schädigung führen (Paulus et al. 2007). Bei der regelmäßigen TMS-Anwendung sind Grenzwerte einzuhalten für Stimulusanzahl, Intensität und Frequenz. Trotzdem geben diese Hinweise keine absolute Sicherheit, da innerliche Einflüsse wie der aktuelle Zustand des Gehirns zum Stimulationszeitpunkt, beeinflusst durch Medikation oder Schlafentzug oder andere pathologische Zustände eine Rolle spielen kann (Rossi et al. 2009). Um das Risiko für Zwischenfälle möglichst gering zu halten oder im besten Falle zu vermeiden, wurde in unserer Studie ein enger Bereich von Ein- und Ausschlusskriterien definiert.

\section{Material und Methoden}

\subsection{Teilnehmerkollektiv}

\subsubsection{Aufklärung und Einverständnis}

Alle Teilnehmer wurden vor Beginn der Experimente ausführlich mündlich und schriftlich aufgeklärt über den Ablauf, die Versuchsrisiken und den Zweck der Studie. Alle Teilnehmer erklärten sich schriftlich bereit an der wissenschaftlichen Studie freiwillig teilzunehmen. Die Ethikkomission der Universität Göttingen hat das positive Votum zum Studienprotokoll 
gegeben (Nr. des Ethikvotums 1/2/12), siehe Abb. 21 im Anhang. Viele Erwachsene wollten aus diversen Gründen (lange Versuchszeit, Angst vor Nebenwirkungen aufgrund der Ausschlusskriterien und Unkenntnis der transkraniellen Magnetstimulation) nicht teilnehmen, sodass es sich schwierig gestaltete, ausreichend Teilnehmer zu finden. In die Studie wurden 18 AWS einbezogen. Zu jedem stotternden Teilnehmer wurde versucht einen gleichaltrigen nichtstotternden Teilnehmer mit gleichem Geschlecht, ähnlicher Händigkeit und mit möglichst ähnlichem Bildungsgrad zur Kontrollmessung zu finden. 16 der AWS wurden über das Institut der Kasseler-Stotter-Therapie (KST) rekrutiert, ein Proband per Aushang am Schwarzen Brett und ein Proband aus der Göttinger Selbsthilfegruppe der Stotterer.

\subsubsection{Ein- und Ausschlusskriterien}

Die Ein- und Ausschlusskriterien wurden von uns mittels Anamnesebogen erhoben. Die allgemeinen Einschlusskriterien für die Teilnahme an den Experimenten waren: Fließende Deutschkenntnisse, Alter über 18 Jahren und unter 70 Jahren. Die allgemeinen Ausschlusskriterien waren: neurologische, internistische oder psychiatrische Erkrankungen; Metallimplantate im Körper oder Herzschrittmacher sowie sonstige metallenthaltenden Objekte; vorliegende Schwangerschaft; Teilnehmer, die Auffälligkeiten bei der neurologischen Untersuchung zeigen sowie alle möglichen Aphasien; Abhängigkeit von Drogen, Alkohol oder Medikamenten.

\subsubsection{Gruppe der stotternden Erwachsenen}

Die Probandengruppe bestand aus 18 AWS, davon 16 Männer und zwei Frauen, das mittlere Alter ist 27,11 Jahre mit einer Standardabweichung (SD) von 9,04. Zusätzlich war für 
die Teilnehmergruppe gefordert: der Beginn des Stotterns darf nicht mit einem hirnschädigenden Ereignis verbunden gewesen sein; das Stottern muss vor der Pubertät begonnen haben.

\subsubsection{Gruppe der nichtstotternden Erwachsenen/Kontrollgruppe}

Die Kontrollgruppe setzte sich aus 17 nichtstotternden Erwachsenen (AWNS) zusammen. Bei neun Männern und acht Frauen ergab sich ein mittleres Alter von 24 Jahren mit einer SD von 3,32. Da bekannt ist, dass genetische Faktoren bei der Entstehung des Stotterns eine Rolle spielen und wir allgemein Sprech- und Sprachstörungen der Kontrollprobanden ausschließen wollten, waren folgende Ausschlusskriterien zusätzlich für die Kontrollgruppe gefordert: Stottern; keine AWS in der Verwandtschaft, einschließlich Verwandter 2. Grades; Teilnahme an logopädischen Behandlungen in der Kindheit sowie generell Personen, die bereits in logopädischer Behandlung waren.

\subsubsection{Neurologische Statuserhebung}

Mit allen Teilnehmern wurde von mir eine ärztliche neurologische Untersuchung durchgeführt hinsichtlich Auffälligkeiten im Gang und der Okulomotorik oder weiterer neurologischer Symptome, die auf zentrale Störungen hindeuten könnten.

\subsubsection{Sprechmotorische Analysen}

Alle Teilnehmer lasen laut einen Text vor laufender Kamera vor und beantworteten offene Fragen. Die Videoaufnahmen wurden verblindet von der Logopädin Bettina Helten analysiert. Sie war in keiner Weise in andere studienspezifische Maßnahmen einbezogen und wurde auf Honorarbasis zur Auswertung der Videoaufnahmen in der Klinik für Klinische Neurophysiologie der Medizinischen Fakultät der Universität Göttingen angestellt. Die 
Sprachprobe beinhaltete das Vorlesen des Textes „Der kleinste Schneesturm“ (von Richard Bräutigam 1980) mit 685 Silben. Zudem wurden einige Fragen zur Person beantwortet und eine Wegbeschreibung vorgetragen, sodass mindestens 500 Silben Lesen und 500 Silben Spontansprache ausgewertet werden konnten. Zur Bestimmung der Stotterschwere und zur Sicherstellung des flüssigen Sprechens wurde das Stuttering Severity Instrument (SSI) 3 (Riley 1994) nach der deutschen Anpassung (Sandrieser und Schneider 2008) bei allen Teilnehmern verwendet. Das ist ein Instrument zur Analyse der gestotterten Silben, bezogen auf die gesprochenen Silben. Hiermit wird die Stotterschwere nach fünf Schweregraden eingeschätzt von „sehr leicht“ bis „sehr schwer“. Diese setzen sich zusammen aus dem Punktwert der Stotterhäufigkeit beim Lesen und Spontansprechen, der Dauer des Stotterereignisses sowie dem motorischen Begleitverhalten. Kumulativ lässt sich ein SSI (Stuttering Severity Instrument)-overall-Score erheben. Wenn im Folgenden der Begriff SSI gebraucht wird, dann ist der SSI-Score-overall damit gemeint. Zur Überschaubarkeit der erhobenen SSI-Scores unterteilten wir in „,kein Stottern“, „, sehr leichtes Stottern“, „leichtes Stottern“, „mittelschweres Stottern“, „schweres Stottern“ und „sehr schweres Stottern“, wie in Abb. 3 dargestellt. Als Grenzmarke zwischen Stottern und Nicht-Stottern wurde der SSIScore von 10 Punkten gewählt. Werte von 0 - 10 werden als ,kein Stottern' gewertet.

\begin{tabular}{|l|l|l|}
\hline Punktewert & Perzentile & Schweregrad \\
\hline $0-10$ & - & Kein Stottern \\
\hline $10-12$ & $1-4$ & Sehr leichtes Stottern \\
\hline
\end{tabular}




\begin{tabular}{|l|l|l|}
\hline $13-17$ & $5-11$ & \\
\hline $18-20$ & $12-23$ & Leichtes Stottern \\
\hline $25-24$ & $41-60$ & Mittelschweres Stottern \\
\hline $32-31$ & $61-77$ & \\
\hline $35-36$ & $78-88$ & Schweres Stottern \\
\hline $37-46$ & $89-95$ & Sehr schweres Stottern \\
\hline
\end{tabular}

Abb. 3: Einteilung der Stotterschwere

(Quelle: „Stuttering Severity Instrument 3“ (Riley 1994))

Die Intention der Sprechprobe war lediglich eine Abschätzung des aktuellen Schweregrades des Stotterns. Bei allen untersuchten AWS ist die Diagnose „Idiopathisches Stottern bzw. originäres neurogenes nicht-syndromales Stottern" durch einen Logopäden oder Sprachheiltherapeuten im Erwachsenenalter gestellt worden, so dass auch diejenigen Teilnehmer, die während der Videoaufnahme nicht eindeutig gestottert haben, in die Studie mit aufgenommen worden sind. Dies traf auf zwei stotternde Erwachsene zu. Von allen Teilnehmern erhielten 20 die Bewertung „kein Stottern“, drei „sehr leichtes Stottern“, drei "leichtes Stottern“, drei „mittelschweres Stottern“, drei „schweres Stottern“, drei „sehr schweres Stottern“. Es zeigte sich ein signifikanter Unterschied des SSI-3-Score zwischen den beiden 
Gruppen AWS und AWNS (für statistische Kennwerte siehe unter Kap. 3.1.9, Tab. 1 Analyse der Teilnehmerdaten).

\subsubsection{Händigkeit}

Die Händigkeit aller Teilnehmer wurde mit Hilfe des Edinburgh-Händigkeits-Inventar (Oldfield 1971) bestimmt. Das ist eine Skala zum Ankreuzen jener Alltagstätigkeiten, die mit den Händen ausgeführt werden. Der Fragebogen bezieht sich auf zehn manuelle Aktivitäten (z.B. Schreiben, Zeichnen, Werfen, Schere u.a.), hiermit kann die Rechts- bzw. Linkshändigkeit jedes Teilnehmers bestimmt werden. Der Teilnehmer muss angeben, ob er die Tätigkeiten nur mit der linken bzw. rechten Hand durchführt oder gar keine Präferenz für eine Hand besteht. Es können 20 Punkte vergeben werden, die sich auf beide Hände verteilen und aus denen sich ein Lateralisierungsquotient errechnet. Die Händigkeit kann zwischen 100 (ausschließlich linkshändig) und + 100 (ausschließlich rechtshändig) liegen. Der Lateralisierungsquotient gibt die Händigkeit in \% an, indem bei 0 eine Grenze zwischen den Händigkeiten gezogen wird (Oldfield 1971). Hierbei war der Unterschied zwischen den Gruppen AWS und AWNS nicht signifikant und beide Gruppen waren als rechtshändig zu werten (siehe Kap. 3.1.9, Tab. 1).

\subsubsection{Bildung}

Als Kriterium wurde zusätzlich noch der Grad der Ausbildung ermittelt, indem wir ein abteilungsinternes Punkteschema zur groben Klassifikation des Ausbildungsgrades verwendeten: $1 \hat{=}$ Haupt-/ Realschulabschluss, $2 \hat{=}$ Abitur/ abgeschlossene Berufsausbildung, $3 \hat{=}$ 


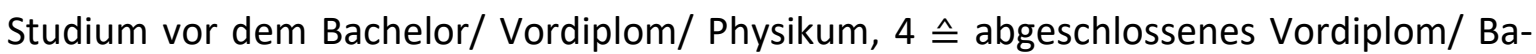
chelor-Studium/ Physikum, $5 \triangleq$ Diplom, Master, Staatsexamen, $6 \triangleq$ Promotion/ Habilitation.

\subsubsection{Sortierung und Auswertung der Teilnehmerdaten}

Wir werteten die Daten von insgesamt 35 Teilnehmern aus, 17 davon waren AWNS und 18 waren AWS. Alle Gruppenunterschiede sind in Tab. 1 dargestellt und wurden mit Ausnahme der Bildung mit einem T-Test bestimmt. Ob es Unterschiede im Bildungsgrad zwischen den Gruppen gab wurde mittels Mann-Whitney U-Test geprüft. Der Mann-Whitney U-Test ergab: $U=95,5, z=-1,93, p=0,057$, es bestand also kein signifikanter Gruppenunterschied in der Bildung. Bezüglich der gemessenen motorischen Reizschwelle (wird angegeben in \% der maximalen Ausgangsleistung des Stimulators, siehe Kap. 2.5.7) ergab sich auch kein signifikanter Gruppenunterschied. Bei den gestotterten Silben ergab sich ein signifikanter Unterschied, in der Kontrollgruppe lagen diese bei 0,62 \%, der SSI-Score war 4,29 und in der AWS-Gruppe ergaben sich gestotterte Silben von 10,80 \% bei einem SSI-Score von 23,33. Zusätzlich wurde bei AWS die Familienanamnese erhoben, bei acht von 18 AWS fanden sich AWS in der Verwandtschaft. Davon waren wiederum fünf Verwandte ersten Grades dabei. Frühkindliche Entwicklungsschäden traten bei keinem der Teilnehmer auf.

\begin{tabular}{|l|l|l|l|}
\hline Analysierte Daten & $\begin{array}{l}\text { Stotternde } \\
\text { Erwachsene }\end{array}$ & $\begin{array}{l}\text { Nichtstotternde } \\
\text { Erwachsene }\end{array}$ & $\begin{array}{l}\text { Signifikanz, F, T, df1, } \\
d f 2\end{array}$ \\
\hline Teilnehmer, $n$ & $\begin{array}{l}18 \text { (16 Männer, } \\
2 \text { Frauen) }\end{array}$ & 17 (9 Männer, 8 Frauen) & - \\
\hline Alter in Jahren & $\begin{array}{l}\text { M 27.11 (SD } \\
9.04)\end{array}$ & M 24 (SD 3.32) & $p=0.185$ (n.s.) \\
\hline
\end{tabular}




\begin{tabular}{|c|c|c|c|}
\hline & & & $\begin{array}{l}F=4.087, \quad T=1.336 \\
\text { mit } d f 1=33 \text { und } T= \\
1.367 \text { mit } d f 2=21.72\end{array}$ \\
\hline $\begin{array}{l}\text { Händigkeit (Score }-100 \\
\text { bis }+100)\end{array}$ & $\begin{array}{l}M \quad 78.07 \quad(S D \\
51.76)\end{array}$ & M 85.96 (SD 16.99) & $\begin{array}{l}p=0.547 \text { (n.s.) } \\
F=3.049, \quad T=-0.598 \\
\text { mit } d f 1=33 \text { und } T=- \\
0.612 \quad \text { mit } \quad d f 2= \\
20.814\end{array}$ \\
\hline $\begin{array}{l}\text { Bildung (ordinalskaliert } \\
\text { Score 1-6) }\end{array}$ & $\begin{array}{l}M \quad 2.67 \quad(M R \\
14.81)\end{array}$ & M 3.65 (MR 21.38) & $p=0.057$ (n.s.) \\
\hline $\begin{array}{l}\text { Motorschwelle } \quad \text { (siehe } \\
\text { Kap. 2.6.2) linke Hemi- } \\
\text { sphäre in } m V\end{array}$ & $\begin{array}{l}M \quad 45.56 \quad(S D \\
7.39)\end{array}$ & M 44.80 (SD 4.23) & $\begin{array}{l}p=0.741 \text { (n.s.) } \\
F=3,896, T=0.328 \\
\text { mit } d f 1=33 \text { und } T= \\
0.333 \text { mit } d f 2= \\
27,330\end{array}$ \\
\hline $\begin{array}{l}\text { SSI-3 Score (siehe } \\
\text { Kap.2.4.5) }\end{array}$ & $\begin{array}{l}M \quad 23.33 \quad(S D \\
11.60)\end{array}$ & M 4.29 (SD 2.49) & $\begin{array}{l}P<0.001 \text { (sig.) } \\
F=24,605, T=6.621 \\
\text { mit } d f 1=33 \text { und } T= \\
6.801 \quad \text { mit } d f 2= \\
18,659\end{array}$ \\
\hline \% gestotterte Silben & $\begin{array}{l}M \quad 10.8 \quad(S D \\
11.28)\end{array}$ & $M 0.62$ (SD 0.00) & $\begin{array}{l}P<0.001 \text { (sig.) } \\
F=24,008, T=3.716 \\
\text { mit } d f 1=33 \text { und } T= \\
3.826 \text { mit } d f 2= \\
17,060\end{array}$ \\
\hline
\end{tabular}

Tabelle 1: Analyse der Teilnehmerdaten

( $\mathrm{M}=$ Mittelwert, $\mathrm{SD}=$ Standardabweichung, $\mathrm{MR}=$ mittlerer Rang, $\mathrm{n}=$ Stichprobe, $\mathrm{n} . \mathrm{s} .=$ nicht signifikant, sig. = signifikant, $d f=$ Freiheitsgrade, Levene-Test der Varianzgleichheit, $\mathrm{T}-$ Test für die Mittelwertgleichheit) 


\subsection{Studiendesign}

Die Vorbereitung der Teilnehmer auf die Experimente war standardisiert und beinhaltete folgende Schritte:

- Aufklärung über mögliche Risiken

- Aufzeichnung einer Sprechprobe jeden Teilnehmers

- Erhebung der Anamnesedaten des Teilnehmers

- Testung der Händigkeit mittels Edinburgh-Händigkeits-Score (Oldfield 1971)

- Orientierende neurologische Untersuchung

- Bestimmen des hotspots der Zungenrepräsentation

- Bestimmen der Motorschwelle und Ermittlung der Stimulusintensität

- Übung: dem Teilnehmer wird detailliert erklärt, wie das Experiment abläuft und es folgt eine Übung mit fünf Wörtern; sollte der Proband unsicher sein, übt er weitere fünf Wörter

- Start mit den Experimenten Nr. 1-3

Nachdem wir die Teilnehmer aufgeklärt hatten über alle möglichen Risiken und Nebenwirkungen, neurologisch keine Auffälligkeiten feststellbar waren und das schriftliche Einverständnis für die Videoaufzeichnung gegeben worden war sowie die personenbezogenen Formalitäten ausgefüllt worden waren, erklärten wir den genauen Ablauf der Experimente. Es wurde darauf hingewiesen, dass keine metallischen Gegenstände, EC-Karten oder Handys in den Taschen getragen werden sollten. Außerdem wurden die individuellen Fragen der Teilnehmer zu TMS beantwortet.

\subsubsection{Datenerfassung mittels Elektromyographie und technischer Geräteaufbau}

Für die Experimente benutzten wir das schmerzlose und nicht-invasive Verfahren der TMS. Durch das für weniger als eine Millisekunde entstehende Magnetfeld (1 - 2 Tesla) auf der Kopfoberfläche (linker Motorkortex des Zungenareals) wird ein Stromfluss induziert, der es schafft, fokale neuronale Entladungen in einem Gehirnareal von einigen Kubikzentimetern zu generieren. Die Stimulation erfolgte mit monophasischen Einzelimpulsen eines 
Magstim-200-Geräts (Magnetstimulator Magstim 200² von der Firma Inomed). Durch die Stimuli der TMS werden die zu quantifizierenden muskelevozierten Potenziale hervorgerufen. Die EMG dient dazu, die elektrische Muskelaktivität über die vier Klebeelektroden (CareFusion Disposable Ringelectrodes, Firma: Natus - Nicolet Neurodiagnostic) von der Zunge abzuleiten und zu messen (Abb. 4).

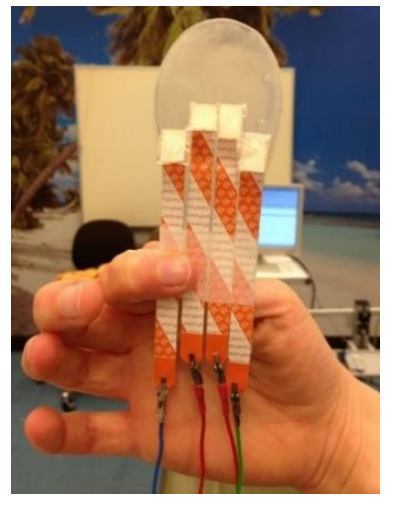

Abb. 4: Zungenlöffel mit Elektroden

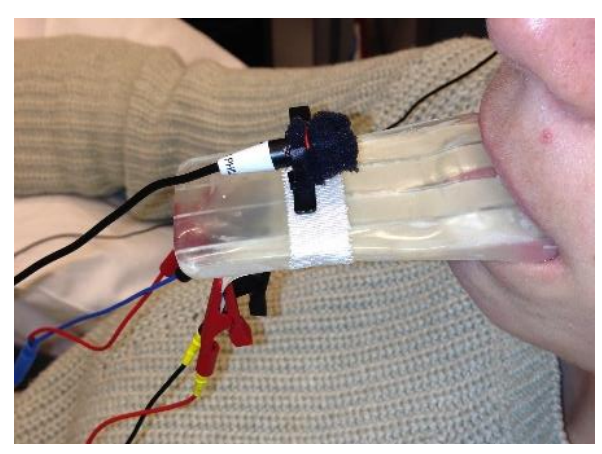

Abb. 5: Mikrofon auf Zungenlöffel

Die Teilnehmer wurden aufgefordert, den Mund locker zu schließen, ständigen Kontakt zwischen Elektroden und Zunge zu gewährleisten und Muskelanspannung zu vermeiden, wie es in vorausgegangen Studien der Fall war (Neef et al. 2015a). Außerdem durfte der Zungenlöffel nicht mit der rechten Hand festgehalten werden, um eine Vorinnervation (der Zungenmuskulatur und Muskeln des rechten Handareals durch Muskelanspannung) zu verhindern. Auf dem Zungenlöffel klemmte ein Mikrofon (Produkt: SR 40 Flexx, Firma: Harman AKG. Abb. 5), welches die Tonspur aufzeichnete. Die abgeleiteten EMG-Signale wurden mittels D360 Digitimer von Störsignalen befreit (Firma Digitimer, Produkt: D360 8-Channel Patient Amplifier), das biologische Signal wurde verstärkt und in ein analoges Signal umgewandelt. 


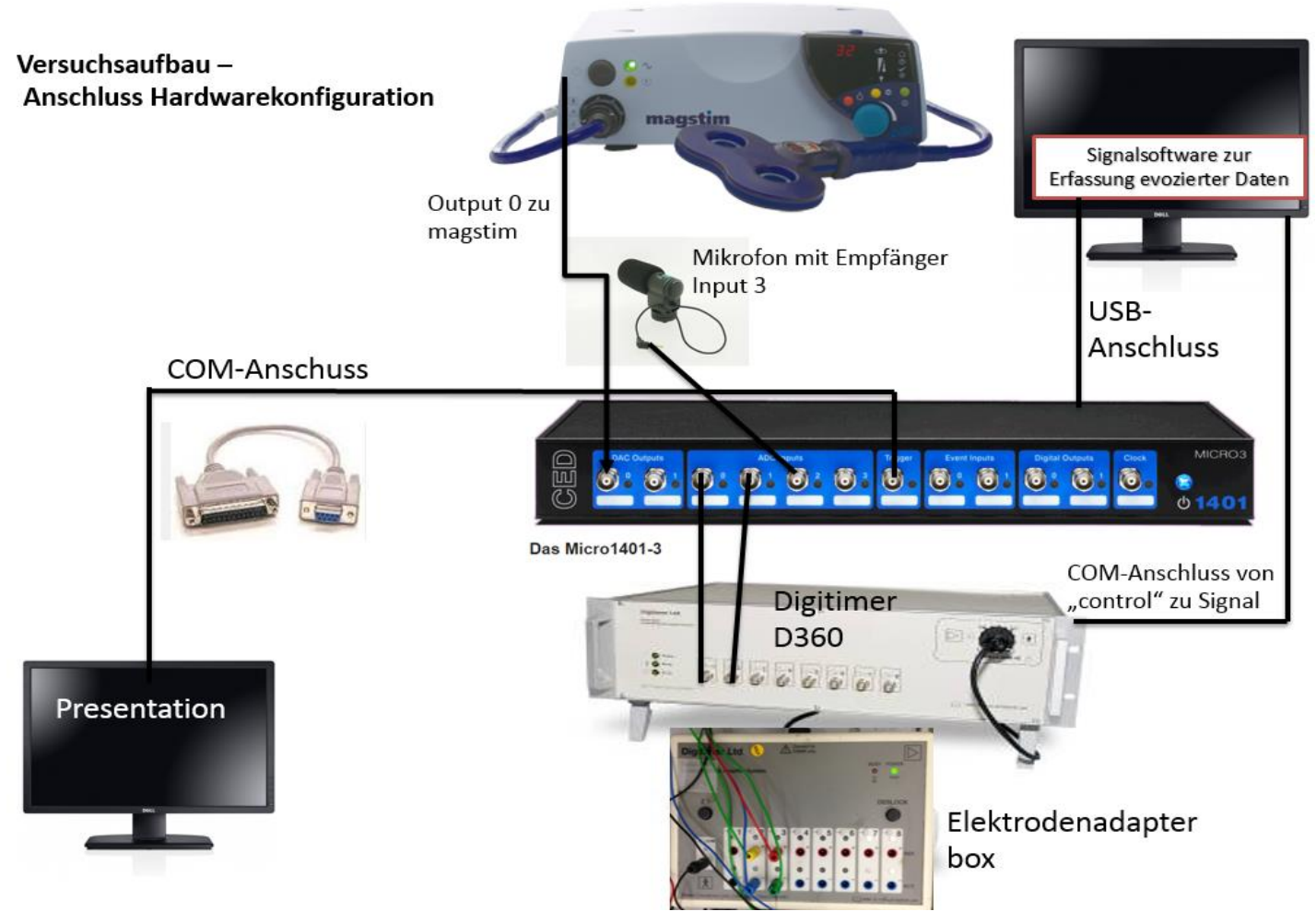

Abb. 6: Hardwarekonfiguration

Das Anschlussdiagramm stellt die Hardware-Konfiguration von dem Versuchsaufbau dar (Abb. 6). Mit dem CED Mikro 1401 (mk II, Cambridge Electronic Design, Cambridge, UK) folgte die Wandlung von einem analogen in ein digitales Signal. Dieses wurde registriert mit dem Datenaufnahmeprogramm „Signal 2.16“ (Cambridge Electronic Design, Cambridge, UK). Vom CED Mikro geht eine Verbindung zum Magstim-Gerät (Magnetstimulator Magstim 200² von der Firma Inomed), hierüber erhält der Magstim-200 den Einsatz zur Impulsgabe, der über die Signalsoftware gesteuert wird. Ein TMS-Impuls folgt über die Magnetspule auf die linke Kopfhälfte des Patienten. Über die Software „Signal 2.16“ werden Trigger-Zeiten und Stimulus-Intensität gesteuert, sodass, wie im Experiment geplant, zum exakten Zeitpunkt über die online zu erwerbende Software Presentation (Neurobehavioral Systems Inc., Albany, Kalifornien, http://www.neurobs.com) der Magnetstimulus 
vom Magstim-200 ausgelöst wird. CED Micro leitet den Impuls zum Magstim-200 weiter. Um die Versuchsbedingungen zu verbessern wurde eine Erdungselektrode an der Erdung des Digitimers angeschlossen, hierfür wurde die Stirn des Teilnehmers mit einem Hautdesinfektionsmittel (Softasept ${ }^{\circledR}$ N; Firma: B. Braun Melsungen AG, Melsungen) entfettet und anschließend eine Erdungselektrode (CareFusion Disposable Ground Electrodes, Firma: Medequip Depot, Dallas) nach Verfliegen des Desinfektionsmittels platziert (Abb. 7).

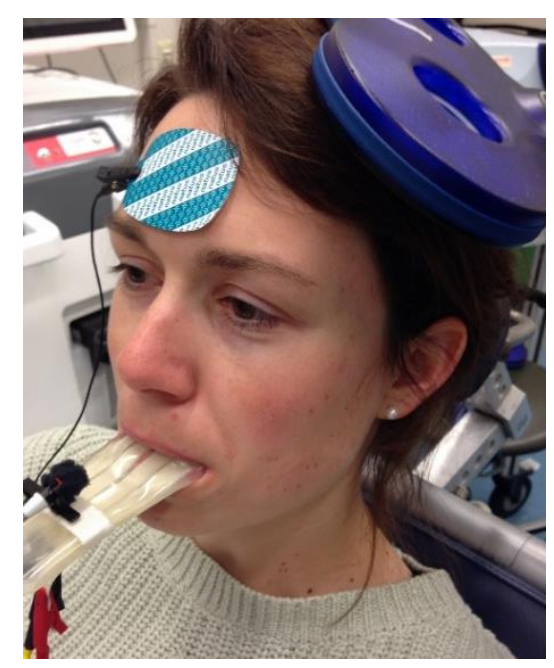

\section{Abb. 7: Erdungselektrode}

Die Teilnehmerin schaut auf den Bildschirm, während auf der Stirn die Erdungselektrode klebt und TMS-Impulse über die Magnetspule linkshemisphärisch appliziert werden. Auf dem Zungenlöffel klemmt der Mikrofonempfänger.

\subsubsection{Drei Experimente - Aufbaubeschreibung}

Der Teilnehmer sitzt entspannt im Sessel und schaut auf einen ca. 2 m entfernten Bildschirm, auf dem das Aufmerksamkeitssignal und die Signale zum Sprechen präsentiert werden. Die Erdungselektrode klebt auf der Stirn und der Zungenlöffel mit den vier Klebeelektroden liegt der Zunge auf. Über der linken Hemisphäre werden vom Versuchsleiter mit einem Magstimgerät-200-Stimulator TMS Impulse abgegeben. Die dabei entstehenden MEPs 
werden mit einem CED-power-Gerät aufgezeichnet und können zeitgleich vom Versuchsleiter auf dem Bildschirm verfolgt werden. Das erste Experiment (Abb. 8) heißt „spontanes Sprechen" und besteht aus insgesamt 120 Trials (Durchgängen). Ein Trial dauert 6300 ms an. In jedem Trial bekommt der Teilnehmer ein Verb zu sehen. Zuerst sieht der Teilnehmer auf dem schwarzen Bildschirm einen weißen Punkt. Der weiße Punkt gibt dem Teilnehmer zu verstehen, dass die Aufgabe direkt im Anschluss beginnt und soll so für die Aufmerksamkeit und Vorbereitung des Teilnehmers sorgen. 800 ms später folgt ein Verb, welches für 800 ms Bildschirm erscheint, das ist das Signal für den Teilnehmer zum Aussprechen des Verbs inklusive vorgeschaltetem Präfix. Anschließend folgt für 4700 ms ein schwarzer Bildschirm. Die Aufgabe des Teilnehmers ist es, auf den Bildschirm zu schauen und, während das Verb erscheint, dieses mit dem Präfix „auf“ zu verbinden und direkt auszusprechen. Währenddessen wird bei jedem Trial jeweils ein (oder kein) TMS-Impuls eingestreut zu jeweils neun verschiedenen Zeitpunkten (States): 0) kein TMS

1) bei $400 \mathrm{~ms}$ 2) 500 ms
3) $800 \mathrm{~ms}$
4) $960 \mathrm{~ms}$
5) $1040 \mathrm{~ms}$
6) $1120 \mathrm{~ms}$
7) $1200 \mathrm{~ms}$
8) 1280

ms $\quad$ 9) 1360 ms. Die States sind randomisiert, sodass der Teilnehmer nicht weiß, zu welchem Zeitpunkt der Magnetstoß (TMS) auf den Kopf kommt. Bei 9 von den 10 States bekommt der Teilnehmer einen TMS-Impuls appliziert, der State ohne TMS-Impuls soll einen Gewöhnungseffekt verhindern bzw. möglichst gering halten. Die ersten beiden States applizieren TMS-Pulse bevor der Teilnehmer das Sprechsignal bekommt, die anderen States werden in der Sprechvorbereitungsphase appliziert. So kann eine Basiserregung (Fazilitation wenn keine Sprechvorbereitung stattfindet) während der Aufmerksamkeitsphase für 
jeden Teilnehmer ermittelt werden und im Vergleich dazu die Fazilitation kurz vor und während des Sprechens. Die vielen verschiedenen States in der Sprechvorbereitungsphase dienen dazu eine mögliche Dynamik während der Sprechvorbereitung zu erfassen. 30 Trials mit 10 möglichen States (also auch 30 verschiedene Worte) laufen am Stück hintereinander ab, es folgt dann eine Pause, nach der Pause folgen erneut 30 Trials. Danach läuft das Experiment mit einer neuen Wortliste noch einmal ab, sodass jedes Verb nur einmal erscheint: 30 Trials - Pause - 30 Trials. Am Ende des ersten Experiments sind somit insgesamt 120 Trials mit unterschiedlichen Worten durchlaufen. Die Gesamtdauer von Exp. 1 beträgt ca. 12 - 15 min.

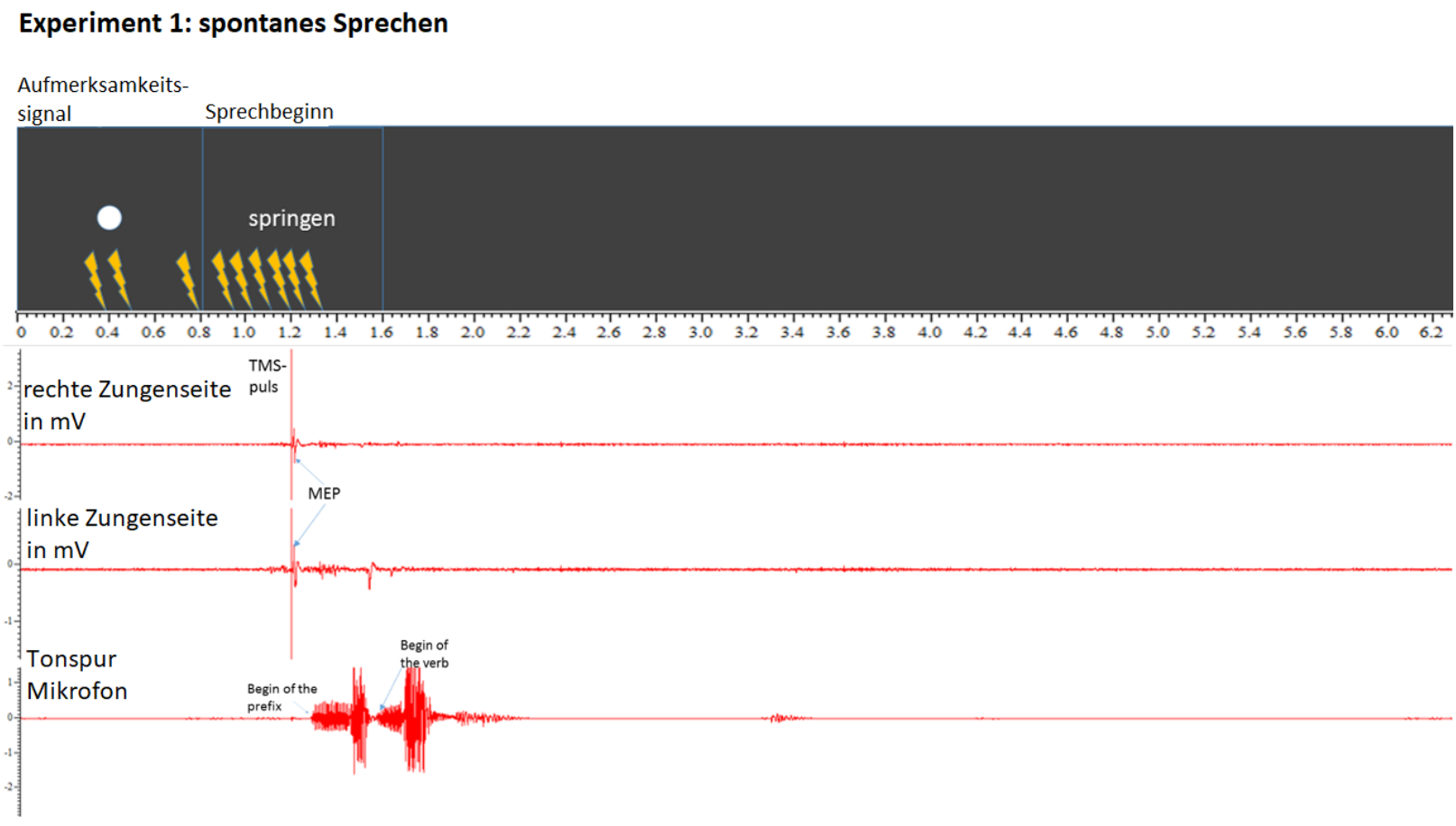

\section{Abb. 8: Experiment $1-$ „spontanes Sprechen“}

Die schwarzen Vierecke stellen den Bildschirm dar, den der Teilnehmer sieht. Die x-Achse zeigt den Zeitstrahl in ms. Die gelben Blitze symbolisieren die TMS-Impulse, welche zu 9 verschiedenen Zeitpunkten (States) eingestreut werden. Pro Trial gibt es maximal einen 
TMS-Puls. Zudem sind die drei Ableitungen (rechte und linke Zungenseite sowie Tonspur) dargestellt.

Anschließend folgt Experiment Nr. 2: Dieses heißt "Geplantes Sprechen ohne Taktung" (Abb. 9). Dem Teilnehmer wird die neue Aufgabe erklärt. Das Experiment besteht aus neun States und insgesamt 108 Trials, die Pause ist nach jeweils 27 Trials. In den ersten 800 ms wird der Aufmerksamkeitspunkt gezeigt. Anschließend erscheint für weitere 800 ms ein Verb. Dieses soll sich der Teilnehmer einprägen. Zum Beispiel könnte hier „springen“ auf dem Bildschirm stehen. Dann wird der Bildschirm für 3500 ms schwarz, es folgt für die Dauer von 1500 ms ein Ausrufezeichen. Jetzt soll der Teilnehmer das Verb mit dem Präfix „auf“ verbinden und laut aussprechen. Für weitere 2200 ms wird der Bildschirm schwarz. Dann folgt für 800 ms erneut der weiße Punkt, welcher auf das kommende Verb vorbereiten soll. Ein Trial dauert im zweiten Experiment 8800 ms. Zu folgenden Zeiten werden die TMS-Impulse eingestreut: 0 ) kein TMS

1) 400

2) 4100

3) 5180
4)5260
5)5340
6) 5420
7) 5500
8) $5580 \mathrm{~ms}$. Genau wie

im ersten Experiment gibt es auch hier einen State Null, der ohne TMS Impuls abläuft, sowie zwei Wortlisten. Das Experiment läuft einmal mit der ersten Wortliste (54 Worte) ab und darauffolgend mit der zweiten Wortliste (54 Worte). Die Gesamtdauer von Experiment 2 beträgt mit Pause ca. 16 - 20 min. 


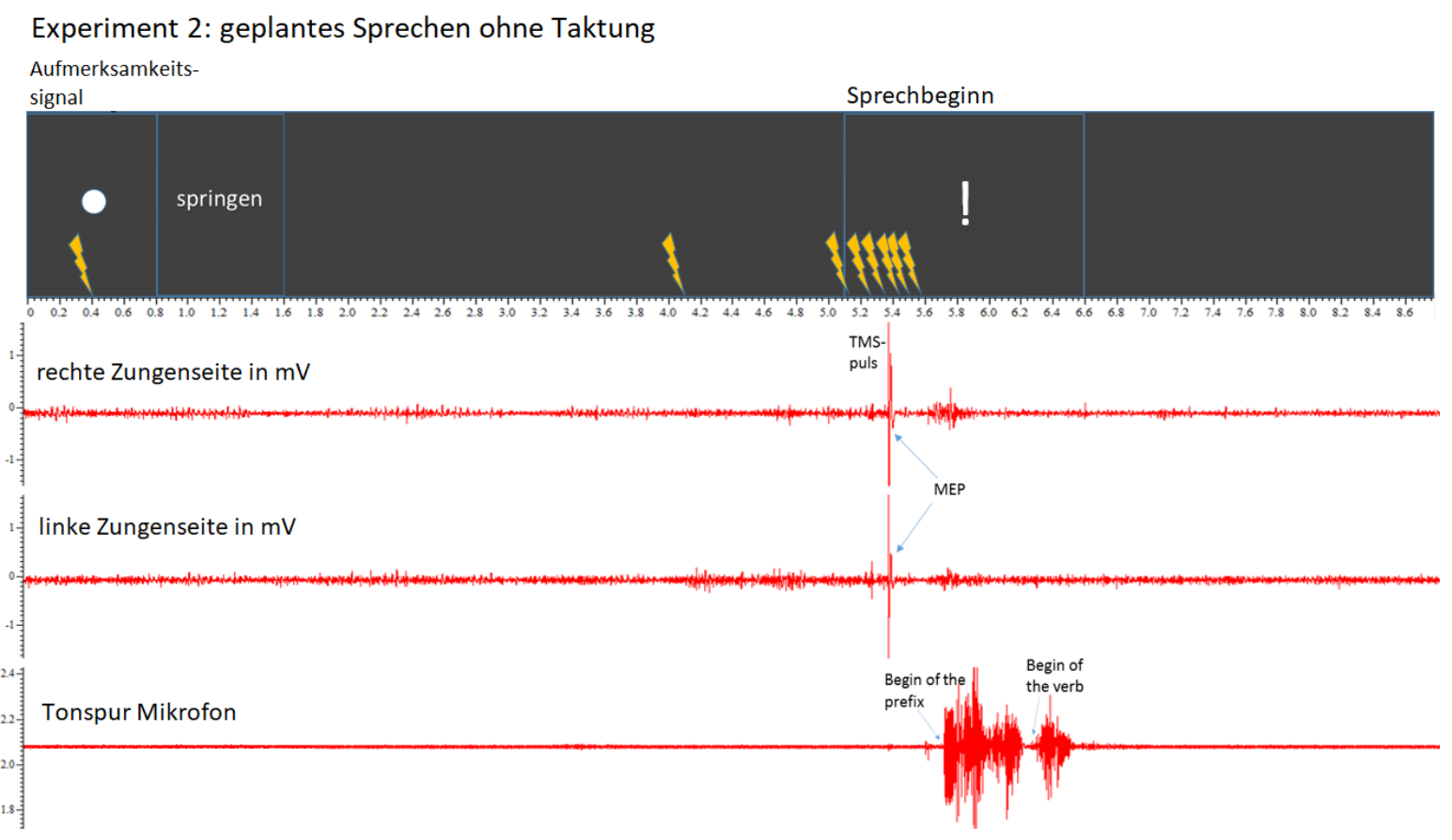

Abb. 9: Experiment 2 - „geplantes Sprechen ohne Taktung“

Als letztes Experiment folgt das dritte Experiment, benannt als „Geplantes Sprechen mit Taktung“ (Abb. 10). In den ersten 800 ms sieht der Teilnehmer den Aufmerksamkeitspunkt, dann für weitere 800 ms das Verb, welches er sich einprägen soll. Dann wird für 1500 ms der Bildschirm schwarz. Nun erscheint für 2000 ms das Präfix auf dem Bildschirm. Das Präfix ist das Signal mit dem Sprechen zu beginnen, es soll prolongiert werden. Der Proband soll [auffffff] sagen und während für 1500 ms das Ausrufezeichen zu sehen ist, soll der Proband das Verb anhängen. Danach folgt 2200 ms lang ein schwarzer Bildschirm und erneut für 800 ms ein weißer Punkt, mit dem der Trial von neuem beginnt. Die neun States sind randomisiert. 0) Kein TMS

1) 400

2) 1300

3) 4100

4) 5180
5) 5260
6) 5340
7) 5420
8) 5500 ms. Genau wie im ersten und

zweiten Experiment gibt es auch hier zwei Wortlisten. Das Experiment läuft einmal mit der ersten Wortliste (54 Worte) und danach mit der Zweiten (54 Worte) ab (insgesamt 108 
Trials). Nach 27 Trials erfolgt jeweils eine kurze Pause. Die Gesamtdauer vom dritten Experiment beträgt mit Pause ca. $16-20$ min.

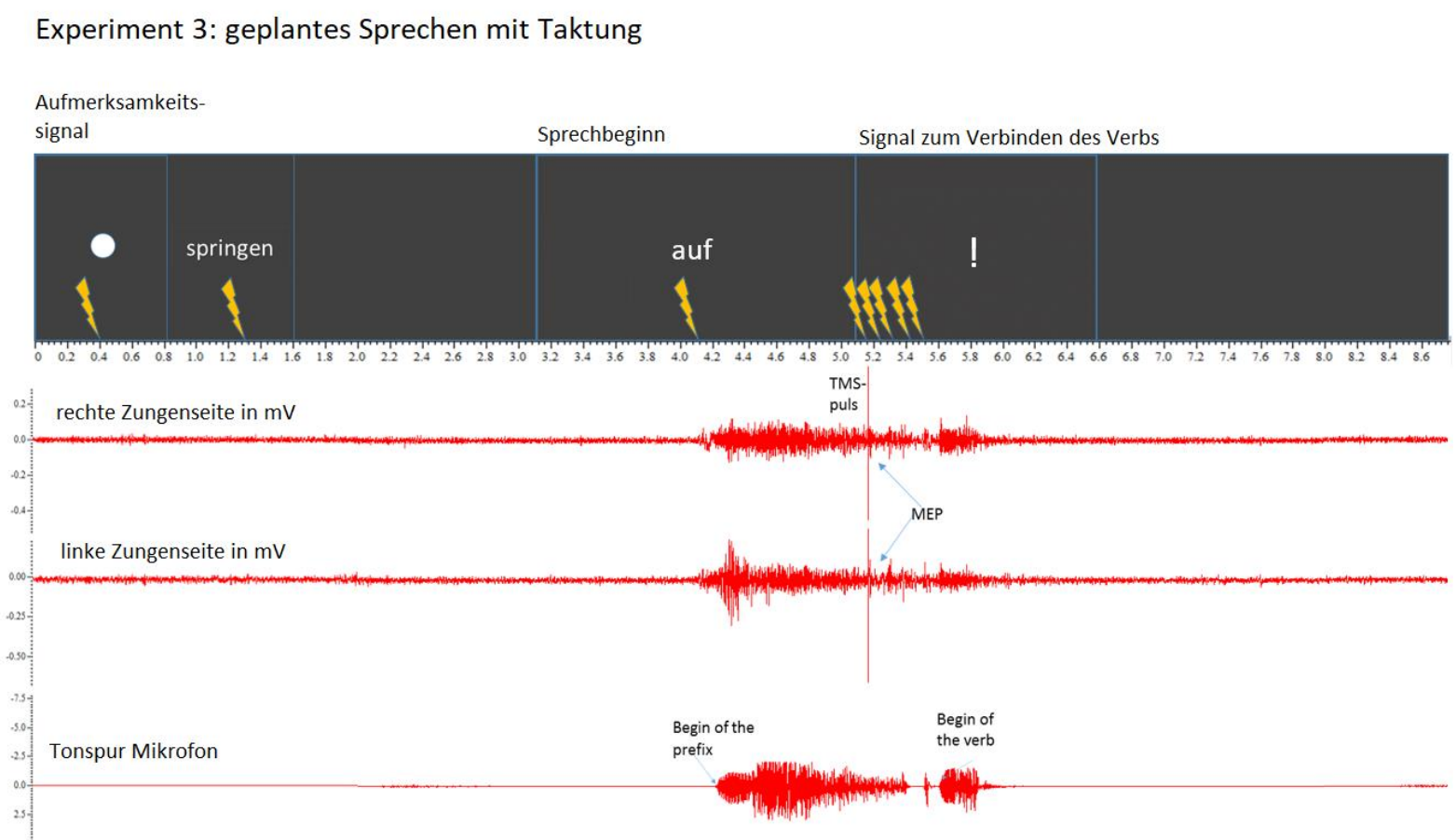

Abb. 10: Experiment 3- „geplantes Sprechen mit Taktung"

Die Reihenfolge der Experimente wurde so gewählt, dass mit der simpelsten Arbeitsanweisung und der anspruchsvollsten Sprechanforderung begonnen wurde. Das sollte eine Antizipation und somit einen Gewöhnungs- und Übungseffekt für die Arbeitsanweisungen und die Sprechanforderung der folgenden Experimente vermeiden. Würde die Sprechanforderung chronologisch steigen, dann könnten die Ergebnisse von einem Trainingseffekt überlagert werden. Genauso könnte es einen Trainingseffekt geben, wenn die kompliziertere Arbeitsanweisung zuerst ausgeführt würde. Exp. 1 stellt in unserer Studie mit dem „Spontanen Sprechen“ die kognitiv anspruchsvollste Aufgabe dar und Exp. 2 „geplantes Sprechen ohne Taktung" die weniger anspruchsvolle Aufgabe. In Exp. 2 gibt es durch das Ausrufezei- 
chen, welches als Startsignal zum Aussprechen fungiert, nur einen Taktgeber. In Exp. 3 „geplantes Sprechen mit Taktung" hingegen, gibt es mit dem Präfix und dem Ausrufezeichen zwei Taktgeber. Die Sprechaufgabe ist dadurch extrem entzerrt, AWS haben mehr Zeit das Sprechen vorzubereiten und können so vermutlich das bestehende Defizit kompensieren. Deshalb gehen wir davon aus, dass der kognitive Anspruch von Exp. 1 zu Exp. 3 sinkt.

\section{3 Überleitung zur aktuellen Studie}

In meiner Studie lege ich den Fokus auf die kortikale Erregbarkeit in der Sprechvorbereitung, aufbauend auf die von Neef und Kollegen in 2015 veröffentlichte Studie (siehe Kap. 1.1 „Ziel und Motivation“ sowie Kap. 2.4 „Aktueller Forschungsstand der zerebralen Befunde zum Stottern“). Hier wurde die inadäquate Aktivierung des sensomotorischen Plans im linken orofazialen Motorkortex während des Sprechens mittels TMS gezeigt. Diese Beobachtung ließ sich sogar machen, wenn AWS flüssig sprachen (Neef et al. 2015a), was auf ein chronisch physiologisches Defizit hinweist, das nicht ständig von der Symptomatik begleitet ist. Neef konnte in ihrer Studie eine erhöhte Exzitabilität im linken Kortex und erniedrigte Exzitabilität im rechten Kortex während des Sprechens bei AWNS nachweisen. Bei AWS fehlte die linksseitige Exzitabilität, dafür zeigte sich eine erhöhte Exzitabilität im rechten Motorkortex. Betrachtet wurde hierbei immer die Zeitspanne zwischen Präfix und Verb. Alle Teilnehmer sollten jeweils das Präfix „,auf“ an einen Wortstamm anhängen und den labiodentalen Reibelaut [aufffff] dehnen. Hierbei wurde das Intervall zwischen Präfix und Verb hinsichtlich der Kortexexzitabilität betrachtet und die Größe der MEPs verglichen (Neef et al. 2015a). Busan und Kollegen unterstützen mit ihrer Studie die Ergebnisse von Neef und Kollegen. Sie beobachteten ebenfalls ein Defizit in der dominanten Hemisphäre 
des Sprechens, das sich durch fehlende Erregung im beschriebenen Areal bemerkbar macht (Busan et al. 2013). Des Weiteren fanden Neef und Kollegen eine negative Korrelation zwischen der Stotterschwere und der Fazilitationsgröße, dies impliziert einen möglichen pathophysiologischen Zusammenhang (Neef et al. 2015a). Das bisherige Paper gibt also Einblicke in die Rolle der Kortexexzitabilität des Stotterns in der Mitte eines Wortes oder einer Phrase. Kritisch hinterfragen könnte man zur vorausgegangenen Studie, ob ein gleichbleibender Ablauf und Zeit zur Planung beim Sprechen einen Einfluss auf das Stottern hat und die Studie eventuell nicht die normalen Sprechbedingungen simuliert. Untersuchungen zur Sprechvorbereitung oder zum Sprechbeginn hinsichtlich der Kortexerregbarkeit wurden bisher nicht durchgeführt, obwohl der Sprechanfang beim OS die bedeutendste Symptomatik darstellt. Beim OS treten die stottertypischen Unflüssigkeiten oft am Wortbeginn oder Phrasenbeginn auf sowie in bedeutungsvollen Wörtern oder syntaktisch komplizierten Äußerungen (Neumann et al. 2016). Motivation und Ziel meiner Arbeit ist es herauszufinden, ob bei AWS eine verminderte MEP-Erregung im linken Kortex im Bereich des Zungenareals vorliegt, bevor ein Wort gesprochen wird. Die Kortexerregbarkeit in der Sprechvorbereitung soll verglichen werden zwischen drei unterschiedlich anspruchsvollen Aufgaben, sowie zwischen den Gruppen und in Anbetracht der Stotterschwere um Rückschlüsse auf die Stotterätiologie ziehen zu können. Aufgrund der vorangegangenen Studienergebnisse und weiterhin offenen Fragen hinsichtlich der Kortexerregbarkeit in der Sprechvorbereitung stellte ich folgende Hypothesen auf: 


\subsection{Hypothesen}

H1: Die MEP-Fazilitation steigt zum Sprechbeginn hin bei allen Teilnehmern (AWS und AWNS) in allen drei Experimenten an.

H2: AWS zeigen im Gegensatz zu AWNS ein reduziertes Level der Fazilitation im Sprechvorbereitungsintervall des linken Kortex in allen Experimenten.

Mit der ersten Hypothese soll gezeigt werden, dass im Kortexareal der Zunge eine progrediente Erregung während der Sprechvorbereitung herrscht, bevor es zur Artikulation des ersten Lautes kommt. Da Stottern besonders oft am Wortanfang auftritt (Seth and Maruthy 2019), legte ich unseren Fokus auf das Sprechvorbereitungsintervall des Präfixes und im dritten Experiment auf das Sprechvorbereitungsintervall des Verbs. Neef und Kollegen beobachteten in ihrer Studie lediglich das Intervall zwischen Präfix und Verb. Unser drittes Experiment dient dazu die Ergebnisse von Neef et al. zu reproduzieren. Mit der zweiten Hypothese soll einerseits das Ergebnis von Neef et al. (Neef et al. 2015a) reproduziert werden, andererseits liegt bei Experiment 1 und 2 hier der Fokus auf dem Sprechvorbereitungsintervall des Präfixes. Es soll herausgefunden werden, ob die gestörte Fazilitation bei AWS nur während dem Anhängen des Verbs oder auch in der Sprechvorbereitung zum Präfix zu detektieren ist. Denn es ist unklar ob die reduzierte Fazilitation bei AWS auch auftritt, wenn vorher mehrere Sekunden lang kein Wort ausgesprochen wurde. Insbesondere der Aufbau der ersten beiden Experimente dient dazu die Fazilitation in der Sprechvorbereitung zu Beobachten und einen Gruppenunterschied zu detektieren. 
H3: AWS zeigen einen weniger hohen Anstieg der MEP-Fazilitation in der Sprechvorbereitung bezogen auf die TSO (Zeiten bevor das erste Wort ausgesprochen wird), verglichen mit AWNS. Dies macht sich durch einen Interaktionseffekt zwischen Gruppe und MEP-TSO deutlich.

Die Hypothese ist, dass AWS einen geringeren Fazilitationsanstieg in der Vorbereitungszeit bis zum Sprechbeginn zeigen als AWNS. Wir gehen davon aus, dass sich bei AWNS die Fazilitation in der Sprechvorbereitung langsam aufbauscht, bis es schließlich zum Sprechenvorgang kommt. Bei AWS erwarten wir ein abgeschwächtes Aufbauschen der Fazilitation. Der Unterschied soll detektiert werden indem wir beide Gruppen zu unterschiedlichen Vorbereitungszeitpunkten hinsichtlich des MEP-Zuwachses vergleichen. Hiermit wollen wir auBerdem den kritischen Zeitpunkt des Sprechvorbereitungsdefizits bei AWS sowie die fehlende Dynamik in Bezug auf die Vorbereitungszeit detektieren, die vermutlich zur fehlenden Synchronisation des Stotterns beiträgt. Die Hauptvorbereitungszeitspanne für das Sprechen soll durch die MEPs eingegrenzt werden, um schließlich das Defizit besser eingrenzen zu können. Es könnte zum Beispiel sein, dass AWS eine fehlerfreie Sprechvorbereitungsaktivität haben, diese jedoch nur zu früh oder zu spät ausgeführt wird und es deshalb zur Symptomatik kommt. Andererseits könnte die Dynamik, also das Aufbauschen der Fazilitation komplett fehlen und nur eine monotone Fazilitation herrschen. Die dritte Hypothese haben wir formuliert, um die Fazilitationsdynamik bei AWS beurteilen zu können.

H4: Der Gruppenunterschied in der MEP-Fazilitation ist am größten, wenn die kognitive Anstrengung am höchsten ist. Das ist der Fall während der Spontansprache (Exp. 1), 
denn diese impliziert höchste kognitive Anstrengung. Am geringsten sind die kognitive Anstrengung und der Gruppenunterschied beim geplanten Sprechen mit externer Taktung und Unterbrechung zwischen Präfix und Verb (Exp. 3).

Wie bereits im Kapitel „2.4.2 Neurofunktionelle Auffälligkeiten“ gemutmaßt wurde, bildet die Therapie des Fluency Shaping und die getaktete Sprechaufgabe (Exp. 2 und 3) einen externen Schrittmacher, der AWS zu flüssigerem Sprechen verhilft. Der Erfolg der Fluency Shaping Therapie lässt vermuten, dass AWS von einer Verlangsamung und Taktung des Sprechens profitieren. Unsere Hypothese ist, dass verzögertes und getaktetes Sprechen zu einer ausgedehnteren Sprechvorbereitung verhilft und somit eine Erleichterung für AWS darstellt. Die Erleichterung in Form der entzerrten Sprechvorbereitung müsste sich für AWS in einer höheren oder mindestens gleichhohen Fazilitation wie bei AWNS bemerkbar machen. Die Spontansprache stellt im Umkehrschluss eine kognitive Überforderung für AWS dar. Hierbei erwarten wir deutliche Größenunterschiede in der Fazilitation zwischen den beiden Gruppen. Seit langem werden eine erhöhte kognitive Belastung und eine längere Bearbeitungszeit zum Kodieren von semantischen Phrasen mit dem Stottern in Verbindung gebracht (Bosshardt 2006). In der Studie von Maxfield wird sogar so weit gegangen, dass gemutmaßt wird, AWS fehle die Möglichkeit genug Kapazität des Arbeitsgedächtnisses zu rekrutieren um eine adäquate Sprechvorbereitung zu leisten (Maxfield et al. 2015). In der vorausgegangenen Studie von Neef und Kollegen wurden keine Stotterereignisse während ihrer Studie beobachtet (Neef et al. 2015a). Geht man davon aus, dass die Taktung eine kognitiv anspruchslosere Aufgabe darstellt als das spontane Sprechen, dann kann das der 
Grund für die abwesende Symptomatik sein. Andererseits kann für die fehlende Stottersymptomatik das Mundstück verantwortlich gewesen sein, das AWS zum Flüssigsprechen verhalf (Büchel und Sommer 2004) oder aber, dass aufgrund des Mundstücks die Stotterereignisse nicht detektiert wurden (Neef et al. 2015a). Die vierte Hypothese wurde aufgestellt um Klarheit darüber zu schaffen, ob AWS von einem externen Schrittmacher profitieren. Das Ergebnis wird mittels MEPs messbar gemacht. Exp. 1 stellt in unserer Studie mit dem „Spontanen Sprechen“ die kognitiv anspruchsvollste Aufgabe dar und Exp. 2 mit „geplantem Sprechen ohne Taktung" eine etwas weniger anspruchsvolle Aufgabe. In Exp. 2 gibt es durch das Ausrufezeichen, welches das Startsignal zum Aussprechen repräsentiert, einen Taktgeber und dadurch mehr Sprechvorbereitungszeit. Deshalb gehen wir davon aus, dass der kognitive Anspruch von Exp. 1 zu Exp. 2 sinkt. In Exp. 3 hingegen „geplantes Sprechen mit Taktung", gibt es mit dem Startsignal zum Aussprechen des Präfixes und dem Startsignal zum Aussprechen des Verbs zwei Taktgeber. Durch die beiden Taktgeber ist die Sprechaufgabe entzerrt und es entsteht hier die größte Zeitspanne zur Sprechvorbereitung. Wir gehen somit davon aus, dass Exp. 3 die geringste kognitive Anstrengung für AWS darstellt. Unsere Hypothese ist, dass durch die zunehmende Taktung der Experimente 1 - 3 eine absteigende kognitive Herausforderung von Exp. 1 zu 3 repräsentiert wird, die sich in den Fazilitationsunterschieden der Gruppen widerspiegelt.

Die ausbleibende Stottersymptomatik während des Experiments in der vorausgegangenen Studie von Neef könnte auch für die gleichen Reaktionszeiten zwischen den beiden Gruppen verantwortlich sein (Neef et al. 2015a). Es wird seit langem angenommen, dass AWS eine langsamere Reaktionszeit bei Sprechaufgaben im Vergleich zu anderen motorischen 
Reaktionsaufgaben zeigen (Reich et al. 1981). Welchem Teil (Sprechplanung oder Bewegungsausführung) der Sprechausführung diese Verzögerung zugesprochen werden kann, ist jedoch weiterhin unklar (Natke und Alpermann 2010). Aufgrund der Studienlage gehen wir davon aus, dass AWS bei der Sprechaufgabe sowohl aufgrund der äußeren Störfaktoren (TMS-Puls, Start-Signal, Gewöhnungseffekt) als auch unter Ausschluss dieser, eine verzögerte Reaktion zeigen. Deshalb haben wir die fünfte Hypothese aufgestellt.

H5: AWS reagieren langsamer als AWNS in allen drei Experimenten, auch unter Ausschluss der Störfaktoren wie dem TMS-Puls, des Start-Signals und des Gewöhnungseffekts. Wie bei vielen Entwicklungsstörungen wurde auch beim Stottern vermutet, dass Stottern nicht als kategorische Diagnose, sondern als Kontinuum mit variierender Symptomatik vorkommt (Guntupalli et al. 2006, Maassen et al. 2004). Wie bei unseren Voruntersuchungen festgestellt, zeigen Teilnehmer bei denen kein Stottern diagnostiziert wurde ebenfalls geringe Sprechunflüssigkeiten. Das müsste sich auch in der MEP-Größe ablesen lassen. Um zu prüfen ob die herkömmliche Gruppeneinteilung, AWS versus AWNS oder der prozentuale Anteil der Sprechunflüssigkeiten besser mit der MEP-Größe korreliert, haben wir die sechste Hypothese aufgestellt. Schließlich müsste die MEP-Größe mit den prozentual gestotterten Silben invers korrelieren, wenn Stottern als Kontinuum vorkommt.

H6: Die prozentualen Stotterunregelmäßigkeiten korrelieren deutlicher mit der MEPFazilitationsgröße als mit der angewandten Methode der Gruppenzuordnung in AWS und AWNS. 


\subsection{Datenbearbeitung}

Um die erhobenen Daten für eine statistische Analyse vorzubereiten, markierten wir die Minimal- und Maximalwerte sowie den Beginn und das Ende der einzelnen MEP-Amplituden, die sich in einem Zeitfenster von 10 - 30 ms nach dem TMS-Puls befanden. Zur Vermeidung eines systematischen Fehlers wurden Ausreißer im Vorhinein herausgefiltert. Messungen wurden als Ausreißer betrachtet, wenn durch Artefakte die MEP-Größe oder die EMG-Signale nicht abzugrenzen waren vom Grundrauschen, wenn die Trials zu falschen Zeitpunkten als den definierten States appliziert wurden, wenn das Audiosignal nicht erkennbar war oder die MEPs kleiner als $0.1 \mathrm{mV}$ waren. Insgesamt wurden so $14 \%$ aller Trials ignoriert. Die restlichen Trials konnten in die Analyse eingeschlossen werden. Dann sortierten wir die MEPs nach Amplitudengröße für jeden Teilnehmer und für jedes Experiment, sodass ein Mittelwert der MEPs für jeden Teilnehmer ermittelt wurde. Um die Unterschiede in der Reaktionszeit und Verzögerung zwischen den Trials und den Teilnehmern besser herausarbeiten zu können, haben wir alle Daten zum Zeitpunkt des Sprechbeginns referenziert - in Experiment 1 und 2 auf das Präfix und in Experiment 3 auf das Verb bezogen. Die Trials wurden dann nach den States $(0-9)$ sortiert. Vor der Datenanalyse sollte man sich verdeutlichen, dass die MEP-Antworten, die wir als MEP-Erregung gewertet haben durch zwei verschiedene Mechanismen entstehen können: einerseits können die Veränderungen als Anstieg der Fazilitation (Hochregulierung in einem positiven Feedback-System) im Kortex zustande kommen, andererseits durch eine verminderte Hemmung (also Herunterregulierung in einem negativen Feedback-System). In unserem Experiment ist es unklar, ob die MEP-Antworten das Ergebnis einer ansteigenden Fazilitation oder vermin- 
derten Hemmung sind. Der Einfachheit halber bezeichneten wir sie als ansteigende Fazilitation, jedoch kann der Grund auch eine Hemmung sein. Schlussendlich können wir das nur vermuten. Wir werteten die Ergebnisse auf der Annahme aus, dass die MEP-Fazilitation eine Kortexerregung darstellt.

\section{Datenanalysen und Ergebnisse}

Wir analysierten die Daten in einem benutzerdefinierten EMG-Browser-Programm namens Signal Software (Firma: Cambridge Electronic Design, Version 2.16), im Folgenden verkürzt als Signal bezeichnet, und in Matlab (Firma: The MathWorks, Inc. Version 2015b). Mit Hilfe von Signal wurden die Tonaufnahmen und die MEPs über die Zungenelektroden visualisiert, wie oben in der Darstellung der Experimente abgebildet. Die Datenanalyse erfolgte mit Matlab.

\subsection{Vorbereitende Datenanalyse}

Aus der Frage, ob die MEP-Amplitude zum Sprechbeginn hin bei allen Teilnehmern progredient ansteigt, resultiert die Korrelationsanalyse der Spitze-zu-Spitze-Amplitude mit der MEP-TSO (MEP-time before speech onset/Zeitspanne zwischen MEP und Sprechbeginn des Teilnehmers). Um die Beziehung zwischen der Sprechvorbereitungsphase und der MEPAmplitude darzustellen und somit die erste Hypothese zu testen, bildeten wir den Mittelwert von der Basiserregung, also aller States $1+2$ (Teilnehmer befindet sich noch nicht in der Sprechvorbereitung) und den Mittelwert aller States 3 - 9 (Teilnehmer befindet sich in der Sprechvorbereitung). Für jedes Experiment und jeden Teilnehmer fassten wir die Daten 
von State $1+2$ zusammen um die Aussagekraft zu stärken. Die T-Tests zur Prüfung, inwieweit sich die MEPs beider States unterscheiden, zeigten, dass die MEPs zu den zwei TMSPulsen nicht signifikant unterschiedlich waren über alle Experimente. Dann teilten wir jede MEP-Amplitude in der Sprechvorbereitung (State 3 bis 9) durch den Wert der Basiserregung (State $1+2)$ jedes einzelnen Teilnehmers für jedes Experiment. Auf diese Weise repräsentierten die MEP-Werte einen Verhältniswert (MEP-Ratio), der mit den anderen Teilnehmern vergleichbar ist. Für jeden Teilnehmer wird der Beginn des Sprechens als Referenzpunkt festgelegt, da er allen Teilnehmern gemein ist und so eine Vergleichbarkeit der Messwerte gewährleistet. Der Sprechbeginn entspricht dem Nullpunkt der Zeitskala. Als die MEPs zum Sprechbeginn zentriert wurden, war die MEP-Größe 600 ms vor Sprechbeginn und darüber hinaus deutlich reduziert. Deshalb benutzten wir ein 500 ms langes Fenster, welches 460 ms vor Sprechbeginn startete und bei 40 ms nach Sprechbeginn endete. Um herauszufinden, ob Unterschiede zwischen AWS und AWNS in der Sprechvorbereitung bestehen, die sich durch MEPs messen lassen, wendeten wir drei verschiedene Analysen an: erstens die lineare Einfachregression, zweitens die hierarchische multiple lineare Regression (HMRA) und drittens die nichtlineare Regression. Unsere Daten veröffentlichten wir bereits vorab, lediglich ausgewertet mit der linearen Analyse in dem Paper „Adults who stutter lack the specialised pre-speech facilitation found in non-stutterers" (Whillier et al. 2018). Die zusätzliche Auswertung mit der nichtlinearen Regression (curved regression) zogen wir in Erwägung, um unsere Ergebnisse durch die exaktere Methode zu prüfen. Wir gehen davon aus, dass „feuernde“ Neurone, die in der Größe und Form stark variabel sind, in einer Kurve realitätsgetreuer abgebildet werden können als in einer Geraden. Schließlich 
besteht unser MEP aus einer progredienten, nichtlinearen Steigung und anschließend aus einer Rückbildung des Anstiegs, die theoretisch besser mit einer dynamischen Methode darstellbar ist. Diese Dynamik zeigt sich nicht nur innerhalb des einzelnen MEPs sondern auch zwischen den einzelnen MEPs. Der gesamte Sprechvorgang kann ebenfalls von intermittierenden Erregungen geprägt sein, wenn beispielsweise zwischen Präfix und Verb eine kurze Pause in der Sprechplanung entsteht oder wenn sich die kognitive Anforderung plötzlich ändert. Wir gingen deshalb davon aus, dass die nichtlineare Regression unsere Daten exakter abbildet als die herkömmliche lineare Regression.

\subsection{Ergebnisse zu den Hypothesen 1 - 3}

Um die ersten drei Hypothesen zu prüfen haben wir für jedes Experiment die lineare Einfachregression, die HMRA und die nichtlineare Regressionsanalyse durchgeführt. Für das erste Experiment (spontanes Sprechen) wurden 3916 Trials in die Analyse eingeschlossen. Anhand der folgenden Tabelle 2 (zusätzliche Information gibt Tabelle 5 im Anhang) werden einmal exemplarisch alle drei Analysen dargestellt. Die MEP-Größe ist unser Untersuchungsgegenstand und stellt somit die abhängige Variable dar. Die beeinflussenden Größen oder auch unabhängigen Variablen entsprechen in unserer Studie der TSO, der Gruppenzugehörigkeit und der Gruppen-TSO-Interaktion.

4.2.1 Ergebnisse zu den Hypothesen 1-3, ausführliche Darstellung für das Experiment 1 unter Auswertung mittels linearer Einfachregression

In den ersten zwei Zeilen von Tabelle 2 sind die Ergebnisse der linearen Einfachregression aufgelistet. Die lineare Einfachregression ist eine statistische Methode um den Zusammenhang zwischen der Einflussgröße x und der Zielgröße y mit Hilfe von zwei unbekannten Parametern $a$ und $b$ zu finden. Es wird eine Gerade ermittelt, die durch ein Streudiagramm 
gelegt werden kann, sodass der lineare Zusammenhang zwischen a und b möglichst gut beschrieben wird. Eine Gerade wird beschrieben durch die Parameter a und b und kann dargestellt werden durch folgende Formel: $y=a+b * x$. Die abhängige Variable oder auch Zielgröße entspricht $y$, in unserem Fall die MEP-Größe. Anhand von a und b soll die bestmögliche Gerade entstehen. Es ist noch wichtig zu erwähnen, dass nur der Erwartungswert von y vorhergesagt wird. Es gibt immer einen kleinen Fehler, den man im linearen Modell $\epsilon$ (Epsilon) nennt, sodass die Regressionsformel lautet: $y=a+b^{*} x+\epsilon$. Die Einflussgröße $x$ ist in unserem Falle der Zeitpunkt in der Sprechvorbereitung (TPO). Die Werte für $a$ und b haben wir durch die Analyse in Matlab ermittelt. Die Ergebnisse der linearen Regression zeigt Tab. 2 in den ersten beiden Zeilen (Model 1):

\begin{tabular}{|c|c|c|c|c|c|c|c|c|}
\hline \multicolumn{2}{|c|}{ Model } & \multicolumn{2}{|c|}{$\begin{array}{l}\text { Unstandardized } \\
\text { Coefficients }\end{array}$} & \multirow{2}{*}{$\begin{array}{l}\text { Standardized } \\
\text { Coefficients } \\
\text { Beta }\end{array}$} & \multirow{2}{*}{$\mathrm{t}$} & \multirow{2}{*}{ Sig. } & \multicolumn{2}{|c|}{$\begin{array}{l}95.0 \% \text { Confidence } \\
\text { Interval for B }\end{array}$} \\
\hline & & B & Std. Error & & & & $\begin{array}{l}\text { Lower } \\
\text { Bound }\end{array}$ & $\begin{array}{l}\text { Upper } \\
\text { Bound }\end{array}$ \\
\hline \multirow{2}{*}{1} & (Constant) & 1.823 & 0.04 & & 45.285 & 0 & 1.744 & 1.902 \\
\hline & TPO & 2.347 & 0.151 & 0.241 & 15.504 & 0 & 2.05 & 2.644 \\
\hline \multirow{4}{*}{2} & (Constant) & 2.19 & 0.083 & & 26.361 & 0 & 2.027 & 2.352 \\
\hline & TPO & 3.155 & 0.216 & 0.323 & 14.634 & 0 & 2.732 & 3.578 \\
\hline & Group & -0.607 & 0.08 & -0.234 & -7.598 & 0 & -0.764 & -0.451 \\
\hline & $\begin{array}{l}\text { Group-TPO- } \\
\text { Interaction }\end{array}$ & -1.585 & 0.301 & -0.183 & -5.274 & 0 & -2.174 & -0.996 \\
\hline \multirow{5}{*}{3} & (Constant) & 2.413 & 0.097 & & 24.901 & 0 & 2.223 & 2.603 \\
\hline & TPO & 6.411 & 0.763 & 0.657 & 8.397 & 0 & 4.914 & 7.908 \\
\hline & Group & -0.651 & 0.106 & -0.25 & -6.123 & 0 & -0.859 & -0.442 \\
\hline & $\begin{array}{l}\text { Group-TPO- } \\
\text { Interaction }\end{array}$ & -2.272 & 1.054 & -0.262 & -2.154 & 0.031 & -4.339 & -0.204 \\
\hline & TPO curved & 7.342 & 1.652 & 0.345 & 4.444 & 0 & 4.103 & 10.581 \\
\hline
\end{tabular}

Tabelle 2: Experiment 1. Übersicht aller drei Analysen mit Gruppeneinteilung

Übersicht aller Analysen für Exp. 1 mit Gruppeneinteilung in AWS und AWNS. Model 1) lineare Einfachregression 2) multiple Regression 3) nichtlineare Regression für Experiment 1. $B$ = nicht standardisierte Koeffizienten. TPO = Intervall, bevor das Präfix gesprochen wird. Gruppe war binär ( 0 = AWNS, 1 = AWS). TPO curved: quadratischer Zusammenhang der 
Zeit. Die Konstante der Regression wurde geprüft gegen die Nullhypothese von $B=1$, statt der Alternativhypothese $B=0$, TPO curved: quadratischer Zusammenhang der Zeit.

Die erste Zeile (Constant) gibt den Regressionskoeffizient a an, die sogenannte Regressionskonstante. Diese entspricht dem Wert der Zielvariablen y, wenn die unabhängige Variable $x$ den Wert 0 aufweist. Dies wäre hier der Fall, wenn TPO $=0$. Eine signifikante Regressionskonstante bedeutet, dass der Y-Achsenabschnitt nicht null beträgt und somit die Regressionsgerade nicht durch den Ursprung geht. Die zweite Zeile gibt den Regressionskoeffizient $b$ an. Dieser misst die Veränderung, wenn sich $x$ um eine Einheit ändert. Um die Koordinaten der Geraden zu ermitteln, werden die Werte in die o.g. Gleichung eingesetzt. $Y=1,823+2,347 * 1$. Die Zielvariable bei TPO $=1$ ergibt beispielsweise 4,17 und bei TPO = 0: 1,823 , sodass man die Koordinaten der Geraden ermitteln kann. Epsilon ist in dem Beispiel nicht berechnet, sodass die berechneten Ergebnisse nur Näherungswerte darstellen. Der Regressionskoeffizient gibt die Steigung der Geraden an. Diese ist mit 2,347 positiv. Die erste Hypothese, dass die MEPs zum Sprechbeginn hin ansteigen, ist hiermit bestätigt. Die zweite Spalte zeigt den Standardfehler, dieser wird für den T-Test benötigt und wird hier nicht direkt interpretiert. Beta ist der standardisierte Regressionskoeffizient und beschreibt die Richtung und Stärke der Variablen normiert auf 1. Das heißt bei Beta $=0$ gibt es keinen linearen Zusammenhang und bei Beta $=1$ gibt es einen perfekten linearen Zusammenhang. Die Stärke der einzelnen Variablen ist also eher gering. Bei mehreren Einflussgrößen, stellt sich die Frage, welche davon die abhängige Variable am stärksten beeinflusst. Den Effekt der einzelnen Variablen misst der jeweilige Regressionskoeffizient. Da unsere Variablen in der folgenden HMRA unterschiedliche Maßeinheiten haben, lässt sich der Regressionsko- 
effizient nicht vergleichen. Es wurde daher zusätzlich der standardisierte Regressionskoeffizient berechnet, der den Einfluss der unterschiedlichen Maßeinheiten ausgleicht. Der tTest des Regressionskoeffizienten prüft unter der Annahme normalverteilter Störgrößen, ob ein Regressionskoeffizient null ist. Dieser Wert wird hier ebenfalls nicht direkt interpretiert. Die Signifikanz der Regressionskoeffizienten bedeutet, dass die Variablen einen signifikanten Einfluss auf die MEP-Größe haben. Die letzten beiden Spalten geben die Spannbreite der Regressionskoeffizienten wieder mit einem Konfidenzintervall von $95 \%$. Bezogen auf unsere erste Hypothese ergibt sich aus den Ergebnissen, dass die Gerade eine positive Steigung hat und somit die Spitze-zu-Spitze-Amplituden der MEPs beider Gruppen zum Sprechbeginn hin ansteigen. Die erste Hypothese kann bei einem Konfidenzintervall von 95,0\% angenommen werden. Die Variable TPO hat also einen signifikanten Einfluss auf die MEPs. Es besteht eine positive Korrelation zwischen dem Sprechvorbereitungszeitpunkt und der MEP-Größe aller Teilnehmer. Die TPO in unserem 500 ms Zeitfenster läuft von 460 bis +40 ms, deshalb wird der Zeitpunkt zum Sprechbeginn in Millisekunden größer. Anders formuliert heißt das, je kürzer das Intervall vor dem Sprechbeginn ist, desto größer sind die MEPs.

4.2.2 Ergebnisse zu den Hypothesen 1-3, ausführliche Darstellung für das Experiment 1 unter Auswertung mittels hierachischer (multipler) Regressionsanalyse

Zeile 3-6 (Model 2) von Tab. 2 zeigen die Ergebnisse der multiplen Regressionsanalyse für Exp. 1. In einer multiplen Regression mit mehreren unabhängigen Variablen spricht man von multiplen Regressionskoeffizienten. Sie messen den Einfluss der jeweiligen unabhängigen Variablen $\mathrm{x}$ auf die Zielvariable $\mathrm{y}$ unter Konstanthaltung aller anderen kontrollierten 
unabhängigen Variablen. Zur Auswertung werden grob gesagt die Einflussgrößen als Vektoren angesehen und spaltenweise in eine Matrix zusammengefasst. Mit Hilfe dieser Matrix und dem Vektor aller Zielgrößen y kann der Vektor der Parameter abgeschätzt werden. Die Analyse beinhaltet nun die Einflussgrößen $x_{1}$ : TPO und $x_{2}$ : Gruppe (AWS und AWNS), zudem wird ein Interaktionseffekt zwischen diesen beiden Einflussgrößen ermittelt. Ein Interaktionseffekt charakterisiert sich dadurch, dass die Wirkung über die einzelnen Hauptwirkungen der Einflussgrößen hinausgeht. Bei einer multiplen Regressionsanalyse mit zwei unabhängigen Variablen $x_{1}$ und $x_{2}$ lautet die vollständige Gleichung: $f\left(x_{1}, x_{2}\right)=\alpha+\beta_{1} x_{1}+\beta_{2} x_{2}+\beta_{3}\left(x_{1} \times x_{2}\right)+\xi$, wobei $\beta 3$ die Stärke des Interaktionseffekts angibt ( $\alpha$ repräsentiert den Achsenabschnitt und $\xi$ den Fehlerterm). Die Haupteffekte $\beta 1$ und $\beta 2$ sind dann nur noch bedingt interpretierbar. Der standardisierte Regressionskoeffizient zeigt mit 0,323 bei TPO den stärksten Einfluss. Die Ergebnisse der HMRA sind in Abb. 11 a und b visualisiert: 


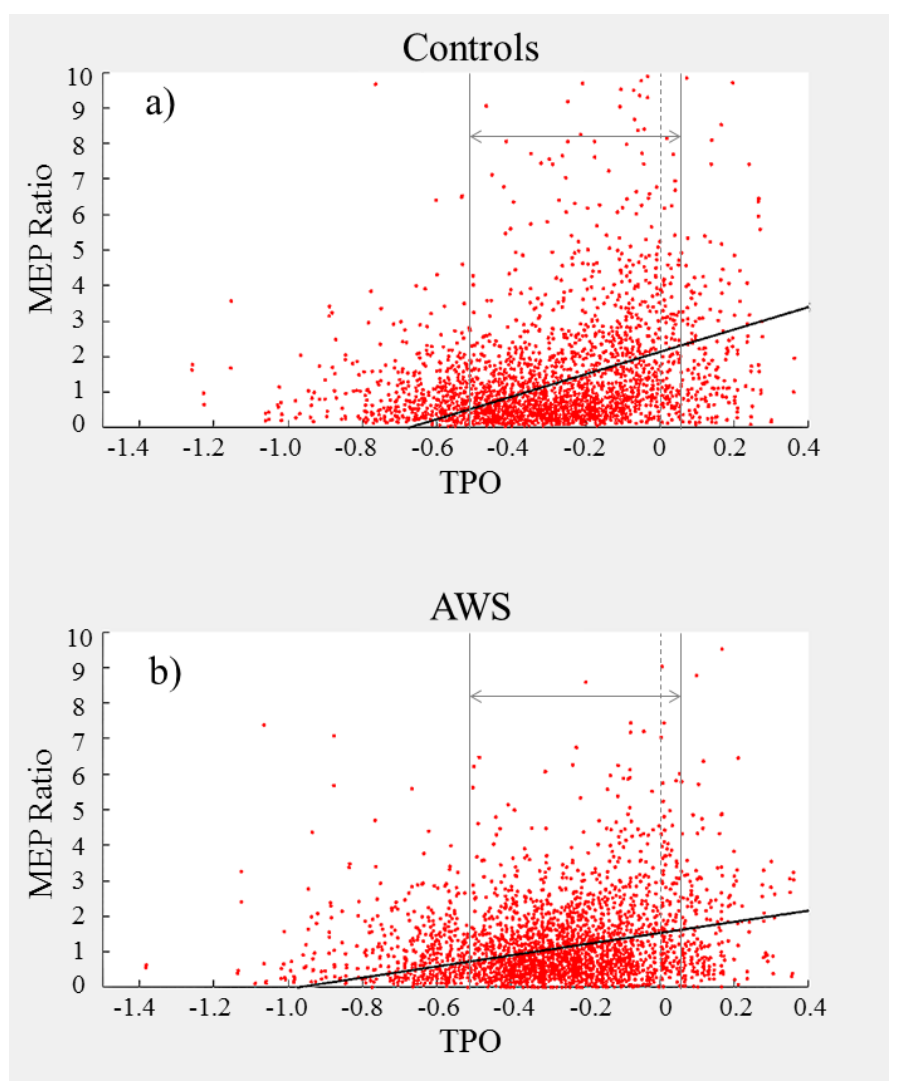

Abb. 11: Diagramm für Exp. 1 - HMRA. AWS vs. AWNS

Hier ist der MEP-Verhältniswert (Abstand zum Sprechbeginn und Spitze-zu-SpitzeAmplitude) relativ zum Präfixbeginn für Controls (= AWNS) und AWS dargestellt. Jeder Punkt repräsentiert einen Trial, die $x$-Achse gibt den Zeitpunkt in Sekunden an und die $y$ Achse den MEP-Verhältniswert. Der Beginn des Präfix markiert die gestrichelte vertikale Linie am Nullpunkt bei TPO $=0$. Die äußeren vertikalen Linien markieren das 500-ms-Zeitfenster, welches wir für die Analyse festlegten. Die Diagonale stellt die lineare Regressionsgerade dar.

Die Ergebnisse lassen sich nachvollziehen in Abb. 11: Auf den ersten Blick fällt auf, dass in beiden Gruppen die Gerade zum Sprechbeginn hin ansteigt. Dies bestätigt noch einmal unsere erste Hypothese, dass die MEP-Größe bei allen Teilnehmern zum Sprechbeginn hin ansteigt. In der zweiten Hypothese erwarten wir, dass AWS insgesamt niedrigere MEPAmplituden haben als AWNS. Es geht also erst einmal nur darum den Gruppenunterschied festzustellen, deshalb kann die Regressionsformel verwendet werden: 
$f\left(x_{1}, x_{2}\right)=\alpha+\beta_{1} x_{1}+\beta_{2} x_{2}+\xi$. Es ergibt sich beispielsweise bei AWS für die Zielvariable ca. 4,738 und bei AWNS ca. 5,345 bei TPO $=1$. Bei TPO $=0$ ergibt sich für AWS ca. 1,583 und für AWNS ca. 2,190, sodass die Geraden ermittelt werden können. Das Ergebnis der Regressionsanalyse für den Gruppenunterschied ist signifikant, wie Tab. 2 bei Model 2, Faktor Group zu entnehmen ist. Die zweite Hypothese, dass AWS kleinere MEPs in der Sprechvorbereitung zeigen, kann für Experiment 1 angenommen werden. Abb. 11 lässt dies ebenfalls schon erahnen. Die dritte Hypothese stellt die Frage nach einem Interaktionseffekt, hiermit soll herausgefunden werden ob die Ausprägung einer Einflussgröße von der Ausprägung der anderen Einflussgröße abhängt. In unserem Falle stellt sich die Frage ob die MEP-Größe zum TPO-Zeitpunkt abhängig von der Gruppe ist. Fügt man die ermittelten Werte in die Regressionsgleichung für den Interaktionseffekt ein, so ergibt sich in Abhängigkeit der TPO eine signifikant größere MEP-Steigung bei AWNS zum Sprechbeginn hin, verglichen mit AWS. Das bedeutet, dass die Gruppe eine signifikante Auswirkung auf die MEP-Größe zum Zeitpunkt der Sprechvorbereitung hat (siehe Tab. 2, Model 2 Group-TPOInteraction). Der Unterschied der MEP-Amplituden zwischen den Gruppen wird größer bei voranschreitender Zeit zum Sprechbeginn. Somit zeigen AWS ein reduziertes MEP-Wachstum in Abhängigkeit von der TPO. Die Hypothesen 1 - 3 können somit angenommen werden und sind signifikant unter der linearen Einfachregression und der HMRA.

4.2.3 Ergebnisse zu den Hypothesen 1-3, ausführliche Darstellung für das Experiment 1 unter Auswertung mittels nichtlinearer Regressionsanalyse

In Tab. 2, Model 3 sind die Ergebnisse der nicht-linearen Regressionsanalyse dargestellt. Die nicht-lineare Regression stellt eine Kurve dar und beinhaltet deshalb eine quadratische Funktion. Die ursprüngliche multiple Regressionsfunktion wird um den Term $x^{2}$ erweitert 
und die ermittelten Werte werden eingesetzt. Da man sich den grafischen Zusammenhang anhand der Zahlen kaum vorstellen kann, sind die Ergebnisse sind in Abb. 12 graphisch dargestellt.

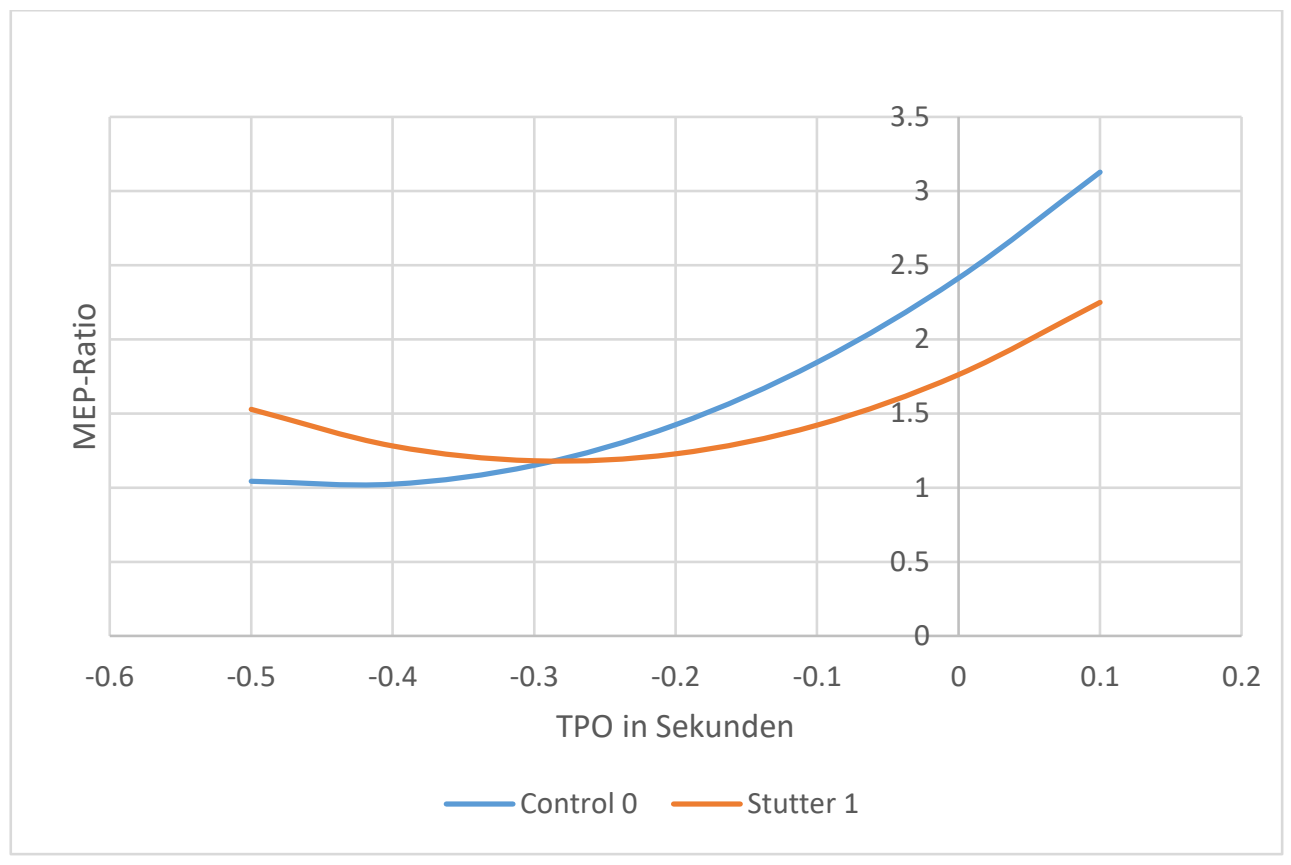

Abb. 12: Visualisierung der nichtlinearen Regression für Experiment 1

MEP-Verhältniswert relativ zum Präfixbeginn für Controls (= AWNS) und Stutter (= AWS). Blaue Linie: nichtstotternde Erwachsene = Control. Orangene Linie: stotternde Erwachsene. Die Grafik zeigt das 500-ms-Zeitfenster. Der Beginn des Präfix markiert die vertikale Linie bei $T P O=0$. Dargestellt ist das 500 ms Zeitfenster von -460 bis +40 ms.

Alle gemessenen Parameter sind signifikant. Das bedeutet, dass der zeitliche Zusammenhang einen quadratischen Effekt auf die MEP-Größe hat, der sich in beiden Gruppen zeigt. Die nichtlineare Regression bestätigt die Ergebnisse der linearen Regression für Exp. 1. Die MEP-Größe steigt in beiden Gruppen zum Sprechbeginn hin an, AWS zeigen eine reduzierte Fazilitation in der Sprechvorbereitung und es gibt einen Interaktionseffekt der TPO und der Gruppe. Der absolute Gruppenunterschied bestätigt sich allerdings erst ungefähr ab 300 
ms vor Sprechbeginn. Die Hypothese 1, 2 und 3 kann für das erste Experiment angenommen werden. Die Ergebnisse der nichtlinearen Regression zeigen von allen Analysen das größte angepasste R-Quadrat (0.08, siehe Tab. 5 im Anhang). Das bedeutet, dass die Ergebnisse mit der nichtlinearen Regression exakter und realitätsnäher abgebildet werden als mit den beiden vorherigen Analysen. Die ersten drei Hypothesen können also für Exp. 1 auch unter der exakteren Methode angenommen werden.

Die drei o.g. Analysen wurden für Experiment 2 und 3 in gleicher Weise angewendet und sind im Folgenden dargestellt. Um die Datenanalyse und die Ergebnisse übersichtlicher zu gestalten, sind die Tabellen von Exp. 2 und 3 im Anhang zu finden und die Ergebnisse lediglich in Graphiken dargestellt.

\subsubsection{Ergebnisse zu den Hypothesen 1 - 3 für Experiment 2}

Für das zweite Experiment (geplantes Sprechen ohne Taktung) wurden 3443 Trials in die Analyse mit einbezogen (siehe Tab. 6 und 7 im Anhang). Die ermittelten Werte können Tab. 6 im Anhang entnommen werden. Die Steigung der Geraden für alle Teilnehmer in Exp. 2 ist: 1,679, siehe Tab. 6 im Anhang, Model 1. Das heißt die Gerade hat eine positive Steigung und die MEPs steigen bei allen Teilnehmern zum Sprechbeginn hin an. Die erste Hypothese kann für Exp. 2 angenommen werden. Der Regressionskoeffizient des Gruppenunterschieds ist - 0,302, siehe Tab. 6 im Anhang, Model 2. Es zeigt sich beim Einsetzen in die Gleichung ein deutlicher Gruppenunterschied der MEP-Fazilitation. Das Ergebnis ist signifikant, siehe Tab. 6 im Anhang, Model 2, Faktor Group. Hypothese 2 kann für Exp. 2 angenommen werden. In Exp. 2 zeigt sich also ein deutlicher Fazilitationsunterschied zwischen AWS und AWNS in der Sprechvorbereitung. Der Interaktionseffekt lässt sich für Exp. 2 mit 
einem Regressionskoeffizienten von - 0,943 ebenfalls zeigen, das Ergebnis ist auch hier signifikant, siehe Tab. 6 im Anhang, Model 2, Faktor Group-TPO-Interaction. Abb. 13 a und b visualisieren die Ergebnisse der HMRA.

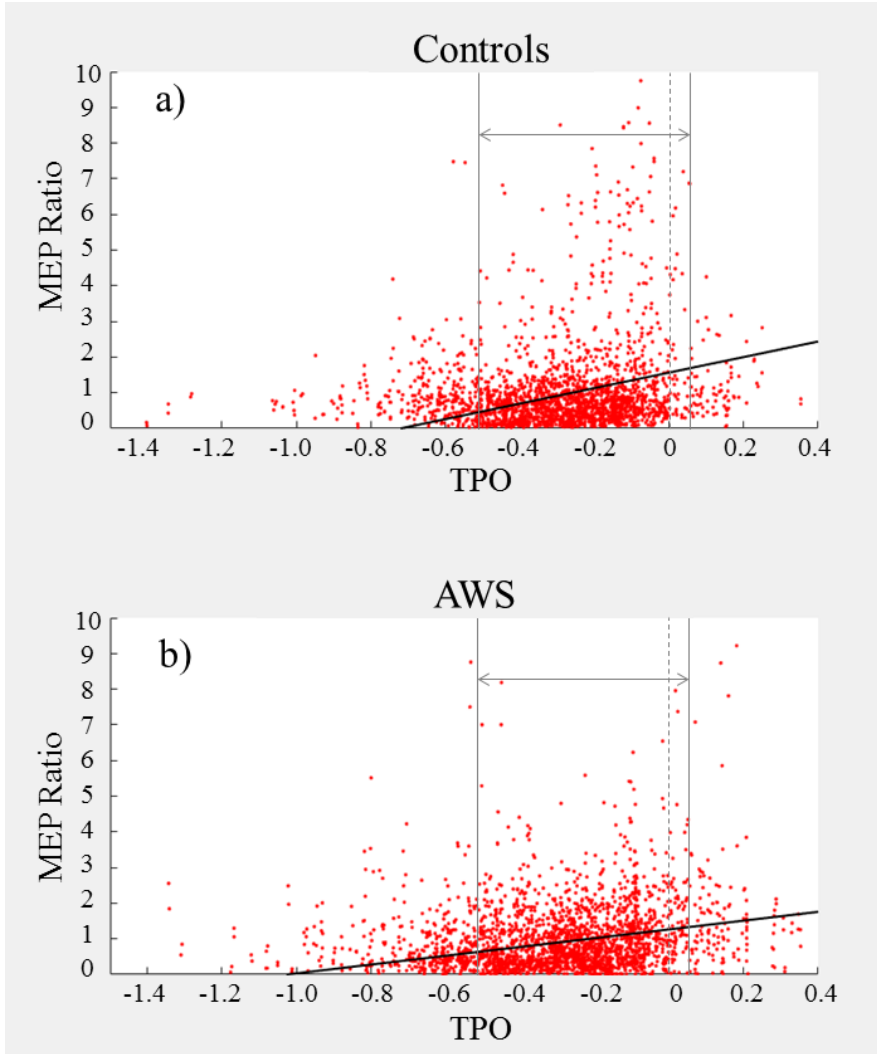

Abb. 13: Diagramm für Exp. 2 - Hierarchische multiple Regressionsanalyse AWS vs. AWNS

MEP-Verhältniswert relativ zum Präfixbeginn für Controls (= AWNS) und AWS. Jeder Punkt repräsentiert einen Trial, die $x$-Achse gibt den Zeitpunkt in Sekunden an und die $y$-Achse den MEP-Verhältniswert. Der Beginn des Präfix markiert die gestrichelte vertikale Linie am Nullpunkt bei TPO =0. Die äußeren vertikalen Linien markieren das 500-ms-Zeitfenster, welches wir für die Analyse festlegten. Die Diagonale stellt die lineare Regressionsgerade dar.

In der Nichtlinearen-Regressionsanalyse des 2. Experiments kann man die positive Korrelation der MEP-Fazilitation zum Sprechbeginn und die reduzierte Fazilitation in der Sprechvorbereitung bei AWS deutlich erkennen, siehe Tab. 6, Model 3, Faktor TPO und Faktor 
Group. Hypothese 1 und 2 können angenommen werden und die Ergebnisse sind signifikant. Den einzigen Unterschied bei Exp. 2 stellt die Betrachtung der Hypothese 3 (Interaktionseffekt) dar, siehe Tab. 6, Model 3, Faktor Group-TPO-Interaction. Es zeigt sich zwar in der HMRA und der nichtlinearen Auswertung eine negative Korrelation. In der HMRA ist das Ergebnis signifikant. In der nichtlinearen Regression ist das Ergebnis jedoch nicht signifikant. Die nichtlineare Regression gibt nachgewiesenermaßen das exaktere Ergebnis wieder. Das angepasste R-Quadrat ist mit 0.044 auch hier am größten von den drei Analysen (siehe Tab. 7 im Anhang). Somit können wir davon ausgehen, dass AWS in der Sprechvorbereitung einen weniger hohen Fazilitationsanstieg haben als AWNS. Jedoch ist dieses Ergebnis im zweiten Experiment nicht signifikant. Es gibt also keine signifikante Interaktion zwischen den Faktoren TPO und Gruppe. Abb. 14 stellt die nichtlineare Regression für das zweite Experiment dar.

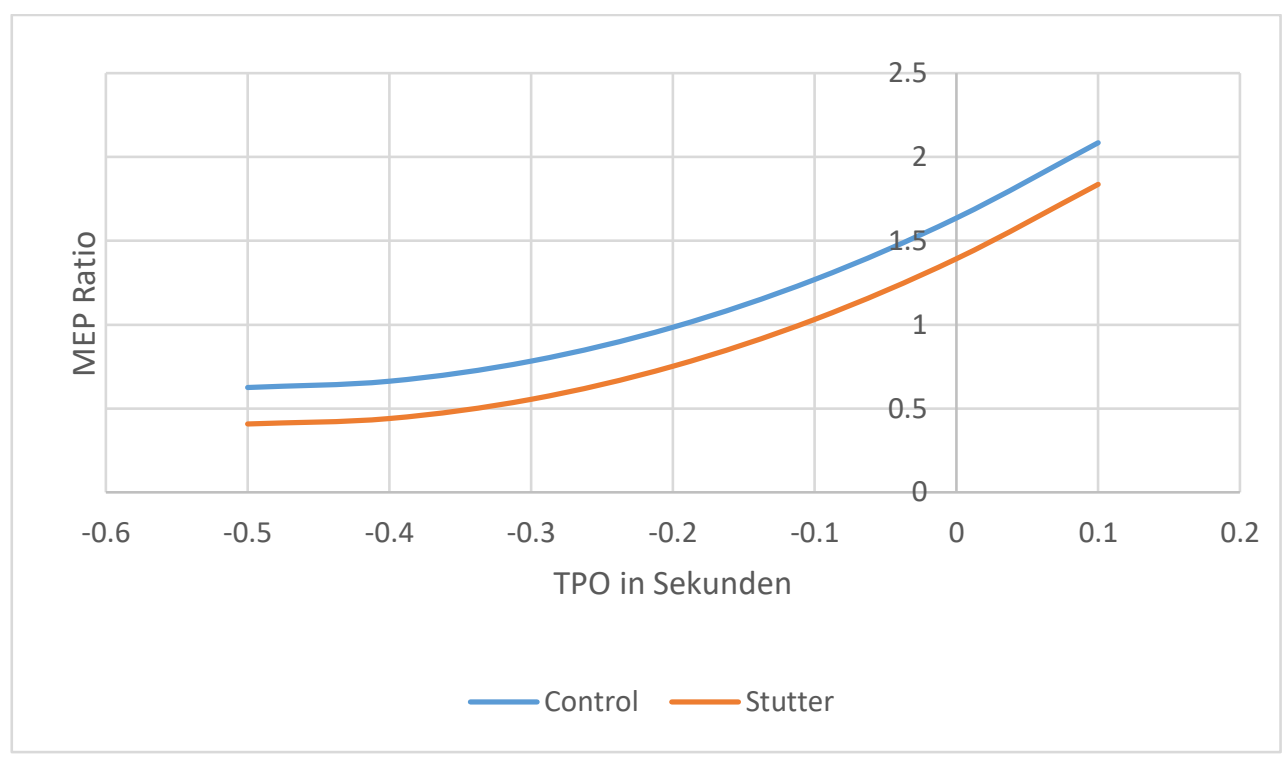

Abb. 14: Visualisierung der nichtlinearen Regression für Experiment 2

MEP-Verhältniswert relativ zum Präfixbeginn für Controls (= AWNS) und Stutter (= AWS). Blaue Linie: nichtstotternde Erwachsene = Control. Orangene Linie: stotternde Erwachsene. 
Die Grafik zeigt das 500-ms-Zeitfenster. Der Beginn des Präfix markiert die vertikale Linie bei $T P O=0$. Dargestellt ist das 500 ms Zeitfenster von -460 bis $+40 \mathrm{~ms}$.

Im zweiten Experiment waren die MEP-Größen im deskriptiven Vergleich zum ersten Experiment vermindert, das lässt sich an der Größe der Regressionskoeffizienten ablesen, Vgl. Tab. 1 und 2, Model 1, Constant, sowie graphisch an Abb. 12 und 14 erkennen.

\subsubsection{Ergebnisse zu den Hypothesen 1 - 3 für Experiment 3}

Für das dritte Experiment (geplantes Sprechen mit Taktung) wurden 2678 Trials in die Analyse einbezogen (siehe Tab. 8 und 9 im Anhang). Wie in den beiden vorherigen Experimenten zeigte sich hier ein signifikantes Ergebnis beim Fazilitationsanstieg aller Teilnehmer zum Sprechbeginn in allen drei Analysen, sodass die erste Hypothese angenommen werden kann, siehe Tab. 8, Model 1, 2 und 3 bei Faktor TPO. Der Gruppenunterschied hinsichtlich der Fazilitation zeigte sich auch in Exp. 3 deutlich, siehe Tab. 8, Model 2 und 3 bei Faktor Group. Das Ergebnis war in der HMRA mit einem Regressionskoeffizienten von $-0,305$ und der nichtlinearen Regression mit -0,352 signifikant. Hypothese 2 kann also auch angenommen werden. AWS zeigten auch in Exp. 3 beim Interaktionseffekt einen weniger hohen Anstieg der MEP-Fazilitation in der Sprechvorbereitung bezogen auf die TSO. Jedoch war das Ergebnis in der HMRA und der nichtlinearen Regression nicht signifikant. Die Hypothese 3 kann für das dritte Experiment nicht angenommen werden. Somit besteht kein signifikanter Interaktionseffekt bei Exp. 3. In Abb. 15 und 16 sind die Ergebnisse von Exp. 3 graphisch dargestellt: 

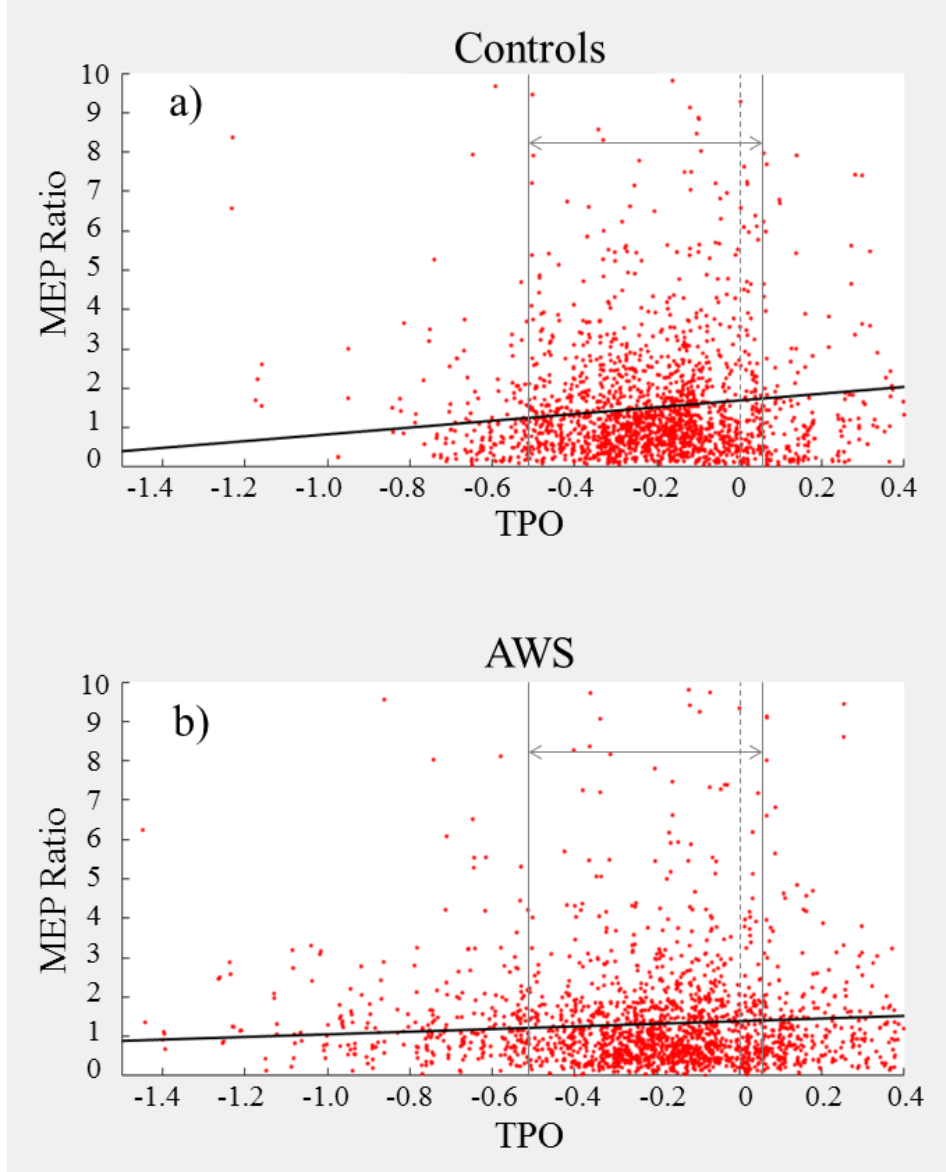

Abb. 15: Diagramm für Exp. 3 - Hierarchische multiple Regressionsanalyse AWS vs. AWNS

Abb. 15 a für AWNS + b für AWS: Exp. 3 - HMRA. MEP-Verhältniswert relativ zum Verbbeginn für Controls (= AWNS) und AWS. Jeder Punkt repräsentiert einen Trial, die $x$-Achse gibt den Zeitpunkt in Sekunden an und die y-Achse den MEP-Verhältniswert. Der Beginn des Verbs markiert die gestrichelte vertikale Linie am Nullpunkt bei TPO $=0$. Die äußeren vertikalen Linien markieren das 500-ms-Zeitfenster, welches wir für die Analyse festlegten. Die Diagonale stellt die lineare Regressionsgerade dar. 


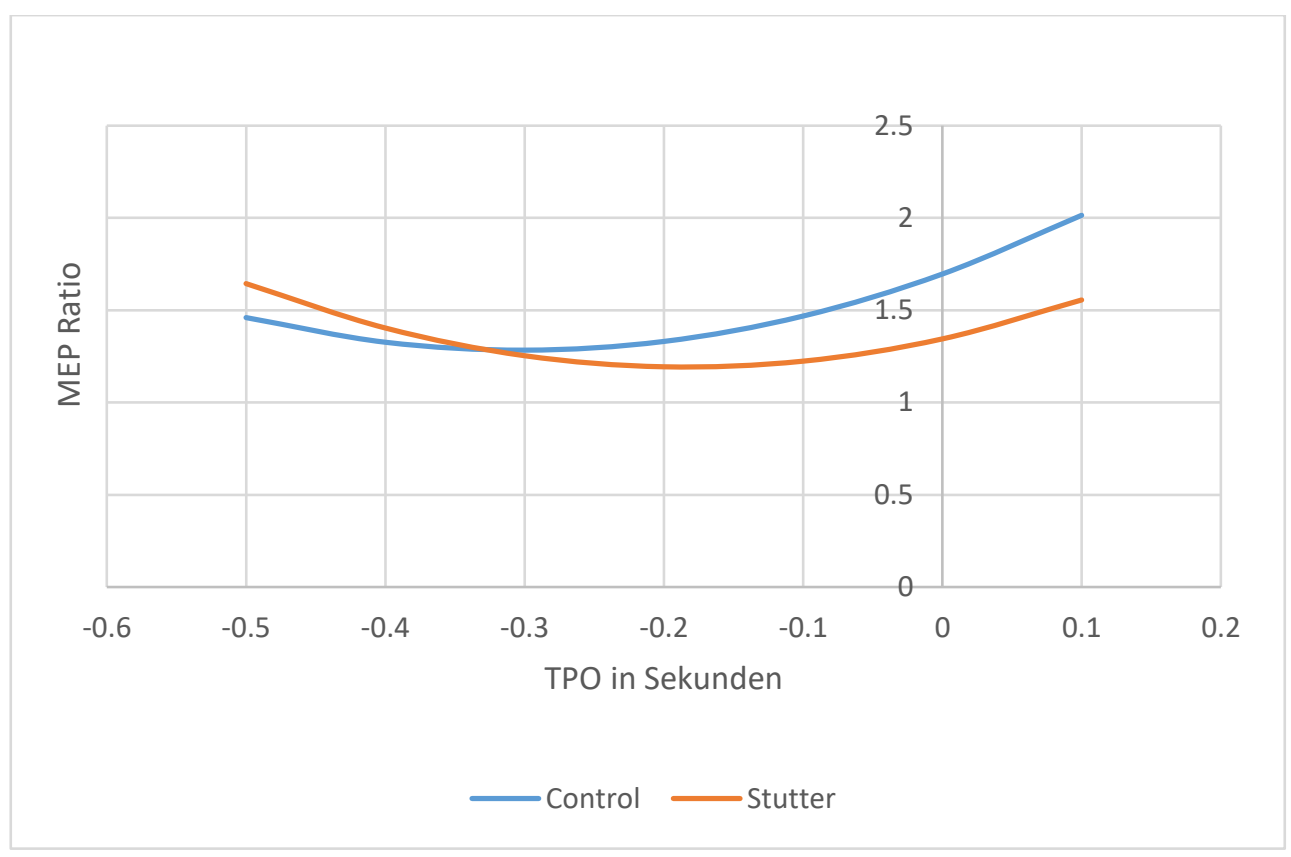

Abb. 16: Visualisierung der Nichtlinearen Regression für Experiment 3

MEP-Verhältniswert relativ zum Verbbeginn für Controls (= AWNS) und Stutter (= AWS). Blaue Linie: nichtstotternde Erwachsene = Control. Orangene Linie: stotternde Erwachsene. Die Grafik zeigt das 500-ms-Zeitfenster. Der Beginn des Verbs markiert die vertikale Linie bei $T P O=0$. Dargestellt ist das 500 ms Zeitfenster von -460 bis +40 ms.

Im dritten Experiment wiesen die gesamten MEP-Amplituden im Vergleich zum ersten Experiment kleinere Spitzenwerte auf, aber die MEPs der AWS blieben während des gesamten Experiments relativ zur Basiserregung auf einem mäßig hohen Niveau, wie man im visuellen Vergleich zwischen Abb. 16 und Abb. 12 erkennen kann. Zudem geben auch die Regressionskoeffizienten in Tab. 2 und 8, Model 1, Faktor Constant für Exp. 3 kleinere Werte an. Außerdem fällt auf, dass AWS zu Beginn des 500 ms Zeitfensters größere MEPAmplituden zeigen als AWNS (Abb. 16). Je kürzer der Abstand zum Sprechbeginn wird, desto kleiner werden die MEP-Amplituden und erst kurz vor dem Sprechbeginn nimmt die MEP-Größe der AWS wieder zu. Zwischenzeitlich holen die AWNS auf und überholen vor dem Sprechbeginn die MEP-Größe der AWS. Es ist zu beachten, dass alle drei Experimente eine geringe Effektgröße nach R2 aufwiesen (siehe Tab. 5, 7, 9 im Anhang). 


\subsection{Post-hoc Analyse zur Untersuchung der Hypothese 4}

In der Post-hoc-Analyse verglichen wir die HMRA-Ergebnisse des ersten Experiments mit den anderen beiden Experimenten, um herauszufinden, ob die MEP-Größe und Dynamik die kognitive Anstrengung widerspiegeln kann. Unsere Hypothese war, dass der Gruppenunterschied hinsichtlich der MEP-Verhältnisse am größten ist, wenn die kognitive Anstrengung am höchsten ist. Das erste Experiment entspricht der Spontansprache und impliziert somit die größte kognitive Anstrengung. Das dritte Experiment impliziert die geringste kognitive Anstrengung in der Studie mit geplantem Sprechen bei externer Taktung und Unterbrechung zwischen Präfix und Verb. Die Analyseergebnisse der HMRAs wurden verglichen und die Unterschiede wurden auf Signifikanz geprüft. Um die Experimente zu vergleichen, führten wir ungepaarte t-Tests der Verteilungen zwischen den Experimenten durch. Wir haben einen Online-Rechner namens GraphPad (GraphPad Software, Inc. Version 8, 2018) verwendet, um die nicht standardisierten Koeffizienten (B), Standardfehler und die Stichprobengröße (n) zu vergleichen. Alle Blöcke der Regressionsausgabe wurden verglichen. Zur Kontrolle verwendeten wir die Bonferroni-Korrektur (sig. bei $p=0,0125$ ). Den Tabellen 10 und $11 \mathrm{im}$ Anhang sind die Ergebniswerte zu entnehmen. In Tabelle 10 ist die spezifische statistische Analyse zum Vergleich zwischen Experiment 1 und 2 dargestellt. Die Regressionskonstante (Mittelwert $(M)=0.711$, SED (Standardfehler des Unterschieds) $=0.117, p<$ $.001)$, die TPO $(M=0.980$, SED $=0.306, p<.01)$ und die Gruppe $(M=-0.305$, SED $=0.113, p$ $<.01)$ waren überall niedriger als während des spontanen Sprechens, auch nach der Bonferroni-Korrektur (sig. $p<0.0125$ ). Der Unterschied des Interaktionseffekts war nicht signifikant $(M=-0.642, S E D=0.427, p=.133)$. Der Vergleich ergab für Experiment 2 signifikant kleinere MEPs in allen Variablen, außer beim Interaktionseffekt. Das heißt die MEPs und 
insbesondere der Gruppenunterschied unterschieden sich signifikant von Exp. 1 zu 2. Bezogen auf unsere Hypothese, bedeutet es, dass AWS in der Sprechplanung beim spontanen Sprechen eine signifikant niedrigere Fazilitation als AWNS produzieren. Hypothese 4 kann für den Vergleich zwischen Exp. 1 und 2 angenommen werden. In Tabelle 11 ist die spezifische statistische Analyse zum Vergleich zwischen Experiment 1 und 3 dargestellt: Die Regressionskonstante $(\mathrm{M}=0.617, \mathrm{SED}=0.133, \mathrm{p}<.001)$ und die TPO/TVO $(\mathrm{M}=2.295, \mathrm{SED}=$ 0.356, $\mathrm{p}<.001$ ) war signifikant kleiner als im ersten Experiment. Der Gruppenunterschied $(M=-0.302, S E D=0.126, p=.0167)$ und der Interaktionseffekt hingegen waren $(M=-1.059$, SED $=0.503, p=.035$ ) geringfügig nicht signifikant nach der Bonferroni Korrektur (sig. $p<$ 0.0125). Im Vergleich zwischen Exp. 1 und 3 zeigte das dritte Experiment ebenfalls deutlich niedrigere MEPs als das erste Experiment - die gesamte MEP-Fazilitation war signifikant. Der Gruppenunterschied und der Interaktionseffekt unterschieden sich jedoch geringfügig nicht signifikant (siehe Tab. 11 im Anhang für die Vergleiche). Die Hypothese vier kann für den Vergleich zwischen Exp. 1 und 3 nicht angenommen werden, obwohl die Gruppenunterschiede sich deutlich unterscheiden. Für den Vergleich zwischen Exp. 2 und 3 muss die Hypothese ebenfalls abgelehnt werden. Der visuelle Vergleich der Regressionskonstanten Constant und Group in Tab. 10 und 11 (im Anhang) zeigt, dass sich die Werte fast gleichen und sich hier keine signifikanten Unterschiede ergeben.

\subsection{Ergebnisse zu Hypothese 5 - zum Gruppenunterschied in den Reaktionszeiten}

Die Zeitpunkte zum Messen der Reaktionszeit (RT) konnten anhand der Audiospur von der Sprechaufforderung bis zum Sprecheinsatz ermittelt werden. Insgesamt führten wir 4 
HMRAs durch: drei für die RT vom Startsignal bis zum Einsetzen des Präfix (Exp. 1 - 3, Tab. 3 a - c) und eine für die RT vom Startsignal bis zum Einsetzen des Verbs (Exp. 3, Tab. 3 d).

\begin{tabular}{|c|c|c|c|c|}
\hline $\begin{array}{l}n \\
3623\end{array}=$ & $\begin{array}{l}\text { Auf } \\
R T\end{array}$ & Group & Pulse & Trial \\
\hline Auf $R T$ & & $\begin{array}{l}- \\
0.044 * \\
*\end{array}$ & $\begin{array}{l}0.185^{*} \\
* *\end{array}$ & $-0.078 * * *$ \\
\hline (Sig.) & & 0.004 & $\begin{array}{l}\text { (<0.001 } \\
f^{2}\end{array}$ & $(<0.001)$ \\
\hline $\begin{array}{l}\text { Group } \\
\text { (Sig.) }\end{array}$ & & - & $\begin{array}{l}-0.01 \\
0.275\end{array}$ & $\begin{array}{l}0.001 \\
0.48\end{array}$ \\
\hline $\begin{array}{l}\text { State } \\
\text { (Sig.) }\end{array}$ & & & - & $\begin{array}{l}0.052 * * \\
(<0.001)\end{array}$ \\
\hline Trial & & & & - \\
\hline
\end{tabular}

\begin{tabular}{|c|c|c|c|c|}
\hline $\begin{array}{l}n \\
3211\end{array}$ & $\begin{array}{l}\text { Auf } \\
R T\end{array}$ & Group & Pulse & Trial \\
\hline Auf $R T$ & & -0.018 & $\begin{array}{l}0.135 * \\
* *\end{array}$ & 0.022 \\
\hline (Sig.) & & 0.156 & $\begin{array}{l}<<0.001 \\
j^{1}\end{array}$ & 0.106 \\
\hline Group & & & -0.001 & -0.007 \\
\hline (Sig.) & & & 0.478 & 0.346 \\
\hline State & & & & 0.016 \\
\hline (Sig.) & & & & 0.184 \\
\hline Trial & & & & - \\
\hline
\end{tabular}

Tabelle 3: Ergebnisse der Hierarchischen multiplen Regressionsanalyse für Reaktionszeiten

Tab. 3 a Ergebnisse für Exp. 1

\begin{tabular}{|c|c|c|c|c|}
\hline $\begin{array}{l}n \\
3172\end{array}=$ & $\begin{array}{l}\text { Auf } \\
R T\end{array}$ & Group & Pulse & Trial \\
\hline Auf $R T$ & & -0.014 & 0.002 & $\begin{array}{l}- \\
0.068 * * *\end{array}$ \\
\hline (Sig.) & & 0.221 & 0.445 & $(<0.001)$ \\
\hline Group & & & -0.001 & -0.015 \\
\hline (Sig.) & & & 0.476 & 0.192 \\
\hline State & & & - & -0.012 \\
\hline
\end{tabular}

Tab. 3 b Ergebnisse für Exp. 2

\begin{tabular}{|c|c|c|c|c|}
\hline $\begin{array}{l}n \\
3172=\end{array}$ & $\begin{array}{l}\text { Verb } \\
R T\end{array}$ & Group & Pulse & Trial \\
\hline $\begin{array}{l}\text { Verb } \\
R T\end{array}$ & & $\begin{array}{l}- \\
0.040^{*}\end{array}$ & $0.030 *$ & $\begin{array}{l}- \\
0.032^{*}\end{array}$ \\
\hline (Sig.) & & 0.013 & 0.043 & 0.036 \\
\hline Group & & & -0.001 & -0.015 \\
\hline (Sig.) & & & 0.476 & 0.192 \\
\hline State & & & - & -0.012 \\
\hline
\end{tabular}




\begin{tabular}{|l|l|l|l|} 
(Sig.) & & & 0.245 \\
\hline Trial & & & - \\
\hline
\end{tabular}

Tab. 3 c Ergebnisse für Exp. 3

\begin{tabular}{|l|l|l|l|} 
(Sig.) & & & 0.245 \\
\hline Trial & & & - \\
\hline
\end{tabular}

Tab. 3 d Ergebnisse für Verbbeginn

Tabelle 3a-d: Hierarchische multiple Regressionsanalyse für die Reaktionszeiten (RT) bis zum Einsatz des Präfixes (Auf) in jedem Experiment $(3 a-c)$ und bis zum Einsatz des Verbs in Experiment $3(3 d)$. Korrelationswerte für jedes Paar, mit dem Signifikanzniveau in Klammern $\left({ }^{*}=p<.05,{ }^{* *}=p<.01,{ }^{* * *}=p<.001\right)$. Group zeigt RT-Unterschiede der Gruppen an. Pulse untersuchen den Einfluss der TMS-Pulse auf die RT. Trial untersucht den Einfluss der ca. 120 hintereinander ablaufenden Trials auf die RT. Mit der Variablen State les gibt zehn verschiedene States) und der Einflussgröße Trial, soll gezeigt werden, ob es einen Zusammenhang zwischen States und Trials gibt in dem randomisierten Versuchsaufbau.

Negative Korrelationswerte zeigen eine Reduktion der Reaktionszeit (RT) und damit eine schnellere Antwort der Teilnehmer. In allen drei Experimenten reagierten AWS langsamer (siehe Tab. 3 a - d, Zeile 1, Spalte 1). AWS waren im ersten Experiment $44 \mathrm{~ms}$ und in der Verbkomponente des dritten Experiments 40 ms langsamer als AWNS (siehe Tab. 3 a und d, Zeile 1, Spalte 1). Die zweite Spalte „Pulse“ gibt die RT unter Berücksichtigung der Verzögerung durch den TMS-Puls an und die dritte Spalte „Trial“ gibt die RT unter Berücksichtigung der Habituation an (schließlich könnte es durch den TMS-Puls eine Verzögerung der RT geben oder es könnte aufgrund der ca. 120 Trials eine Antizipation und dadurch eine Habituation des Startsignals zum Sprechen geben). Auch unter Berücksichtigung der Pulsverzögerung und der Habituation reagierten AWS langsamer (Tab. 3 a - d, Zeile 1, Spalte 3). Die Ergebnisse sind für Exp. 1 und 3 unter Berücksichtigung der Pulsverzögerung und der Habituation signifikant, jedoch nicht für Exp. 2 und die Verbkomponente in Exp. 3 (Tab. 3 a - d, Zeile 2, Spalte 3). Zusammenfassend kann die Hypothese 5 für Exp. 1 und 3 angenommen werden, jedoch nicht für Exp. 2. Setzt man die Regressionskoeffizienten in die o.g. Formel ein, dann wird bei zunehmenden Trials die RT kleiner. Die Teilnehmer erlernten also 
die präzise Zeittaktung in Exp. 1 und 3, denn unter Berücksichtigung der Trials wurden die Regressionskoeffizienten der RT kleiner (Tab. 3 a und c, Zeile 2, Spalte 3). In Tab. 3 a - d, Zeile 3 und 4, Spalte 3 und 4 zeigen die Regressionskoeffizienten mit zugehörigen Signifikanzen den Einfluss der TMS-Pulse und der Trials unabhängig der Gruppe an. Die Zeilen 5 und 6 sowie Spalten 3 und 4 geben den Zusammenhang zwischen State und Trial an. Die Signifikanz $(<0.001)$ in Exp. 1 impliziert in den späteren Trials durchschnittlich mehr auftretende späte States.

4.5 Lineare Einfachregression und Hierarchische multiple Einfachregression mit prozentual gestotterten Silben zur Untersuchung von Hypothese 6

Um die sechste Hypothese und Frage klären zu können, ob die prozentualen Stotterunregelmäßigkeiten (\% SS) besser mit der MEP-Fazilitation korreliert als unsere herkömmliche Einteilung in die zwei Gruppen, werteten wir alle Experimente noch einmal im Hinblick auf die prozentuale Stotterhäufigkeit aus. Die ermittelten Werte sind im Anhang zu finden unter Tab. 12 - 17. Zur besseren Übersichtlichkeit haben wir die AWS in drei Kategorien von prozentual gestotterten Silben unterteilt: leichtes Stottern, mittleres Stottern und schweres Stottern ( $0 \%, 5 \%, 12,5 \%$ und $25 \%$ ). Abbildung 17 zeigt die Graphen der linearen Regression aller drei Experimente unter Einteilung des \% SS in vier Gruppen. 

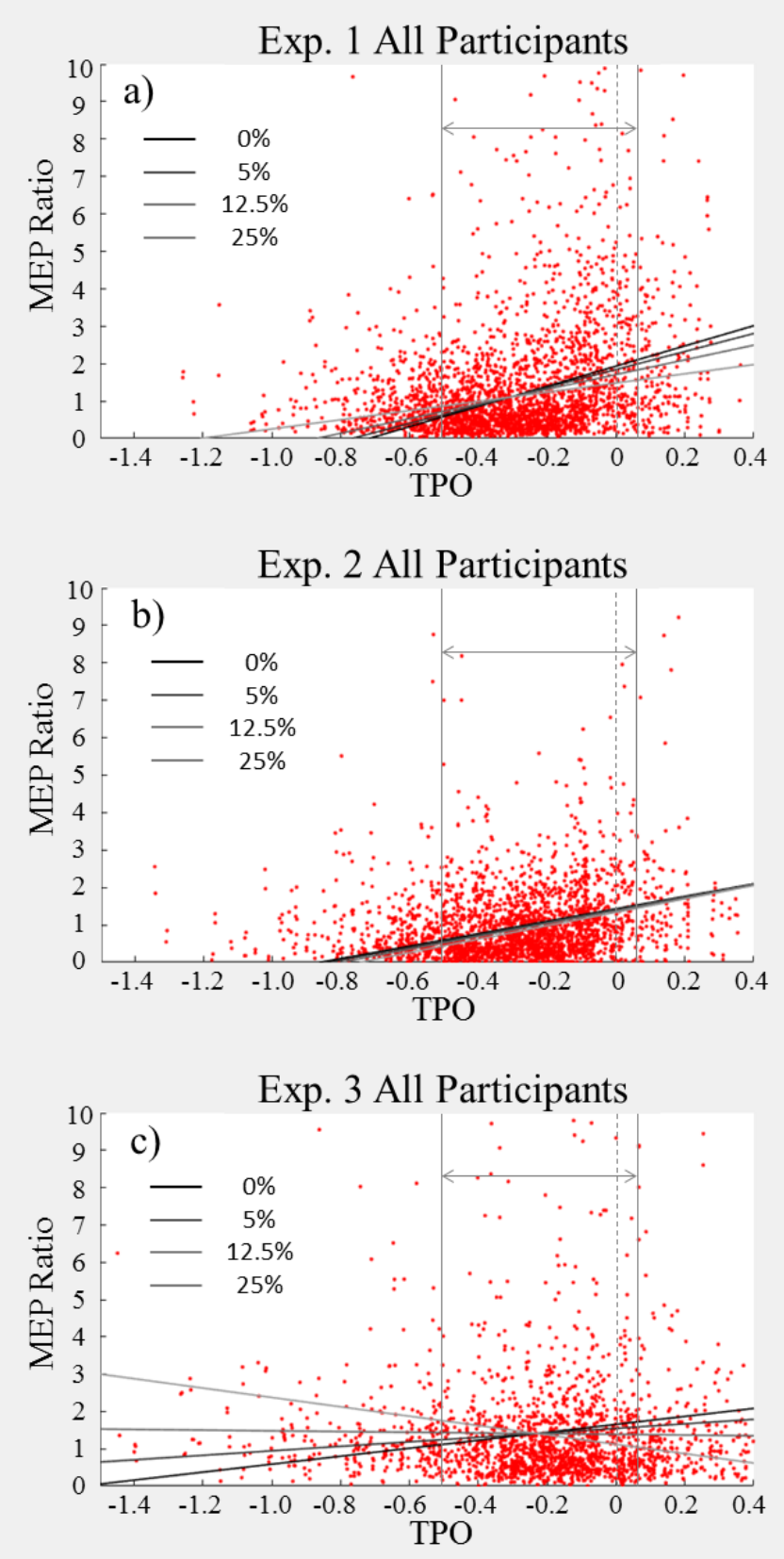

Abb.17: Lineare Regression für Exp. 1 - 3 mit \% SS

MEP-Verhältniswert relativ zum Präfixbeginn für alle Teilnehmer (unabhängig von der Gruppe). Jeder Punkt repräsentiert einen Trial. Beginn des Präfix (Abb. 14 a und 14 b) und Beginn des Verbs (Abb. 14 c) für jeden Trial ist markiert mit der gestrichelten vertikalen Linie bei TPO $=0$. Die äußere vertikale Linie markiert das $500 \mathrm{~ms}$ Fenster, welches wir für die Analyse auswählten. Die Geraden repräsentieren MEP-Steigungen, welche zwischen den Stotterschweregrad-Einteilungen differenziert (0\%, $5 \%, 12,5 \%$ und $25 \%$ ). 
Vergleicht man die Analysen der binären Einteilung mit denen der \% SS, dann zeigt sich in Exp. 1 ebenfalls eine signifikante negative Korrelation zwischen der MEP-Größe und der \% SS. Hypothese 1 kann für Exp. 1 auch unter \% SS angenommen werden. Der Gruppenunterschied und Interaktionseffekt waren ebenfalls signifikant, jedoch in der binären Einteilung deutlicher zu erkennen. Im zweiten Experiment zeigte sich der größte Unterschied zwischen den Analysen, denn das einzige signifikante Ergebnis unter Einbeziehung der Stotterschwere (\% SS) statt der binären Gruppeneinteilung war, dass die MEPs zum Sprechbeginn hin größer werden. Die erste Hypothese ist die einzige, die bei Exp. 2 unter \% SS angenommen werden kann. Der Grund dafür ist, dass die MEP-Größen aller Teilnehmer sich in Exp. 2 annähern und somit kein signifikanter Gruppenunterschied mehr sichtbar ist. Im zweiten Experiment zeigte sich für die \% SS eine negative Korrelation der MEPs, die zwar nicht signifikant war, jedoch trotzdem für Exp. 2 aussagt, dass flüssigeres Sprechen tendenziell mit höheren MEPs einhergeht.

Exp. 3 ist das Einzige, das unter den \% SS bessere Ergebnisse lieferte, siehe F-Change (Tab. 9 und 17). Ein signifikanter F-Change bedeutet, dass die in diesem Schritt hinzugefügten Variablen die Vorhersage für den jeweiligen Ansatz (binär vs. kontinuierlich \% SS) signifikant verbessern, das trifft für Exp. 3 unter \% SS zu. Somit ist das Ergebnis des Interaktionseffekts aus Experiment 3 mit \% SS haltbarer als aus der binären Analyse. Hier zeigte sich ein starker Interaktionseffekt, der sich unter der binären Einteilung nicht zeigte (Tab. 16, Model 2, \% SS-TVO-Interaction). Dieser negative Effekt zeigt für schwer stotternde Erwachsene (25 \% SS), dass die MEP-Fazilitation nach Aussprechen des Präfixes wieder rückläufig wird, 
obwohl das Verb noch nicht angehängt (ausgesprochen) wurde. Schwer stotternde Erwachsene zeigen einen MEP-Einbruch nachdem das Präfix vorbereitet wurde, wohingegen AWNS und leicht stotternde Erwachsene die MEP-Fazilitation weiterhin hoch halten. Das könnte ein entscheidender Hinweis auf die gesamte Sprechplanung bei AWS liefern.

Anschließend wurden die Vorhersagewerte der binären Einteilung und des \% SS verglichen. Schließlich geht es in der Hypothese um die Frage, welche der Einteilungen sensitiver die Stotterschwere berücksichtigt. Hierfür verglichen wir (rein deskriptiv) die Gütekriterien (RQuadrat) der binären Einteilung aus Tabelle 5, 7 und 9 mit den Gütekriterien der \% SSEinteilung aus Tab. 13, 15 und 17. Insgesamt kann man sagen, dass die \% SS die MEP-Fazilitation nicht passender darstellen können als unsere herkömmliche Einteilung in die beiden Gruppen und somit ist die herkömmliche binäre Gruppeneinteilung das passendere Modell für unsere Analyse.

\section{Diskussion}

Zusammenfassend zeigen unsere Ergebnisse in der Sprechvorbereitung eine reduzierte Fazilitation in allen Experimenten bei stotternden Erwachsenen (AWS), verglichen mit nichtstotternden Erwachsenen (AWNS). Dieser Unterschied ist allerdings nicht über alle Experimente gleichbleibend. Hier noch einmal zur Übersicht die Bezeichnung der drei Experimente:

Experiment 1 = spontanes Sprechen.

Experiment 2 = geplantes Sprechen ohne Taktung. 
Experiment 3 = geplantes Sprechen mit Taktung.

AWS zeigen im Gruppenvergleich ein generell reduziertes Fazilitationslevel in allen Experimenten sowie einen weniger hohen Anstieg der Fazilitation zum Sprechbeginn hin. Der Unterschied war während des spontanen Sprechens am größten. AWNS zeigten beim spontanen Sprechen eine sehr hohe Fazilitation. Beim geplanten Sprechen mit und ohne Taktung (geringste kognitive Anstrengung) war die Fazilitation vermindert und ähnlich groß wie bei AWS während aller drei Experimente. Die Reaktionszeit war bei AWS beim spontanen Sprechen und beim geplanten Sprechen mit Taktung verlängert. Unsere herkömmliche Einteilung der Gruppenzuordnung in AWS oder AWNS korrelierte besser mit der MEP-Fazilitation als die kontinuierliche Einteilung nach prozentualen Stotterunregelmäßigkeiten. Im Folgenden werden die Ergebnisse unter Bezug auf die einzelnen Hypothesen diskutiert.

5.1 Hypothese 1: Die MEP-Fazilitation steigt zum Sprechbeginn hin bei allen Teilnehmern und in allen drei Experimenten an.

Mit der ersten Hypothese sollte gezeigt werden, dass im Kortexareal der Zunge eine progrediente Erregung während der Sprechvorbereitung herrscht, bevor es zur Artikulation des ersten Lautes kommt. In der Zeit kurz vor dem Sprechbeginn zeigt die neuronale Aktivität einen Höhepunkt, diesen haben wir in der Periode der Sprechvorbereitung MEP-reguliert nachgewiesen. Die Kortexerregbarkeit bildet die Grundlage für die sprechmotorische Aktivität und hierbei zeigt sich, dass eine positive Korrelation zwischen der MEP-Amplitude und dem Zeitintervall zwischen MEP und Sprechbeginn (MEP-TSO) bei der gesamten Gruppe der Teilnehmer zu verzeichnen ist. Hiermit bestätigt sich unsere erste Hypothese: Die MEP-Fazilitation steigt zum Sprechbeginn hin bei allen Teilnehmern und in allen Analysen signifikant an. Analog zu unserem Ergebnis war in der Studie von Neef und Kollegen 
(Neef et al. 2015a) eine erhöhte Kortexerregbarkeit in Form von erhöhten MEP-Amplituden in der Übergangsphase vom Präfix zum Verb erkennbar. Die Sprechplanung scheint sich sowohl vor Beginn als auch zwischen zwei Worten in einer erhöhten Kortexerregbarkeit widerzuspiegeln.

\subsection{Hypothese 2: Insgesamt ist das Fazilitationslevel bei AWS reduziert}

Stottern ist besonders mit Kontrollverlust beim Sprechbeginn assoziiert ist. Deshalb vermuteten wir, dass AWS eine reduzierte MEP-Fazilitation in der Sprechvorbereitung und insbesondere kurz vor dem Sprechbeginn zeigen. Unsere Ergebnisse bestätigen dies in allen drei Experimenten und allen Analysen - die MEP-Amplituden waren bei AWS linkshemisphärisch signifikant niedriger als bei AWNS. Unsere Ergebnisse werden gestützt durch die Studienergebnisse von Ning und Kollegen, die mittels kontingenter negativer Variationen (Contingent Negative Variation, CNV) eine niedrigere kortikale Erregbarkeit bei AWS in der Sprechvorbereitung nachwiesen (Ning et al. 2017). CNV gehören wie das Bereitschaftspotenzial (BP) zur Gruppe der langsamen antizipatorischen Potenziale. Das sind elektrophysiologisch messbare Erregungen, die kurz vor selbstinitiierten Bewegungen im supplementärmotorischen Kortex (SMA) auftreten und als Aktivierungs- und Vorbereitungsprozesse aufgefasst werden. Das BP entsteht endogen im Gehirn ohne vorherigen externen Stimulus bevor eine Bewegung ausgeführt wird. Das Hirnpotenzial der CNV wird im Gegensatz zum BP nach einem externen Stimulus abgeleitet, der den Teilnehmer in die Erwartungshaltung bringt bevor der zweite, externe Stimulus als Signal zur Bewegungsausführung erscheint (Kornhuber und Deecke 1965). Der Teilnehmer hat also schon die Aufforderung zur Bewegungsvorbereitung bekommen und befindet sich in einer Erwartungshaltung. Das ist analog 
zu unserem Experiment, wo der Teilnehmer ein Signal bekommt um sich auf die Sprechvorbereitung zu konzentrieren, bevor das Startsignal zum Aussprechen erscheint. In der Studie von Ning und Kollegen war die Amplitudengröße der CNV bei AWNS während der Sprechvorbereitung signifikant größer als bei AWS (Ning et al. 2017). Ähnlich wie Stottern ist Morbus Parkinson mit einer Starthemmung bei Bewegungsausführungen assoziiert (Manenti et al. 2016). Passend dazu fiel in einer TMS-Studie mit Parkinsonpatienten auf, dass bei willkürmotorischer Aktivität verminderte MEP-Amplituden und eine erhöhte aktive motorische Reizschwelle zu verzeichnen waren im Vergleich zu Gesunden. Das Studienergebnis weist auf ein ineffektiv erregbares kortikales System bei Parkinsonpatienten hin (VallsSolé et al. 1994). In unserer Studie fielen zwar keine signifikanten Unterschiede der motorischen Reizschwelle auf (siehe Tab. 1, Zeile 5), aber die verminderte Amplitudengröße lässt Rückschlüsse zu auf ein weniger effektiv erregbares kortikales System bei AWS im Bereich des Zungenareals. Viele Bewegungsstörungen wie beispielsweise Parkinson sind außerdem mit einem gestörten Bereitschaftspotenzial assoziiert (Colebatch 2007). Das BP fehlt vor den willkürlichen Bewegungen bei der Parkinsonerkrankung (Colebatch 2007, Manenti et al. 2016) und ist hyperaktiv bei Ticstörungen (van der Salm et al. 2012). Das Muster der ansteigenden MEP-Fazilitation vor dem Sprechen ist analog zur messbaren Erregung des BP. Übertragen auf AWS liegt hier ebenfalls ein ineffektiv erregbares kortikales System vor. Die Studienergebnisse zum BP haben zwei eindeutige Abschnitte gezeigt - das frühe (BP1) und das späte BP (BP2), welche entsprechend um 1200 ms und 500 ms vor der Bewegungsinitiation beginnen. Es wird angenommen, dass das BP1 im SMA und im Prä-SMA entsteht, 
die eher für die Planung komplexer Bewegungsmuster stehen, während das späte BP wahrscheinlich in beidem, der SMA und im kontralateralen Motorkortex entsteht (Colebatch 2007). Übertragen auf unser MEP stellt sich die Frage, ob wir den MEP-Höhepunkt bei AWS eventuell nicht erfasst haben mit dem 500 ms Abschnitt in der Sprechvorbereitung, der lediglich von uns beobachtet wurde (Vgl. Kap 4.2.2 Ergebnisse zu den Hypothesen 1-3, Abb. 11). Eventuell existiert eine noch frühere Fazilitation zur Sprechvorbereitung bei AWS, wie beim BP. Hinweise auf zeitliche Unterschiede bei den Erregungen finden sich in der Studie von Busan und Kollegen (Busan et al. 2019). Busan und Kollegen haben AWS und AWNS mittels TMS und EEG in Bezug auf Aktivierungsunterschiede in bestimmten Hirnregionen untersucht. Hierbei zeigten AWS ca. 60 - 90 ms nach dem TMS-Puls deutlich niedrigere Aktivitäten in der linken SMA und im linken inferioren frontalen Kortex. Ca. 200 ms später waren deutliche Aktivitätssteigerungen rechtstemporal und im rechten prämotorischen Kortex bei AWS zu sehen (Busan et al. 2019). Die Ergebnisse lassen bei AWS eine verzögerte neuronale Erregbarkeit in verschiedenen Hirnarealen vermuten. Vermutlich kompensieren AWS die fehlende Erregung mit Aktivitätssteigerungen in anderen Hirnregionen zu früheren oder späteren Zeitpunkten, wie bereits schon von Neumann und Euler vermutet wurde. Sie wiesen, wie bereits im Kap „2.4.1. Neuromorphologische Auffälligkeiten“ beschrieben, eine kompensatorische, vor allem rechtshemisphärisch Substanzzunahmen in frontalen, parietalen und anderen temporalen Regionen nach (Neumann und Euler 2010). Ebenso gehen Brown und Kollegen bei AWS von einer Kompensation durch das homologe rechtshe- 
misphärische Areal der Broca-Region (BA 47) aus (Brown et al. 2005). Zum flüssigen Sprechen scheint nicht nur die Intensität der Fazilitation beizutragen, sondern auch die zeitliche und örtliche Kongruenz der Fazilitation.

5.3 Hypothese 3: AWS zeigen einen reduzierten Anstieg der MEP-Fazilitation in der Sprechvorbereitung bezogen auf die TSO, dies zeigt der Interaktionseffekt.

Es fällt auf, dass der Interaktionseffekt zwischen Gruppe und MEP-TSO signifikant im ersten Experiment nachweisbar ist, aber nicht signifikant in Exp. 2 und 3. In Exp. 1 zeigen AWS einen weniger hohen Anstieg der MEP-Fazilitation in der Sprechvorbereitung bezogen auf die TSO. Das bedeutet, je mehr sich AWS zeitlich der Aussprache annähern, desto größer ist der Fazilitationsunterschied zu AWNS. AWS haben in Exp. 1 Schwierigkeiten eine adäquat hohe kortikale Erregung zu produzieren. Zudem reduziert sich in Exp. 2 und 3 die MEPGröße bei AWNS. Es scheint so, als haben die AWNS Schwierigkeiten aufgrund der Sprechaufgabe in Exp. 2 und 3 eine adäquate kortikale Erregung zu produzieren, oder aber eine hohe kortikale Erregung ist bei AWNS nicht notwendig um die Sprechaufgabe zu erledigen. Anzumerken ist, dass im Exp. 3 - „Geplantes Sprechen mit Taktung“ viele MEPs erst nach der Präfixprolongation und somit kurz vor und während der Verbaussprache aufgezeichnet wurden, wie in der Studie von Neef und Kollegen. In dem Fall befinden sich die 35 Teilnehmer zwischen Präfix und Verb - währenddessen wird das MEP aufgezeichnet. Man könnte also argumentierten, dass MEPs aufgrund der großen motorischen Bewegung und Aktivität verzerrt waren. Bei der Auswertung zeigten sich jedoch nicht mehr verzerrte MEPs verglichen mit den anderen Experimenten. Naheliegender wäre, dass die ausreichende Vorbe- 
reitungszeit für AWS, die aufgrund der Prolongation in Exp. 2 und 3 gegeben ist, eine gleichgroße Fazilitation wie bei AWNS hervorbringt, da die längere Vorbereitungszeit eine adäquate Sprechvorbereitung begünstigt.

In Kombination mit den signifikanten Gruppenunterschieden vorher suggeriert dies, dass AWS einen anders getakteten Dynamikbereich der Sprechvorbereitungszeit haben und die ausgedehnte Vorbereitungszeit in Exp. 2 und 3 den AWS zugutekommt. Ist das Sprechen extrem entzerrt, zum Beispiel durch einen äußeren Taktgeber, so verschwindet der Unterschied der AWS zu den AWNS. In Exp. 2 und insbesondere in Exp. 3, kann man von einer Entzerrung ausgehen. AWS profitieren hier von einer längeren Vorbereitungszeit. In der bereits oben zitierten Studie von Ning und Kollegen wird außerdem gezeigt, dass die topographische Verschiebung von der Frühphase zur Spätphase in den CNV bei AWS viel früher erscheint als bei AWNS (Ning et al. 2017). Man könnte daraus folgern, dass der Prozess der unmittelbaren motorischen Vorbereitung bei AWS früher einträte als bei AWNS. Die Frühphase der CNV repräsentiert ein Aktivitätsmaximum frontal und in dem supplementärmotorischen Areal (SMA) sowie im anterioren zingulären Kortex (ACC), und spiegelt die Orientierung, Aufmerksamkeit und Erwartung wider (Gómez et al. 2003). Die Spätphase teilt sich gewöhnlich zentral-parietal auf mit Ursprüngen im primärmotorischen Kortex, SMA, im posterior-parietalen und sekundärsensorischen Kortex und ist assoziiert mit fortgeschrittenen motorischen und sensorischen Vorbereitungen kurz vor der Bewegung (Shibasaki et al. 1993, Gómez et al. 2003). Die frühe topographische Verschiebung suggeriert, dass der motorische Vorbereitungsprozess bei AWS früher eintritt als bei AWNS. Zudem scheint die Früh- und Spätphase der Sprechvorbereitung bei AWS nicht nur früher 
einzusetzen als bei AWNS, sondern auch früher zu enden. Denn in derselben Studie hatten AWS größere Probleme, eine bereits in der Sprechplanung befindliche Antwort zu stoppen (Ning et al. 2017). Dazu passt unsere Beobachtung, dass schwer stotternde Erwachsene in Exp. 3 kurz vor der Verbaussprache kleinere MEPs zeigen. Vermutlich liegt dies an der vorzeitig endenden Spätphase, die sich bei schwer stotternden Erwachsenen deutlicher bemerkbar macht. Umgekehrt kann man folgern: wird den AWS eine längere Vorbereitungsphase eingeräumt, so ergaben sich MEP-Größen auf dem Level von AWNS.

5.4 Hypothese 4: Der Fazilitationsunterschied zwischen stotternden und nichtstotternden Erwachsenen ist beim spontanen Sprechen am größten

Seit langem werden eine erhöhte kognitive Belastung und eine längere Bearbeitungszeit zum Kodieren von semantischen Phrasen mit der Stottersymptomatik in Verbindung gebracht (Bosshardt 2006). Ebenso konnte eine konkurrierende motorische Aktivität während des Sprechens als Verstärker der Stottersymptomatik identifiziert werden (Bajaj 2007). Auch unabhängig von Sprechaufgaben zeigten stotternde Kinder eine Verlangsamung beim parallelen Bearbeiten von Konzentrationsaufgaben in einer Studie mit acht unterschiedlichen Aufmerksamkeitstests (Doneva et al. 2018). Man könnte also argumentieren, dass die Teilnehmer durch die Präfixprolongation in unserem Experiment eine längere Vorbereitungszeit haben und somit die kognitive Belastung für AWS sinkt. In weiteren Studien wird die verminderte kortikale Erregbarkeit bei AWS mit einem Defekt in der Sprechperformance assoziiert und die Ursache in der kognitiven Verarbeitungskapazität diskutiert: Capa und Kollegen stellten aufgrund ihrer Forschungsergebnisse die Behauptung auf, dass generell größere CNV-Amplituden mit mehr Investition in das Arbeitsgedächtnis und besserer Performance beim Sprechen assoziiert sind (Capa et al. 2013). Die o.g. Studie von 
Ning und Kollegen zeigt große CNV-Amplituden bei AWNS und eine Amplitudenabnahme bei AWS in der Sprechvorbereitung (Ning et al. 2017). Maxfield et al. zeigte mittels CNV unter Beobachtung der Frühphase, dass die Erregung bei AWS nur während der Sprechaufgaben reduziert war und bei allen anderen Aufgaben, die nicht das Sprechen forderten, eine hohe Erregung zeigte. Das widerspricht der o.g. Studie von Doneva et al. 2018, wo AWS auch bei reinen Aufmerksamkeitstests langsamere Reaktionen zeigten. Allerdings ist zu beachten, dass die Aufmerksamkeitstests parallel erledigt werden mussten - es könnte hier lediglich ein Kapazitätsproblem vorliegen, was sich beim seriellen Lösen von Aufmerksamkeitstests nicht bemerkbar macht. Maxfield et al. folgerten, dass AWS nicht ausreichend Kapazität vom Arbeitsgedächtnis für die Sprechvorbereitung rekrutieren können um eine adäquate Sprechvorbereitung zu gewährleisten (Maxfield et al. 2015). Wir untersuchten dieses Phänomen, indem wir unsere drei Experimente verglichen. Im ersten Experiment „Spontanes Sprechen“ wurde der größte Gruppenunterschied detektiert. AWNS zeigten deutlich größere MEP-Amplituden im Vergleich zu AWS während des spontanen Sprechens. Es kann also angenommen werden, das AWS der Anforderung des spontanen Sprechens nicht gerecht werden. Die zunehmende Entzerrung, welche durch das Prolongieren im zweiten und dritten Experiment gegeben ist, dämmt anscheinend die bestehende Hürde für AWS ein, denn die MEP-Amplituden beider Gruppen unterscheiden sich hier fast nicht. Trotzdem waren die Gruppenunterschiede nicht wie erwartet linear über die drei Experimente zu erkennen. Im ersten Experiment zeigte sich die größte MEP-Differenz zwischen den beiden Gruppen und in den beiden anderen Experimenten waren die Gruppenunter- 
schiede gering. Im Vergleich zu den anderen Ergebnissen scheint es, dass AWNS im zeitlichen Verlauf von Exp. 1 bis 3 dynamischere Modulationen der Fazilitation im Sinne einer stetigen Abnahme der Fazilitation zeigen, während AWS einen stabilen Durchschnittswert der MEPs haben. Initial zeigen AWS kurzzeitig im Exp. 1 und 3 sogar größere MEPs als AWNS, näher zum Sprechbeginn hin übersteigt die MEP-Größe der AWNS die der AWS. AWS zeigen insgesamt weniger Modulationen der MEP-Amplitude im Verlauf. Neef und Kollegen (Neef et al. 2015a) vermuteten schon aufgrund der größeren linkshemisphärischen Fazilitation bei AWNS, dass es ein spezielles Fazilitations-Sprechprogramm gibt, welches AWS nicht besitzen und deshalb eine eingeschränkte oder keine Möglichkeit für eine Modulation haben. Wir vermuten ebenfalls, dass es sich um ein sprechspezifisches System handelt, denn eine Verlangsamung bei nicht-sprachlichen Mundbewegungen unter AWS ist bisher nicht nachgewiesen (Natke und Alpermann 2010, Maxfield et al. 2015). Vermutlich besitzen AWS die Spezialisierung für die Sprechkoordination nicht oder diese Spezialisierung ist defekt. Deshalb wenden AWS diverse Kompensationsmechanismen an, die nur unter ausreichend Vorbereitungszeit reibungslos funktionieren. Die genügende Vorbereitungszeit in Exp. 3 ist gegeben, sodass sich die MEP-Größe der AWS fast nicht unterscheidet zu AWNS. Bei der dynamischen MEP-Modulation von AWNS könnte es sich um einen Mechanismus zur Anpassung an verschiedene Sprechanforderungen handeln. Vermutlich benötigen kognitiv anspruchsvolle Aufgaben mehr Fazilitation als entzerrte Sprechaufgaben. Das würde erklären, weshalb die Fazilitation bei AWNS auf ein ähnliches Fazilitationsniveau wie das von AWS absinkt. Andererseits kann man auch vermuten, dass für AWNS die ent- 
zerrten Sprechaufgaben eine größere Herausforderung darstellen und deshalb die Fazilitation auf ein niedrigeres Niveau herabsinkt. Diese Spekulationen müssen allerdings erst in weiteren Studien belegt werden. Ob das Defizit im sprechspezifischen System tatsächlich mit Kapazitäten des Arbeitsgedächtnisses zu vergleichen ist, ist ebenfalls noch zu untersuchen. Da aktuell noch unklar ist, wo genau der Defekt begründet liegt, haben wir keine passende Bezeichnung dafür.

\subsection{Hypothese 5: Stotternde reagieren langsamer als nichtstotternde Erwachsene} Insgesamt reagierten AWS langsamer als AWNS im ersten und dritten Experiment- jedoch nicht im zweiten Experiment. Die Antwortreaktionen wurden außerdem schneller im Verlauf des ersten und dritten Experiments unabhängig von der Gruppe, allerdings nicht im zweiten Experiment - das lässt vermuten, dass alle Teilnehmer eine Konditionierung für die Trial-Zeit und somit die Reaktionszeit im ersten und dritten Experiment entwickelten. Die Randomisierung der States sollte dies verhindern. AWS reagierten ungefähr 40 ms langsamer als AWNS im ersten Experiment und bei der Verb-Aussprache des dritten Experiments, während beim 2. Experiment und in der Präfix-Aussprache des 3. Experiments keine signifikanten Unterschiede waren. Man könnte argumentieren, dass die Gruppenunterschiede allein ein Artefakt des experimentellen Designs sind - zum Beispiel weil unsere Fazilitationsdaten zentriert waren zum Sprechbeginn und dabei eine Reaktionszeitverzögerung aufgrund eines Stotterereignisses direkt am Anfang die Durchschnittsreaktionszeit bei AWS verzögern könnte. Allerdings waren keine Stotterereignisse während der gesamten Experimente zu registrieren und auch keine im Audiosignal zu erkennen. 
Die unterschiedlichen Reaktionszeiten unterstützen ebenfalls die Theorie einer Sprechbewegungsspezialisierung bei AWNS. Beim spontanen Sprechen zeigen AWS die Reaktionszeitverzögerung, da aufgrund des fehlenden spezifischen Sprechvorbereitungsprogramms eine Überforderung besteht. In der Verb-Aussprache des dritten Experiments herrscht ebenfalls eine Verzögerung bei AWS. Hier kann vermutet werden, dass AWS überfordert sind eine länger anhaltende Fazilitation zu gewährleisten, die über den langen Zeitraum der Prolongation aufrecht erhalten werden kann. Das müsste sich in einer abnehmenden Fazilitation bei AWS kurz vor oder während der Verbaussprache widerspiegeln. Diese konnte in Exp. 3 unter Anwendung der \% SS bewiesen werden. Hier zeigten sich mit zunehmender Stotterschwere nach der Präfixaussprache kleinere MEP-Amplituden. AWNS und leicht stotternde Erwachsene hingegen zeigten zu dem Zeitpunkt größere MEP-Fazilitationen um die Verbaussprache adäquat vorzubereiten (s.o.). Wir gehen davon aus, dass die verlängerte Vorbereitungszeit in Exp. 2 und 3 die Überforderung der AWS generell reduzieren, wohingegen die Spontansprache und die Aufrechterhaltung der Prolongation über einen langen Zeitraum mit anschließender Verbaussprache in Exp. 3 eine kognitive Überforderung darstellen. Im Vergleich dazu herrscht im zweiten Experiment eine gleichgroße kognitive Anstrengung für beide Gruppen, genauso wie in der Präfixkomponente des dritten Experiments. Deshalb sind hier, nach unserer Ansicht, keine Unterschiede in der Reaktionszeit zu erkennen.

\subsection{Hypothese 6: Korrelation der Stotterhäufigkeit mit der MEP-Amplitude}

Zusammenfassend kann man sagen, dass die prozentualen Stotterunregelmäßigkeiten die MEP-Fazilitation nicht passender darstellen können als unsere herkömmliche Einteilung in 
die beiden Gruppen. Für Exp. 1 ergaben sich keine Unterschiede in den Analysen. In Exp. 2 ergaben sich unterschiedliche Ergebnisse, wobei die Ergebnisse der binären Methode die exakteren Ergebnisse lieferten. Das dritte Experiment hingegen lieferte mit der \% SS bessere Ergebnisse als unsere herkömmliche Gruppeneinteilung. Der streng negative Effekt zeigte, dass die MEP-Fazilitation bei schwer stotternden Erwachsenen nach dem Präfix rückläufig ist, bevor die Verbaussprache startet. AWNS hingegen zeigten ein stetig hohes Niveau der MEPs. Die rückläufige Fazilitation kurz vor der Verbaussprache deckt sich mit dem Ergebnis der verzögerten Reaktionszeit bei AWS vor der Verbaussprache. Man kann hier spekulieren, dass es wie beim Bereitschaftspotenzial und den kontingenten negativen Variationen, eine Früh- und Spätphase der MEP-Erregung gibt. Vermutlich existieren eine MEP-Frühphase die bei AWS früher beginnt und früher endet, und eine Spätphase, die ebenfalls früher einsetzt und früher endet im Vergleich zu AWNS. Es könnte also sein, dass die rückläufige MEP-Fazilitation das verfrühte Ende der Spätphase bei AWS darstellt. Da die Frühphase früher beginnt, benötigen AWS insgesamt eine ausgedehntere Vorbereitungszeit zum Sprechen und profitieren deshalb von der Entzerrung des Sprechens. Das begünstigt einerseits unsere Beobachtung bei Prüfung der zweiten Hypothese, dass AWS einen weniger hohen Anstieg der MEP-Fazilitation in der Sprechvorbereitung zeigen. Zudem begünstigt dies unsere Beobachtung bei Prüfung von Hypothese 4, dass der Gruppenunterschied hinsichtlich der MEP-Verhältnisse am größten ist, wenn die kognitive Anstrengung am höchsten ist. Schließlich profitieren hier AWS von der entzerrten dritten Sprechaufgabe und dabei lässt sich die mutmaßliche Ursache, dass die MEP-Fazilitation bei schwer stotternden Erwachsenen vorzeitig absinkt, erkennen. Möglicherweise findet bei AWS auch 
eine rechtshemisphärische Kompensation analog zum CNV, die wir in unserer Studie jedoch nicht untersucht haben.

Hätte man die Analyse lediglich mit der binären Einteilung durchgeführt, so wäre die verminderte Fazilitation bei schwer stotternden Erwachsenen vor der Verbaussprache nicht aufgefallen. Zusammenfassend empfehlen wir trotzdem nicht, die \% SS anstatt der binären Einteilung zu benutzen, denn die herkömmliche Gruppeneinteilung scheint aufgrund der gröberen Einteilungsart Fehler verzeihender zu sein und somit die Tendenzen für unsere Studie besser darstellen zu können.

\section{Kritik und Limitationen}

Die Ergebnisinterpretation unserer Studie ist insgesamt kritisch zu betrachten, da weiterhin unklar bleibt, ob die Messung der Hirnaktivität über die MEPs tatsächlich Hinweise auf die Art der Sprechvorbereitung gibt. Klar ist lediglich, dass die kortikale motorische Erregbarkeit die mikrostrukturellen Eigenschaften der weißen Substanz des Gehirns widerspiegelt (Klöppel 2008). Weiterhin ist unklar, ob die Forschungsmethode der Gruppenvergleiche, wie sie bei fast allen Studien vorzufinden ist, nicht häufig nur Stichprobeneffekte darstellt. Hinsichtlich der vierten Hypothese (Gruppenunterschied zeigt eine Effektverstärkung, je größer die kognitive Anstrengung ist) fällt auf, dass der Gruppenunterschied hinsichtlich der MEP-Größe beim spontanen Sprechen doppelt so groß ist verglichen mit den anderen beiden Sprechaufgaben. Das Ergebnis impliziert bei ähnlich niedriger Fazilitation in Exp. 2 und 3, das sich die beiden Experimente vom kognitiven Anspruch nicht unterscheiden. Würde man Exp. 2 und 3 zusammenfassend als gering kognitiv anspruchsvoll bezeichnen 
und Exp. 1 als kognitiv anspruchsvoll, dann würde die Hypothese 4 zutreffen. Es ist außerdem zu beachten, dass bei der statistischen Untersuchung von Hypothese 4 die Anzahl der Freiheitsgrade (in der Tabelle $\mathrm{df}=$ degrees of freedom) hier die Anzahl der Gesamttrials aus den vergleichenden Experimenten darstellt und somit sehr hoch ist (die intra- und interindividuelle Variabilität wird vermischt). Jedoch war es aufgrund des Studiendesigns die einzige Möglichkeit mit den randomisierten individuellen States, die nicht perfekt ausbalanciert waren und dadurch teilweise nur wenigen Daten pro State lieferten, auszukommen. Beim Untersuchen von Hypothese 5 war ein signifikanter Wert unerwartet - die Korrelation zwischen State und Trial im ersten Experiment. Dies impliziert, dass in den späteren Trials im Durchschnitt mehr späte States auftraten. Aufgrund der zufälligen Reihenfolge der States und der signifikanten Korrelationen zwischen der Reaktionszeit und State sowie Trial waren wir jedoch der Ansicht, dass dies die Studie nicht nachteilig beeinflusst. Hinsichtlich Hypothese 6 können wir die unterschiedlichen Ergebnisse zwischen der Gruppeneinteilung und den \% SS nicht hinreichend erklären. Wir können nur mutmaßen, dass es entweder an der kleinen Teilnehmerzahl liegt, dass wir keine generellen signifikanten Tendenzen bei der Analyse ableiten können, oder dass es eine andere unbekannte Ursache gibt. Ein Erklärungsansatz für die unterschiedlichen Ergebnisse beim Testen der Hypothese 6 könnte auf unsere Analysemethode der Stotterschwere zurückzuführen sein. Die \% SS und die draus resultierende grobe Schweregradeinteilungen des Stotterns wurden erhoben, indem das Spontansprechen sowie eine Leseprobe der Teilnehmer analysiert wurden. Das Spontansprechen findet sich in unserem ersten Experiment wieder und die Leseprobe ist vergleichbar mit dem dritten Experiment. Schließlich ist beim Lesen durch den vorgegebenen Text 
eine äußere Taktung vorhanden, und der Lesende kann aufgrund der Zeitspanne den Beginn des nächsten Worts, wie in Exp. 3, besser antizipieren. Das zweite Experiment bietet sowohl für AWS als auch für AWNS eine ungewohnte Sprechsituation. Außerdem könnte der Teilnehmer hier das Gefühl vermittelt bekommen, es ginge lediglich um die schnelle Reaktion (was nicht der Fall war). Aufgrund der langen Zeitspanne zwischen dem Verb und dem Ausrufezeichen könnte es schwierig sein, den Wortbeginn zu antizipieren und somit die Vorbereitung ideal zu gestalten. Somit kann für den Teilnehmer das subjektive Gefühl entstehen, die Sprechaufforderung komme jedes Mal unerwartet und plötzlich. Im zweiten Experiment zeigten gering-stotternde Erwachsene unerwartet niedrige MEPs, ähnlich den schwer-stotternden Erwachsenen, sodass kein linearer Effekt sichtbar war. Das spricht rückblickend nicht für einen stetig kognitiven Abfall von Exp. 1 zu 3, sondern für eine kognitiv völlig unabhängige Situation zu den anderen beiden Experimenten, zum Beispiel, dass Exp. 2 lediglich die Reaktionsschnelligkeit herausfordert. Betrachtet man Exp. 1 und 3, unabhängig von Exp. 2, so ist die Tendenz klar zu sehen: Die Stotterschwere korreliert negativ mit der MEP-Amplitude vor dem Sprechbeginn und unter Berücksichtigung der \% SS ergeben sich deutlichere Korrelationen.

Insgesamt müssen die Ergebnisse hinsichtlich der Gütekriterien kritisch betrachtet werden. Wir bestimmten zur Beurteilung der besten Analysemethode das korrigierte $\mathrm{R}^{2}$ der HMRA und nichtlinearen Regression. Prinzipiell passt das angewandte Modell umso besser auf die Daten, je höher das angepasste $R^{2}$ ist. Ergibt das angepasste $R^{2}=1$, dann passt das Modell perfekt. Unsere Zahlen befinden sich bei der linearen Regression im Tausendstel-Bereich 
und bei der nichtlinearen (curved) Regression im Hundertstel-Bereich. Die nichtlineare Regression ist das beste von uns angewandte Verfahren, jedoch nicht perfekt für diese Art der Datenverteilung. Die Alternative dazu wäre, kein Modell anzuwenden, hierbei würde $\mathrm{R}^{2}=0$ entsprechen.

\section{Zusammenfassung}

In Zusammenschau aller Befunde zeigen unsere Daten, dass AWS und AWNS bei klaren funktionellen Absichten unterschiedlich mit externen Störfaktoren in der Sprechplanung umgehen. Unsere Ergebnisse suggerieren die Existenz eines spezifischen Sprechvorbereitungsprogramms bei AWNS, welches bei AWS fehlerhaft oder nicht in dieser Form vorhanden ist. Die Theorie eines spezifischen Sprechvorbereitungsprogramms wird unterstützt durch die reduzierte Fazilitation bei AWS in allen Sprechbedingungen sowie die reduzierte Fazilitation in Abhängigkeit von der Vorbereitungszeit. Außerdem spricht die rückläufige Fazilitation bei schwerem Stottern und länger anhaltendem Sprechen für eine zu früh endende Sprechvorbereitung bei AWS. Bei ausreichender Vorbereitungszeit scheinen AWS das insuffiziente oder nicht vorhandene spezifische Sprechvorbereitungsprogramm kompensieren zu können. Die verzögerten Reaktionszeiten beim spontanen Sprechen und nach stattgefundener Prolongation bei AWS, könnten durch den größeren Zeitaufwand zur Kompensation zustande kommen. Insgesamt unterstützen die fehlende Modulation der MEPGrößen bei AWS und die ungleichen Reaktionszeiten beider Gruppen bei sprechspezifischen kognitiven Herausforderungen die Theorie eines spezifischen Sprechvorbereitungs- 
programms. Unsere Daten erlauben ebenfalls, einen Zusammenhang zwischen der Stotterschwere und der motorischen Fazilitation zu interpretieren, wie dies in der vorangegangen Studie von Neef (Neef et al. 2015a) der Fall war. Im 1. und 3. Experiment bestätigte sich eine negative Korrelation zwischen der Stotterschwere und der MEP-Fazilitation, im zweiten Experiment jedoch nicht. Wir vermuten, dass Teilnehmer mit milder Stottersymptomatik eine schwache Sprechspezialisierung besitzen, welche bei geringer und mittelgroßer kognitiver Anforderung einfach unsere Beeinflussung überwältigen kann und somit fast normal große MEPs zeigt. Bei stark stotternden Erwachsenen vermuten wir einen größeren Defekt, sodass die spezifische Sprechspezialisierung komplett fehlt. Das könnte unser Ergebnis der rückläufigen Fazilitation bei schwer stotternden Erwachsenen während länger andauernder Sprechaufgaben erklären. Unsere Ergebnisse unterstützen außerdem den grundlegenden Mechanismus der Wirksamkeit der Stottertherapie Fluency Shaping, indem sie den positiven Einfluss der externen Taktung präsentieren. Denn mit der Reduktion der überladenen Anforderung an die spezifische Sprechvorbereitung und der Ausdehnung der Vorbereitungszeit wird in der Therapie des Fluency Shaping gearbeitet.

Neben der ausgedehnten Sprechvorbereitungszeit könnte ein Ansatz für zukünftige Forschungsmodelle in der transkraniellen Wechselstromstimulation (tACS) liegen, die neuroplastische Veränderungen nach transkranieller kortikaler Stimulation hervorrufen kann (Antal und Paulus 2013), um in unserem Falle die Sprechvorbereitungsfazilitation nach oben zu regulieren. Diese könnte dann wiederum zur besseren Vorbereitung in der Spontansprache führen und Ansatzmöglichkeiten für eine neue Therapie darstellen, so wie es bei Stimulationsstudien mit der Parkinsonerkrankung der Fall war (Boggio et al. 2006). Ein 
Forschungsansatz wurde bereits in der Kombination von transkranieller linkshemisphärischer Stimulation bei gleichzeitiger Fluency-shaping-Therapie angewandt, wie 2018 von Chesters und Kollegen veröffentlicht. Hier wird das Flüssigsprechen von AWS signifikant verbessert, indem die transkranielle Stimulation als Therapie parallel zur Fluency-shapingTherapie angewandt wird. Insbesondere bei Therapieversagern nach alleiniger Fluencyshaping-Therapie wird die transkranielle Stimulation als potenzieller Hoffnungsträger angesehen (Chesters et al. 2018). Hier könnte man davon ausgehen, dass die transkranielle Stimulation den zum flüssig Sprechen nötigen Impuls für neuroplastische Veränderungen abgibt und damit das spezifische Sprechvorbereitungsprogramm bei AWS reaktiviert oder zumindest kompensiert.

Zusammenfassend können wir mit unseren Ergebnissen grundlegende Unterschiede zwischen stotternden und nichtstotternden Erwachsenen mit Hilfe transkranieller Stimulation des Zungenareals in der Sprechvorbereitung darstellen. Mit dieser Erkenntnis können erfolgversprechende Anwendungen für die Wirksamkeit der Therapie des Fluency Shaping für stotternde Erwachsene abgeleitet werden.

\section{Literaturverzeichnis}

Andrews G, Craig A, Feyer AM, Hoddinott S, Howie P, Neilson M (1983): Stuttering: a review of research findings and theories circa 1982. J Speech Hear Disord 48, 226-246

Antal A, Paulus W (2013): Transcranial alternating current stimulation (tACS). Front Hum Neurosci 7, 1-3

Aumüller G, Doll A: Mundhöhle und Kauapparat. In: Aumüller G, Doll A, Engele J, Kirsch J, Mense S, Wurzinger LJ (Hrsg.): Anatomie. Thieme, Stuttgart 2006, 1009-1018. 
Bajaj A (2007): Working memory involvement in stuttering: exploring the evidence and research implications. J Fluen Disord 32, 218-238

Belyk M, Kraft SJ, Brown S (2015): Stuttering as a trait or state - an ALE meta-analysis of neuroimaging studies. Eur J Neurosci. 41(2):275-84

Boggio PS, Ferrucci R, Rigonatti SP, Covre P, Nitsche M, Pascual-Leone A, Fregni F (2006): Effects of transcranial direct current stimulation on working memory in patients with Parkinson's disease. J Neurol Sci 249, 31-38

Bohland JW, Bullock D, Guenther FH (2010): Neural representations and mechanisms for the performance of simple speech sequences. J Cogn Neurosci. 22(7): 1504-1529

Bosshardt H-G (2006): Cognitive processing load as a determinant of stuttering: Summary of a research programme. Clin Linguist Phon 20, 371-385

Brodmann K: Vergleichende Lokalisationslehre der Großhirnrinde in ihren Prinzipien dargestellt auf Grund des Zellenbaues. Johann Ambrosius Barth, Leipzig 1909

Brown S, Ingham RJ, Ingham JC, Laird AR, Fox PT (2005): Stuttered and fluent speech production: An ALE meta-analysis of functional neuroimaging studies. Hum Brain Mapp $25,105-117$

Brownsett SL, Warren JE, Geranmayeh F, Woodhead Z, Leech R, Wise RJ (2014): Cognitive AWNS and its impact on recovery from aphasic stroke. Brain: 137(1): 242-254

Büchel C, Sommer M (2004): What Causes Stuttering? PLoS Biol 2, e46

Budde KS, Barron DS, Fox PT (2014): Stuttering, Induced Fluency, and Natural Fluency: A Hierarchical Series of Activation Likelihood Estimation Meta-Analyses. Brain Lang. 139: 99-107.

Busan P, D’Ausilio A, Borelli M, Monti F, Pelamatti G, Pizzolato G, Fadiga L (2013): Motor excitability evaluation in developmental stuttering: a transcranial magnetic stimulation study. Cortex J Devoted Study Nerv Syst Behav 49, 781-792

Busan P, Battaglini PP, Sommer M (2017): Transcranial magnetic stimulation in developmental stuttering: Relations with previous neurophysiological research and future perspectives. Clin Neurophysiol. 128(6):952-964

Busan P, Del Ben G, Russo LR, Bernardini S, Natarelli G, Arcara G, Manganotti P, Battaglini PP (2019): Stuttering as a matter of delay in neural activation: A combined TMS/EEG study. Clin Neurophysiol. 130(1):61-76 
Capa RL, Bouquet CA, Dreher J-C, Dufour A (2013): Long-lasting effects of performancecontingent unconscious and conscious reward incentives during cued task-switching. Cortex. 49(7):1943-54

Caruso A, Chodzko-Zajko W, Bidinger D, Sommers R (1994): Adults who stutter: responses to cognitive stress. J Speech Hear Res 4, 746-54.

Catani M, Jones DK, Ffytche DH (2005): Perisylvian language networks of the human brain. Ann Neurol 57, 8-16

Chang S-E, Erickson KI, Ambrose NG, Hasegawa-Johnson MA, Ludlow CL (2008): Brain Anatomy Differences in Childhood Stuttering. Neurolmage 39, 1333-1344

Chen KS, Chen R (2019): Invasive and Noninvasive Brain Stimulation in Parkinson's Disease: Clinical Effects and Future Perspectives. Clin Pharmacol Ther. 106(4):763-775

Chesters J, Möttönen R, Watkins KE (2018): Transcranial direct current stimulation over left inferior frontal cortex improves speech fluency in adults who stutter. Brain J Neurol $141,1161-1171$

Civier O, Kronfeld-Duenias V, Amir O, Ezrati-Vinacour R, Ben-Shachar M (2015): Reduced fractional anisotropy in the anterior corpus callosum is associated with reduced speech fluency in persistent developmental stuttering. Brain Lang. 143:20-31

Colebatch JG (2007): Bereitschaftspotential and movement-related potentials: origin, significance, and application in disorders of human movement. Mov Disord 22, 601610

Connally EL, Ward D, Howell P, Watkins KE (2014): Disrupted white matter in language and motor tracts in developmental stuttering. Brain Lang. 131:25-35

Conforto AB, Z'Graggen WJ, Kohl AS, Rösler KM, Kaelin-Lang A (2004): Impact of coil position and electrophysiological monitoring on determination of motor thresholds to transcranial magnetic stimulation. Clin Neurophysiol Off J Int Fed Clin Neurophysiol $115,812-819$

Craig A, Tran Y (2014). Trait and social anxiety in adults with chronic stuttering: conclusions following meta-analysis. J Fluency Disord. 40:35-43

Doneva S, Davis S, Cavenagh P (2018): Comparing the performance of people who stutter and people who do not stutter on the Test of Everyday Attention. J Clin Exp Neuropsychol. 40(6):544-558

Drews U: Taschenatlas der Embryologie. 2., unveränd. Auflage; Thieme, Stuttgart 2006 
Fagnani C, Fibiger S, Skytthe A, Hjelmborg JV (2011): Heritability and environmental effects for self-reported periods with stuttering: a twin study from Denmark. Logoped Phoniatr Vocol Oct; 36(3):114-20

Fedyna A, Drayna D, Kang C (2011): Characterization of a mutation commonly associated with persistent stuttering: evidence for a founder mutation. J Hum Genet 56, 8082

Fox PT, Ingham RJ, Ingham JC, Hirsch TB, Downs JH, Martin C, Jerabek P, Glass T, Lancaster JL (1996): A PET study of the neural systems of stuttering. Nature 382, 158-162

Frigerio-Domingues C, Drayna D (2017): Genetic contributions to stuttering: the current evidence. Mol Genet Genomic Med 5, 95-102

Giraud AL, Neumann K, Bachoud-Levi AC, von Gudenberg AW, Euler HA, Lanfermann H, Preibisch C (2008): Severity of dysfluency correlates with basal ganglia activity in persistent developmental stuttering. Brain Lang 104(2):190-9

Gómez CM, Marco J, Grau C (2003): Preparatory visuo-motor cortical network of the contingent negative variation estimated by current density. Neurolmage. 20(1):216-24

Grados M, Huselid R, Duque-Serrano L (2018): Transcranial Magnetic Stimulation in Tourette syndrome: A Historical Perspective, Its Current Use and the Influence of Comorbidities in Treatment Response. Brain Sci. 8(7): 129

Guenther FH, Ghosh SS, Tourville JA (2006): Neural Modeling and Imaging of the Cortical Interactions Underlying Syllable Production. Brain Lang 96 (3): 280-301 96(3): 280301

Guntupalli VK, Kalinowski J, Saltuklaroglu T (2006): The need for self-report data in the assessment of stuttering therapy efficacy: repetitions and prolongations of speech. The stuttering syndrome. Int J Lang Commun Disord. 41(1):1-18

Hess CW, Mills KR, Murray NM (1987): Responses in small hand muscles from magnetic stimulation of the human brain. J Physiol 388, 397-419

Hess CW: Hirnstimulation - Historischer Überblick. In: Siebner HR, Ziemann U (Hrsg.): Das TMS-Buch: Handbuch der transkraniellen Magnetstimulation. Springer Medizin Verlag, Heidelberg 2007, 4 - 14

Iverach L, Rapee RM (2014). Social anxiety disorder and stuttering: Current status and future directions. J Fluency Disord. 40:69-82

Kaelin-Lang A, Cohen LG (2000): Enhancing the quality of studies using transcranial magnetic and electrical stimulation with a new computer-AWNSled system. J Neurosci Methods 102, 81-89 
Kaelin-Lang A: Motorisch evozierte Potenziale - Eine Einführung. In: Siebner HR, Ziemann U (Hrsg.): Das TMS-Buch: Handbuch der transkraniellen Magnetstimulation. Springer Medizin Verlag, Heidelberg 2007, 59 - 68

Kell CA, Neumann K, von Kriegstein K, Posenenske C, von Gudenberg AW, Euler H, Giraud $A-L$ (2009): How the brain repairs stuttering. Brain J Neurol 132, 2747-2760

Kell CA, Neumann K, Behrens M, von Gudenberg AW, Giraud A-L (2018): Speaking-related changes in cortical functional connectivity associated with assisted and spontaneous recovery from developmental stuttering. J Fluen Disord 55, 135-144

Kikuchi Y, Ogata K, Umesaki T, Yoshiura T, Kenjo M, Hirano Y, Okamoto T, Komune S, Tobimatsu $S$ (2011): Spatiotemporal signatures of an abnormal auditory system in stuttering. Neuroimage. 1;55(3):891-9

Klöppel S, Bäumer T, Kroeger J, Koch MA, Büchel C, Münchau A, Siebner HR (2008): The cortical motor threshold reflects microstructural properties of cerebral white matter. Neuroimage. 40(4):1782-91

Kornhuber HH, Deecke L (1965): Hirnpotentialänderungen bei Willkürbewegungen und passiven Bewegungen des Menschen: Bereitschaftspotential und reafferente Potentiale. Pflügers Archiv - European Journal of Physiology. 284, 1-17

Kraft SJ, Yairi E (2012): Genetic bases of stuttering: the state of the art. Folia Phoniatr Logop. 2012; 64(1):34-47

Maassen B, Kent R, Peters H, van Lieshout P, Hulstijn W: Speech motor control in normal and disordered speech. 1 ed. Oxford: University of Oxford Press; 2004

Manenti R, Brambilla M, Benussi A, Rosini S, Cobelli C, Ferrari C, Petesi M, Orizio I, Padovani A, Borroni B (2016): Mild cognitive impairment in Parkinson's disease is improved by transcranial direct current stimulation combined with physical therapy. Mov Disord. 31(5):715-24

Maxfield ND, Morris K, Frisch SA, Morphew K, Constantine JL (2015): Real-time processing in picture naming in adults who stutter: ERP evidence. Clinical Neurophysiology. 126(2):284-96

McAllister J, Collier J, Shepstone L (2012): The impact of adolescent stuttering on educational and employment outcomes: Evidence from a birth cohort study. Journal of Fluency Disorders 37, 106-121

Miyamoto JJ, Honda M, Saito DN, Okada T, Ono T, Ohyama K, Sadato N (2006): The representation of the human oral area in the somatosensory cortex: a functional MRI study. Cereb Cortex N Y N 1991 16, 669-675 
Müller F, Ziemann U: Bestimmung der zentralmotorischen Leitungszeit. In: Siebner HR, Ziemann U (Hrsg.): Das TMS-Buch: Handbuch der transkraniellen Magnetstimulation. Springer Medizin Verlag, Heidelberg 2007, 71 - 77

Nakamura A, Yamada T, Goto A, Kato T, Ito K, Abe Y, Kachi T, Kakigi R (1998): Somatosensory homunculus as drawn by MEG. Neurolmage 7, 377-386

Natke U, Alpermann A: Stottern: Erkenntnisse, Theorien, Behandlungsmethoden. 3. vollständig überarbeitete und ergänzte Auflage, Verlag Hans Huber, Hogrefe, Bern, 2010

Neef NE, Paulus W, Neef A, von Gudenberg AW, Sommer M (2011): Reduced intracortical inhibition and facilitation in the primary motor tongue representation of adults who stutter. Clin Neurophysiol. 122(9):1802-11

Neef NE, Hoang TNL, Neef A, Paulus W, Sommer M (2015a): Speech dynamics are coded in the left motor cortex in fluent speakers but not in adults who stutter. Brain 138, $712-725$

Neef NE, Anwander A, Friederici AD (2015b): The Neurobiological Grounding of Persistent Stuttering: from Structure to Function. Curr Neurol Neurosci Rep 15, 63

Neumann K, Euler HA, von Gudenberg AW, Giraud A-L, Lanfermann H, Gall V, Preibisch C (2003): The nature and treatment of stuttering as revealed by fMRI A within- and between-group comparison. J Fluen Disord 28, 381-409; quiz 409-410

Neumann K, Preibisch C, Euler HA, von Gudenberg AW, Lanfermann H, Gall V, Giraud AL (2005): Cortical plasticity associated with stuttering therapy. J Fluency Disord 30(1):23-39

Neumann K, Euler HA, Bosshardt HG, Cook S, Sandrieser P, Schneider P, Sommer M, Thum G: Pathogenese, Diagnostik und Behandlung von Redeflussstörungen. Evidenz- und konsensbasierte S3-Leitlinie, AWMF-Registernummer 049-013, Version 1. 2016; http://www.awmf.org/leitlinien/detail/II/049-013.html; Zugriff am 17.06.2018

Ning N, Peng D, Liu X, Yang S (2017): Speech Timing Deficit of Stuttering: Evidence from Contingent Negative Variations. PLoS ONE 12, 1-17

Nippold MA (2012) Stuttering and language ability in children: questioning the connection. Am J Speech Lang Pathol. 21(3):183-96

Oldfield RC (1971): The assessment and analysis of handedness: The Edinburgh inventory. Neuropsychologia 9, 97-113 
Oxford Centre for Evidence-based Medicine - Levels of Evidence: https://www.cebm.net/2016/05/ocebm-levels-of-evidence/; Zugriff am 24.10.2019

Paulus W, Siebner HR: Sicherheitsaspekte und Anwendungsrichtlinien. In: Siebner HR, Ziemann U (Hrsg.): Das TMS-Buch: Handbuch der transkraniellen Magnetstimulation. Springer Medizin Verlag, Heidelberg 2007, 47 - 54

Poeck K, Hacke W: Neurologie. 12. Auflage; Springer-Verlag, Berlin Heidelberg 2006

Rautakoski P, Hannus T, Simberg S, Sandnabba NK., Santtila P (2012): Genetic and environmental effects on stuttering: a twin study from Finland. J Fluency Disord. 37(3):20210

Reich A, Till J, Goldsmith H (1981): Laryngeal and manual reaction times of stuttering and nonstuttering adults. J Speech Hear Res. 24(2):192-6

Riley GD (1994): The Stuttering Severity Instrument for Children and Adults- Third Edition (SSI-3). Austin, TX: Pro-Ed.; 1994.

Rossi S, Hallett M, Rossini PM, Pascual-Leone A (2009): Safety, ethical considerations, and application guidelines for the use of transcranial magnetic stimulation in clinical practice and research. Clin Neurophysiol 120, 2008-2039

Rossini PM, Burke D, Chen R, Cohen LG, Daskalakis Z, Di lorio R, Di Lazzaro V, Ferreri F, Fitzgerald PB, George MS, et al. (2015): Non-invasive electrical and magnetic stimulation of the brain, spinal cord, roots and peripheral nerves: Basic principles and procedures for routine clinical and research application. An updated report from an I.F.C.N. Committee. Clin Neurophysiol Off J Int Fed Clin Neurophysiol 126, 10711107

Rothwell JC, Hallett M, Berardelli A, Eisen A, Rossini P, Paulus W (1999): Magnetic stimulation: motor evoked potentials. The International Federation of Clinical Neurophysiology. Electroencephalogr Clin Neurophysiol Suppl 52, 97-103

Sakamoto K, Nakata H, Kakigi R (2008): Somatosensory-evoked magnetic fields following stimulation of the tongue in humans. Clin Neurophysiol 119, 1664-1673

Salmelin R, Schnitzler A, Schmitz F, Freund HJ (2000): Single word reading in developmental stutterers and fluent speakers. Brain J Neurol 123 ( Pt 6), 1184-1202

Sandrieser P, Schneider P. Stottern im Kindesalter. 3 ed. Stuttgart: Thieme; 2008

Shibasaki H, Sadato N, Lyshkow H, Yonekura Y, Honda M, Nagamine T, Suwazono S, Magata Y, Ikeda A, Miyazaki M (1993): Both primary motor cortex and supplementary motor 
area play an important role in complex finger movement. Brain J Neurol 116 ( Pt 6), 1387-1398

Siebner HR, Ziemann U: Hirnstimulation - Physiologische Grundlagen. In: Siebner HR, Ziemann U (Hrsg.): Das TMS-Buch: Handbuch der transkraniellen Magnetstimulation. Springer Medizin Verlag, Heidelberg 2007, 27 - 42

Sommer M, Koch MA, Paulus W, Weiller C, Büchel C (2002): Disconnection of speech-relevant brain areas in persistent developmental stuttering. Lancet 360, 380-383

Suresh R, Ambrose N, Roe C, Pluzhnikov A, Wittke-Thompson JK, Ng MC, et al. New complexities in the genetics of stuttering: Significant sex-specific linkage signals. Am J Hum Genet 2006 Apr; 78 (4): 554-63

Svensson P, Romaniello A, Arendt-Nielsen L, Sessle BJ (2003): Plasticity in corticomotor AWNS of the human tongue musculature induced by tongue-task training. Exp Brain Res 152, 42-51

Szaflarski JP, Rajagopal A, Altaye M, Byars AW, Jacola L, Schmithorst VJ, Schapiro MB, Plante E, Holland SK (2012): Left-Handedness and Language Lateralization in Children. Brain Res. 1433C: 85-97.

Trepel M: Neuroanatomie: Struktur und Funktion - mit Zugang zum Elsevier-Portal. 7. Auflage; Urban und Fischer Verlag/Elsevier GmbH, München 2017

Urban PP: Motorisch evozierte Potenziale der kranialen Muskeln. In: Siebner HR, Ziemann U (Hrsg.): Das TMS-Buch: Handbuch der transkraniellen Magnetstimulation. Springer Medizin Verlag, Heidelberg 2007, 100 - 104

Valls-Solé J, Pascual-Leone A, Brasil-Neto JP, Cammarota A, McShane L, Hallett M (1994): Abnormal facilitation of the response to transcranial magnetic stimulation in patients with Parkinson's disease. Neurology 44, 735-741

Van der Salm SM, Tijssen MA, Koelman JH, van Rootselaar A F (2012): The bereitschaftspotential in jerky movement disorders. J Neurol Neurosurg Psychiatry 83, 1162-116

Weyh T, Siebner HR: Hirnstimulation - Technische Grundlagen. In: Siebner HR, Ziemann U (Hrsg.): Das TMS-Buch: Handbuch der transkraniellen Magnetstimulation. Springer Medizin Verlag, Heidelberg 2007, 17 - 25

Whillier A, Hommel S, Neef NE, Wolff von Gudenberg A, Paulus W, Sommer M (2018): Adults who stutter lack the specialised pre-speech facilitation found in non-stutterers. PLoS One. 10;13(10)

Yairi E, Ambrose N (2013): Epidemiology of Stuttering: 21st Century Advances. J Fluen Disord $38,66-87$ 


\section{Anhang}

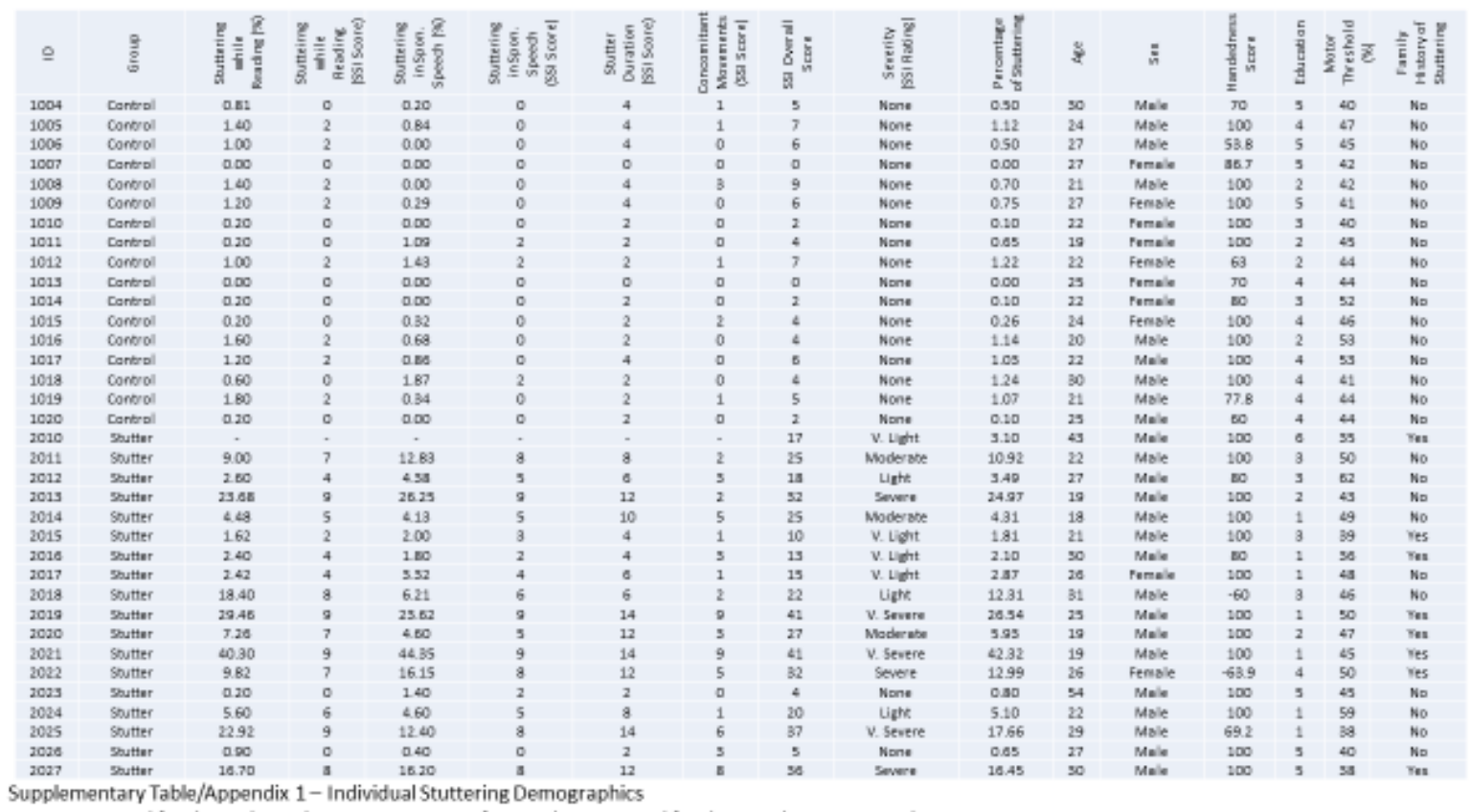

Group was used for the main analyses. Percentage of stuttering was used for the supplementary analyses.

Tabelle 4: Teilnehmerdaten

\begin{tabular}{|c|c|c|c|c|c|c|c|c|c|}
\hline \multirow[b]{2}{*}{ Model } & \multirow[b]{2}{*}{$\mathrm{R}$} & \multirow[b]{2}{*}{$\begin{array}{c}\mathrm{R} \\
\text { Square }\end{array}$} & \multirow[b]{2}{*}{$\begin{array}{c}\text { Adjusted } \\
\text { R } \\
\text { Square }\end{array}$} & \multirow[b]{2}{*}{$\begin{array}{l}\text { Std. Error of } \\
\text { the Estimate }\end{array}$} & \multicolumn{5}{|c|}{ Change Statistics } \\
\hline & & & & & $\begin{array}{c}\text { R } \\
\text { Square } \\
\text { Change }\end{array}$ & $\begin{array}{c}\mathrm{F} \\
\text { Change }\end{array}$ & df1 & $\mathrm{df} 2$ & $\begin{array}{c}\text { Sig. F } \\
\text { Change }\end{array}$ \\
\hline 1 & $.241^{a}$ & .058 & .058 & 1.257922645 & .058 & 240.381 & 1 & 3914 & .000 \\
\hline 2 & $.271^{\mathrm{b}}$ & .073 & .072 & 1.248047942 & .015 & 21.727 & 3 & 3911 & .000 \\
\hline 3 & $.285^{\mathrm{c}}$ & .081 & .080 & 1.243074118 & .008 & 16.680 & 2 & 3909 & .000 \\
\hline
\end{tabular}

Tabelle 5: zugehörig zu Experiment 1. $R^{2}$ Berechnung für Regressionsanalyse 


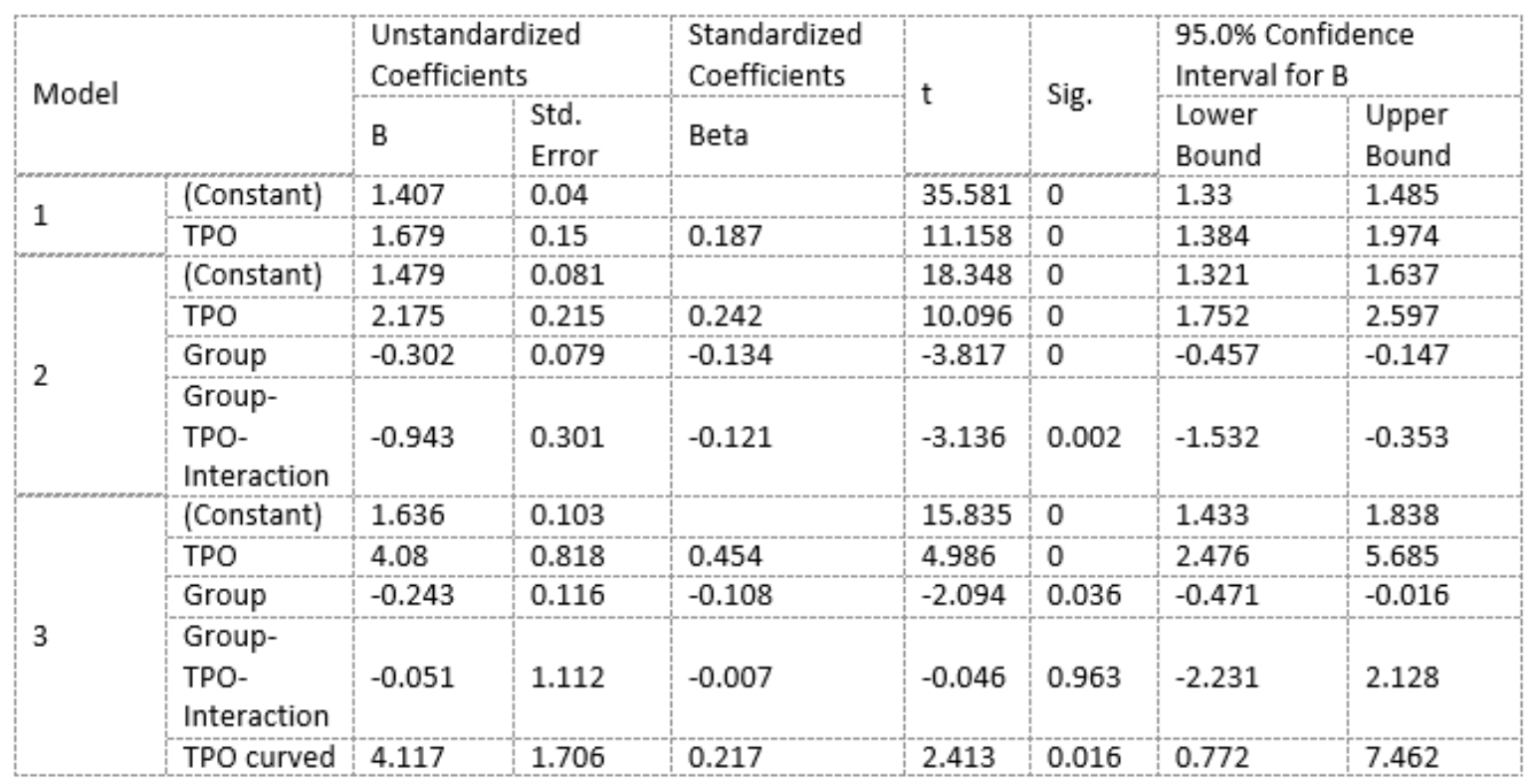

Tabelle 6: Experiment 2. Übersicht aller drei Analysen mit Gruppeneinteilung

Übersicht aller Analysen Exp. 2 mit Gruppeneinteilung. Model 1) lineare Einfachregression 2) multiple Regressionsanalyse 3) nichtlineare Regression für Experiment 2. B = nicht standardisierte Koeffizienten. TPO = Intervall, bevor das Präfix gesprochen wird. Gruppe war binär ( $0=A W N S, 1=A W S)$. Die Konstante der Regression wurde geprüft gegen die NullHypothese von $B=1$ statt der AlternativHypothese $B=0$.

\begin{tabular}{|c|c|c|c|c|c|c|c|c|c|}
\hline \multirow[b]{2}{*}{ Model } & \multirow[b]{2}{*}{$\mathrm{R}$} & \multirow[b]{2}{*}{$\begin{array}{c}\mathrm{R} \\
\text { Square }\end{array}$} & \multirow[b]{2}{*}{$\begin{array}{c}\text { Adjusted } \\
\text { R } \\
\text { Square }\end{array}$} & \multirow[b]{2}{*}{$\begin{array}{l}\text { Std. Error of } \\
\text { the Estimate }\end{array}$} & \multicolumn{5}{|c|}{ Change Statistics } \\
\hline & & & & & $\begin{array}{c}\text { R } \\
\text { Square } \\
\text { Change }\end{array}$ & $\begin{array}{c}\mathrm{F} \\
\text { Change }\end{array}$ & df1 & $\mathrm{df} 2$ & $\begin{array}{c}\text { Sig. F } \\
\text { Change }\end{array}$ \\
\hline 1 & $.187^{a}$ & .035 & .035 & 1.110295823 & .035 & 124.506 & 1 & 3441 & .000 \\
\hline 2 & $.199^{b}$ & .040 & .039 & 1.108020786 & .005 & 5.715 & 3 & 3438 & .001 \\
\hline 3 & $.213^{\mathrm{c}}$ & .045 & .044 & 1.105002159 & .006 & 10.405 & 2 & 3436 & .000 \\
\hline
\end{tabular}

Tabelle 7: zugehörig zu Experiment 2. $R^{2}$ Berechnung für Regressionsanalyse 


\begin{tabular}{|c|c|c|c|c|c|c|c|c|}
\hline & & \multicolumn{2}{|c|}{$\begin{array}{l}\text { Unstandardized } \\
\text { Coefficients }\end{array}$} & \multirow{2}{*}{$\begin{array}{l}\text { Standardized } \\
\text { Coefficients } \\
\text { Beta }\end{array}$} & \multirow[b]{2}{*}{$\mathrm{t}$} & \multirow[b]{2}{*}{ Sig. } & \multicolumn{2}{|c|}{$\begin{array}{l}95.0 \% \text { Confidence } \\
\text { Interval for B }\end{array}$} \\
\hline \multicolumn{2}{|c|}{ Model } & B & $\begin{array}{l}\text { Std. } \\
\text { Error }\end{array}$ & & & & $\begin{array}{l}\text { Lower } \\
\text { Bound }\end{array}$ & $\begin{array}{l}\text { Upper } \\
\text { Bound }\end{array}$ \\
\hline \multirow[t]{2}{*}{1} & (Constant) & 1.537 & 0.049 & & 31.217 & 0.000 & 1.440 & 1.633 \\
\hline & TPO & 0.562 & 0.210 & 0.052 & 2.671 & 0.008 & 0.149 & 0.974 \\
\hline \multirow[t]{4}{*}{2} & (Constant) & 1.573 & 0.106 & & 14.850 & 0.000 & 1.366 & 1.781 \\
\hline & TPO & 0.860 & 0.292 & 0.079 & 2.941 & 0.003 & 0.286 & 1.433 \\
\hline & Group & -0.305 & 0.098 & -0.111 & -3.110 & 0.002 & -0.498 & -0.113 \\
\hline & $\begin{array}{l}\text { Group-TPO- } \\
\text { Interaction }\end{array}$ & -0.526 & 0.420 & -0.049 & -1.252 & 0.211 & -1.351 & 0.298 \\
\hline \multirow[t]{5}{*}{3} & (Constant) & 1.696 & 0.122 & & 13.948 & 0.000 & 1.458 & 1.935 \\
\hline & TPO & 2.730 & 0.955 & 0.251 & 2.859 & 0.004 & 0.858 & 4.602 \\
\hline & Group & -0.352 & 0.126 & -0.128 & -2.784 & 0.005 & -0.599 & -0.104 \\
\hline & $\begin{array}{l}\text { Group-TPO- } \\
\text { Interaction }\end{array}$ & -1.072 & 1.344 & -0.101 & -0.797 & 0.425 & -3.708 & 1.565 \\
\hline & TPO curved & 4.514 & 2.194 & 0.177 & 2.058 & 0.040 & 0.212 & 8.816 \\
\hline
\end{tabular}

Tabelle 8: Experiment 3. Übersicht aller drei Analysen mit Gruppeneinteilung

Model 1) lineare Einfachregression 2) multiple Regressionsanalyse 3) nichtlineare Regression für Experiment 3. $B=$ nicht standardisierte Koeffizienten. TPO = Intervall, bevor das Präfix gesprochen wird. Gruppe war binär $(0=A W N S, 1=A W S)$. Die Konstante der Regression wurde geprüft gegen die Nullhypothese von $B=1$ statt der Alternativhypothese $B=0$.

\begin{tabular}{|c|c|c|c|c|c|c|c|c|c|}
\hline \multirow[b]{2}{*}{ Model } & \multirow[b]{2}{*}{$\mathrm{R}$} & \multirow[b]{2}{*}{$\begin{array}{c}\mathrm{R} \\
\text { Square }\end{array}$} & \multirow[b]{2}{*}{$\begin{array}{c}\text { Adjusted } \\
\text { R } \\
\text { Square }\end{array}$} & \multirow[b]{2}{*}{$\begin{array}{l}\text { Std. Error of } \\
\text { the Estimate }\end{array}$} & \multicolumn{5}{|c|}{ Change Statistics } \\
\hline & & & & & $\begin{array}{c}\text { R } \\
\text { Square } \\
\text { Change }\end{array}$ & $\begin{array}{c}\mathrm{F} \\
\text { Change }\end{array}$ & df1 & df2 & $\begin{array}{c}\text { Sig. F } \\
\text { Change }\end{array}$ \\
\hline 1 & $.052^{\mathrm{a}}$ & .003 & .002 & 1.370628310 & .003 & 7.134 & 1 & 2676 & .008 \\
\hline 2 & $.097^{\mathrm{b}}$ & .009 & .008 & 1.366693719 & .007 & 6.143 & 3 & 2673 & .000 \\
\hline 3 & $.109^{\circ}$ & .012 & .010 & 1.365566882 & .002 & 3.207 & 2 & 2671 & .041 \\
\hline
\end{tabular}

Tabelle 9: zugehörig zu Experiment 3. $R^{2}$ Berechnung für Regressionsanalyse 


\begin{tabular}{|l|l|l|l|l|l|l|l|l|}
\hline & Exp1-Exp2 & \multicolumn{1}{|c}{ SE of Diff } & \multicolumn{1}{l}{ Cl Low } & \multicolumn{2}{c}{ Cl High $t$} & \multicolumn{2}{c|}{$d f$} & Sig. \\
\hline Constant & 0.711 & 0.117 & 0.48184 & 0.94016 & 6.0959 & 7357 & $<0.001$ \\
\hline TPO & 0.98 & 0.306 & 0.37857 & 1.58143 & 3.2014 & 7357 & 0.0014 \\
\hline Group & -0.305 & 0.113 & -0.52699 & -0.08301 & 2.6994 & 7357 & 0.007 \\
\hline Interaction & -0.642 & 0.427 & -1.4818 & 0.1978 & 1.502 & 7357 & 0.1331 \\
\hline
\end{tabular}

Tabelle 10: Datenanalyse der Gruppenunterschiede zwischen Experiment 1 und 2

Datenanalyse zum Vergleich von Exp. 1 und 2. Vergleich zwischen den Experimenten hinsichtlich der Gruppenunterschiede zwischen Experiment 1 und 2. SE = Standarderror (=Standardfehler), $\mathrm{Cl}$ low $=$ Konfidenzintervall Untergrenze, $\mathrm{Cl}$ high $=$ Konfidenzintervall Obergrenze. $D f=$ Anzahl der Gesamttrials aus Experiment 1 und 2. TPO = Intervall, bevor das Präfix gesprochen wird. Gruppe war binär, mit $0=$ AWNS und $1=$ AWS. Die Interaktion repräsentiert die Gruppe* Sprechvorbereitungsintervall bevor das Präfix gesprochen wird Interaktion.

\begin{tabular}{|l|l|l|l|l|l|l|l|}
\hline Constant & 0.617 & 0.133 & 0.35519 & 0.87881 & 4.6301 & 6592 & $<0.001$ \\
TPO/TVO & 2.295 & 0.356 & 1.59612 & 2.99388 & 6.4518 & 6592 & $<0.001$ \\
Group & -0.302 & 0.126 & -0.54995 & -0.05405 & 2.393 & 6592 & 0.0167 \\
Interaction & -1.059 & 0.503 & -2.04746 & -0.07054 & 2.1049 & 6592 & 0.0353 \\
\hline
\end{tabular}

Tabelle 11: Datenanalyse der Gruppenunterschiede zwischen Experiment 1 und 3

Vergleich zwischen den Experimenten hinsichtlich der Gruppenunterschiede zwischen Experiment 1 und 3. TPO/TVO = Intervall, bevor das Präfix/Verb gesprochen wird Gruppe war binär, mit $0=$ AWNS und $1=$ AWS. Die Interaktion repräsentiert die Gruppe*TPO/TVO-Interaktion. 


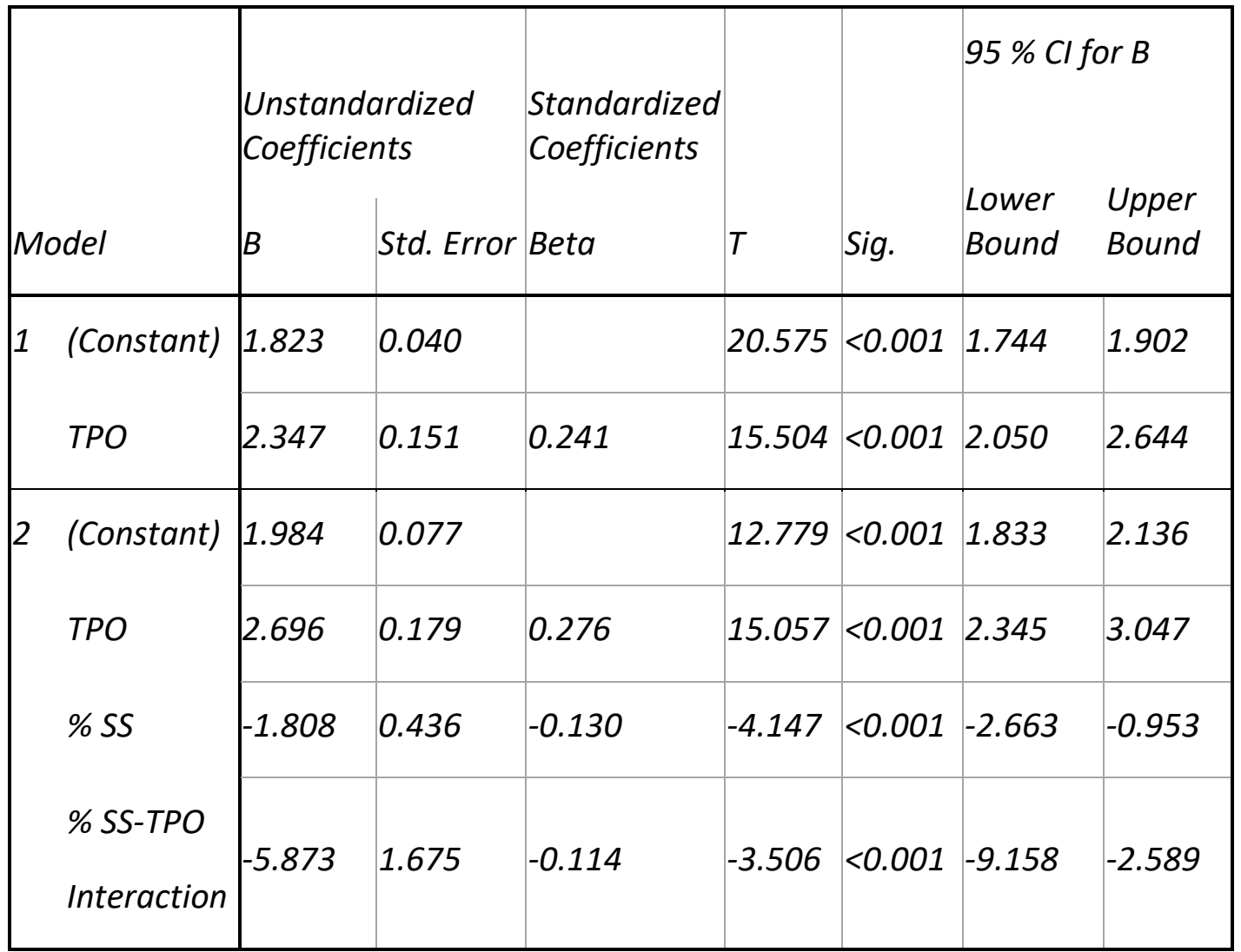

Tabelle 12: lineare Einfachregression und HMRA für Exp. 1 unter Verwendung \% SS

Model 1: lineare Einfachregression. Model 2: HMRA. B = nicht standardisierte Koeffizienten. $T P O=$ Zeitintervall vor Präfixbeginn. \% SS = prozentual gestotterte Silben. \% SS ist eine kontinuierliche Variable inclusive aller vorherigen inkludierten Daten beider Gruppen. Die Konstante der Regression wurde geprüft gegen die Nullhypothese von $B=1$, anstatt der Alternativhypothese $B=0$.

\begin{tabular}{|c|c|c|c|c|c|c|c|c|c|}
\hline Model & $\mathrm{R}$ & $\mathrm{R}^{2}$ & $\begin{array}{c}\text { Adjusted } \\
\mathrm{R}^{2} \\
\end{array}$ & $\begin{array}{l}\text { Std. Error of } \\
\text { the Estimate }\end{array}$ & $\begin{array}{c}\mathrm{R}^{2} \\
\text { Change }\end{array}$ & $\begin{array}{c}\text { Char } \\
\text { F } \\
\text { Change }\end{array}$ & $\begin{array}{l}\text { Ige } S t \\
\text { df1 }\end{array}$ & $\begin{array}{c}\text { atistics } \\
\mathrm{df} 2 \\
\end{array}$ & Sig. F Change \\
\hline 1 & 0.241 & 0.058 & 0.058 & 1.258 & 0.058 & 240.381 & 1 & 3914 & $<0.001$ \\
\hline 2 & 0.249 & 0.062 & 0.061 & 1.256 & 0.004 & 5.966 & 3 & 3911 & $<0.001$ \\
\hline
\end{tabular}

Tabelle 13: zugehörig zu Experiment $1 \%$ SS. $R^{2}$ Berechnung für Regressionsanalyse 


\begin{tabular}{|c|c|c|c|c|c|c|c|}
\hline Model & \multicolumn{2}{|c|}{$\begin{array}{l}\text { Unstandardized } \\
\text { Coefficients }\end{array}$} & $\begin{array}{l}\text { Standardized } \\
\text { Coefficients } \\
\text { Beta }\end{array}$ & $t$ & Sig. & $\begin{array}{l}\text { Lower } \\
\text { Bound }\end{array}$ & $\begin{array}{l}\text { Upper } \\
\text { Bound }\end{array}$ \\
\hline (Constant) & 1.407 & 0.040 & & 10.175 & $<0.001$ & 1.330 & 1.485 \\
\hline TPO & 1.679 & 0.150 & 0.187 & 11.158 & $<0.001$ & 1.384 & 1.974 \\
\hline (Constant) & 1.346 & 0.075 & & 4.613 & $<0.001$ & 1.199 & 1.492 \\
\hline TPO & 1.661 & 0.182 & 0.185 & 9.146 & $<0.001$ & 1.305 & 2.017 \\
\hline$\%$ SS & -0.385 & 0.425 & -0.032 & -0.905 & 0.365 & -1.218 & 0.448 \\
\hline $\begin{array}{l}\text { \% SS-TPO } \\
\text { Interaction }\end{array}$ & 0.510 & 1.582 & 0.012 & 0.322 & 0.747 & -2.593 & 3.612 \\
\hline
\end{tabular}

Tabelle 14: lineare Einfachregression und HMRA für Exp. 2 unter Verwendung \% SS

Model 1: lineare Einfachregression. Model 2: HMRA. B = nicht standardisierte Koeffizienten. $T P O=$ Zeitintervall vor Präfixbeginn. \% SS = prozentual gestotterte Silben. \% SS ist eine kontinuierliche Variable inklusive aller vorherigen inkludierten Daten beider Gruppen. Die Konstante der Regression wurde geprüft gegen die Nullhypothese von $B=1$, anstatt der Alternativhypothese $B=0$.

\begin{tabular}{|c|c|c|c|c|c|c|c|c|c|}
\hline Model & $\mathrm{R}$ & $\mathrm{R}^{2}$ & $\begin{array}{c}\text { Adjusted } \\
\mathrm{R}^{2} \\
\end{array}$ & $\begin{array}{l}\text { Std. Error of } \\
\text { the Estimate }\end{array}$ & $\begin{array}{c}\mathrm{R}^{2} \\
\text { Change }\end{array}$ & $\begin{array}{l}\text { Chan } \\
\text { F } \\
\text { Change }\end{array}$ & $\begin{array}{l}\text { ge St } \\
\text { df1 }\end{array}$ & itistics & Sig. F Change \\
\hline 1 & 0.187 & 0.035 & 0.035 & 1.110 & 0.035 & 124.506 & 1 & 3441 & $<0.001$ \\
\hline 2 & 0.193 & 0.037 & 0.036 & 1.109 & 0.002 & 2.916 & 3 & 3438 & 0.033 \\
\hline
\end{tabular}

Tabelle 15: zugehörig zu Experiment $2 \%$ SS. $R^{2}$ Berechnung für Regressionsanalyse 


\begin{tabular}{|c|c|c|c|c|c|c|c|}
\hline \multirow[b]{2}{*}{ Model } & \multicolumn{2}{|c|}{$\begin{array}{l}\text { Unstandardized } \\
\text { Coefficients }\end{array}$} & \multirow{2}{*}{$\begin{array}{l}\text { Standardized } \\
\text { Coefficients } \\
\text { Beta }\end{array}$} & \multirow[b]{2}{*}{$T$} & \multirow[b]{2}{*}{ Sig. } & \multicolumn{2}{|c|}{$95 \%$ Cl for $B$} \\
\hline & $B$ & Std. Error & & & & Bound & Bound \\
\hline (Constant) & 1.537 & 0.049 & & 10.959 & $<0.001$ & 1.440 & 1.633 \\
\hline TVO & 0.562 & 0.210 & 0.052 & 2.671 & 0.008 & 0.149 & 0.974 \\
\hline (Constant) & 1.536 & 0.099 & & 5.414 & $<0.001$ & 1.343 & 1.730 \\
\hline TVO & 1.067 & 0.244 & 0.098 & 4.371 & $<0.001$ & 0.588 & 1.546 \\
\hline$\%$ SS & -2.141 & 0.561 & -0.129 & -3.813 & $<0.001$ & -3.242 & -1.040 \\
\hline $\begin{array}{l}\text { \% SS-TVO } \\
\text { Interaction }\end{array}$ & -9.291 & 2.329 & -0.141 & -3.990 & $<0.001$ & -13.858 & -4.725 \\
\hline
\end{tabular}

Tabelle 16: lineare Einfachregression und HMRA für Exp. 3 unter Verwendung \% SS

Model 1: lineare Einfachregression. Model 2: HMRA. B = nicht standardisierte Koeffizienten. TVO = Zeitintervall vor Verbbeginn. \% SS = prozentual gestotterte Silben. \% SS ist eine kontinuierliche Variable inclusive aller vorherigen inkludierten Daten beider Gruppen. Die Konstante der Regression wurde geprüft gegen die Nullhypothese von $B=1$, anstatt der Alternativhypothese $B=0$.

\begin{tabular}{|c|c|c|c|c|c|c|c|c|c|}
\hline & \multicolumn{1}{|c}{} & \multicolumn{1}{c|}{ Change Statistics } \\
Model & $\mathrm{R}$ & $\mathrm{R}^{2}$ & $\begin{array}{c}\text { Adjusted Std. Error of } \\
\mathrm{R}^{2}\end{array}$ & $\begin{array}{c}\mathrm{R}^{2} \\
\text { the Estimate }\end{array}$ & $\begin{array}{c}\mathrm{F} \\
\text { Change }\end{array}$ & Change & df1 & df2 & Sig. F Change \\
\hline 1 & 0.052 & 0.003 & 0.002 & 1.371 & 0.003 & 7.134 & 1 & 2676 & 0.008 \\
\hline 2 & 0.099 & 0.010 & 0.008 & 1.367 & 0.007 & 6.380 & 3 & 2673 & $<0.001$ \\
\hline
\end{tabular}

Tabelle 17: zugehörig zu Experiment $3 \%$ SS. $R^{2}$ Berechnung für Regressionsanalyse 


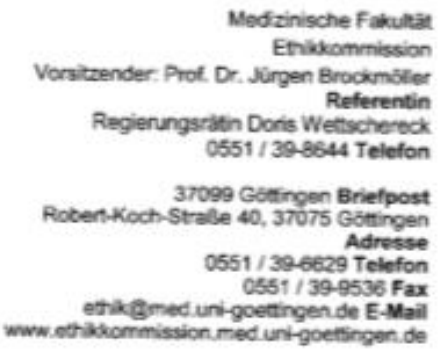

07.05 .2012 schn-gob Datum

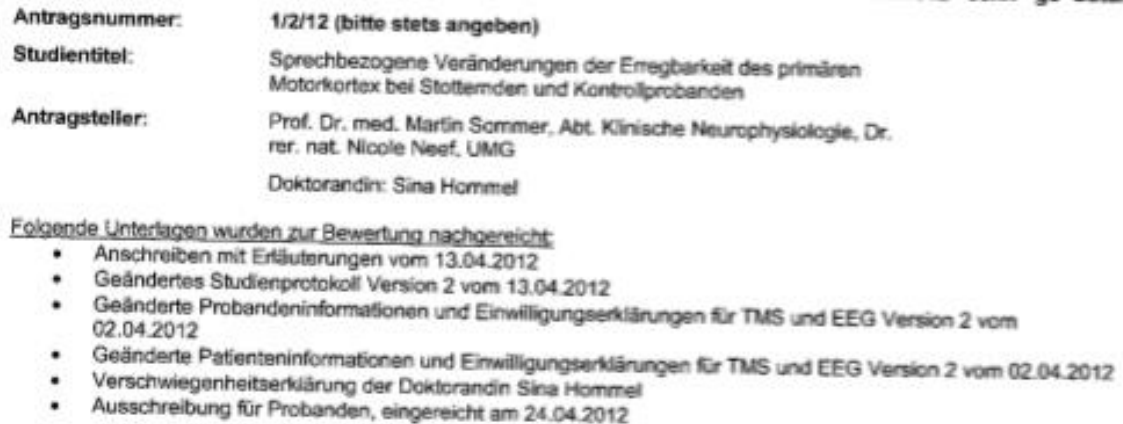

Sehr geehrter Herr Prof. Dr, Sommer, sehr geehrte Damen und Herren

nach Ergälnzung der 0.g. Dokumente und Beantwortung der im vorläufigen Votum aufgefurrten Fragen in ihrem Schreiben vom 13.04.2012 bestehen nunmehr keine ethischen und rechllichen Bedenken gegen die Durchfuhrung des oben genannten

Wir wünschen Ihnen viei Erfolg bei der Durchfuhrung thres Projeictes. Die Ethik-Kommission weist darauf hin, dass die ärtichs und juristache Verantwonung bei den jeweiligen Prifarcten
verbleibt.

Auf die Einhaltung einschlägiger Gesetze und Rechtsvorschritten wird hingewiesen. Dle nach Rechtslage notwendigen

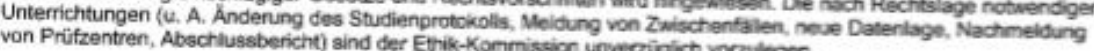
Dis Etik

Oie Ethik-Kcmmission bestätigt, dass sie auf Grundlage nationaler Gesetze, Vorschnten sowie der GCPNCHFichtinie arbeitet

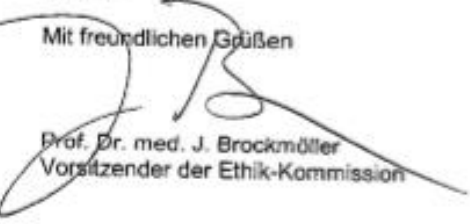

Abb. 17 Ethikvotum 